\title{
A MODEL \\ TECHNOLOGY TRANSFER PROGRAM FOR INDEPENDENT OPERATORS
}

\section{KANSAS TECHNOLOGY TRANSFER MODEL (KTTM)}

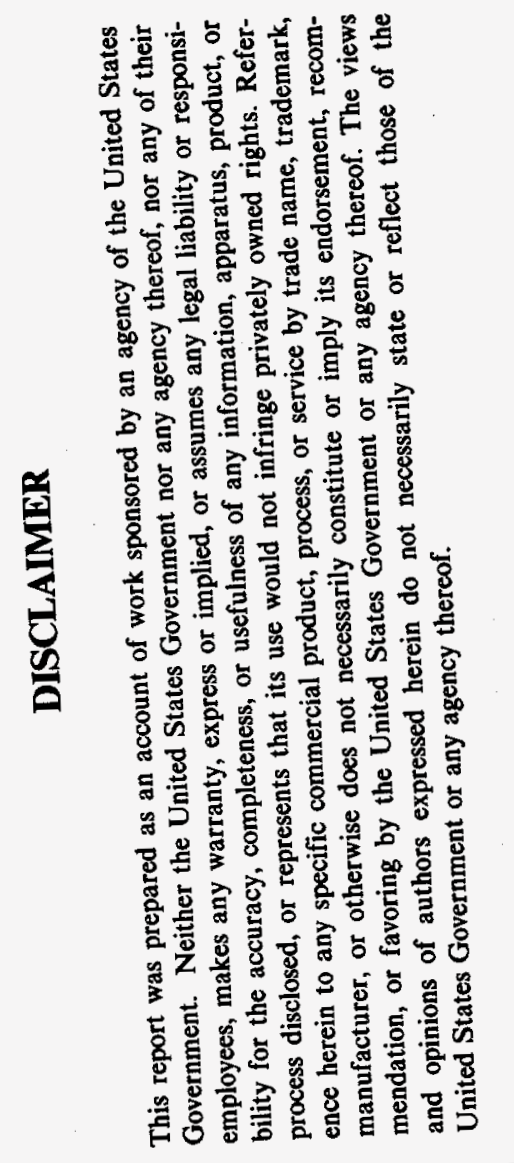

Prepared by the

Energy Research Center

The University of Kansas

SEPTEMBER 1993

Project Sponsors:

KU Kansas Geological Survey KU Tertiary Oil Recovery Project KU Department of Geology U.S. Department of Energy*

* Supported by DOE Grant No. DE-FG22-92BC14856 titled A Technology Transfer Model for Additional Oil Recovery

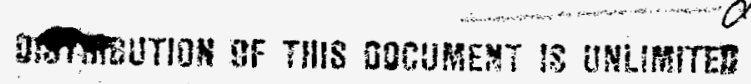




\section{DISCLAIMER}

Portions of this document may be illegible in electronic image products. Images are produced from the best available original document. 


\title{
A MODEL \\ TECHNOLOGY TRANSFER PROGRAM FOR INDEPENDENT OPERATORS
}

\section{KANSAS TECHNOLOGY TRANSFER MODEL (KTTM)}

BY

Lanny G. Schoeling, P.E. Tertiary Oil Recovery Project

\author{
Energy Research Center \\ The University of Kansas \\ Lawrence, Kansas
}

SEPTEMBER 1993

$\begin{array}{lllllllllllllll}\text { A } & \text { C } & \text { K } & \text { N } & \text { O } & \text { W } & \text { L } & \text { E } & \text { D } & \text { G } & \text { E } & \text { M } & \text { E } & \text { N } & \text { T }\end{array}$

This document represents a Technology Transfer Team effort involving the Energy Research Center, the Kansas Geological Survey, and the Tertiary Oil Recovery Project at The University of Kansas. Lee C. Gerhard, Don W. Green, G. Paul Willhite, Lanny G. Schoeling, and W. Lynn Watney reviewed the document and provided project leadership. Contributing team members include E. Lance Cole, Danial F. Merriam, Michael J. Michnick, Kerry D. Parham, Timothy L. Phares, Rodney R. Reynolds, Robert S. Sawin, and Wendell J. Weatherbie.

\section{Disclaimer}

The Energy Research Center, the Kansas Geological Survey, and the Tertiary Oil Recovery Project do not guarantee this document to be free from errors or inaccuracies and disclaim any responsibility or liability for interpretations based on data used in the production of this document or decisions based thereon. This report is intended to make results of research available at the earliest possible date, but is not intended to constitute final for formal publication. 
Abstract

In August 1992, the Energy Research Center (ERC) at the University of Kansas was awarded a contract by the United States Department of Energy (DOE) to develop a technology transfer regional model.

This report describes the development and testing of the Kansas Technology Transfer Model (KTTM) which is to be utilized as a regional model for the development of other technology transfer programs for independent operators throughout oil-producing regions in the United States. It describes the linkage of the regional model with a proposed national technology transfer plan, an evaluation technique for improving and assessing the model, and the methodology which makes it adaptable on a regional basis. The report also describes management concepts helpful in managing a technology transfer program.

The original Tertiary Oil Recovery Project (TORP) activities, upon which the KTTM is based, were developed and tested for Kansas and have proved to be effective in assisting independent operators in utilizing technology. Through joint activities of TORP and the Kansas Geological Survey (KGS), the KTTM was developed and documented for application in other oil-producing regions. During the course of developing this model, twelve documents describing the implementation of the KTTM were developed as deliverables to DOE. These include: 1) a problem identification (PI) manual describing the format and results of six PI workshops conducted in different areas of Kansas, 2) three technology workshop participant manuals on advanced waterflooding, reservoir description, and personal computer applications, 3) three technology workshop instructor manuals which provides instructor material for all three workshops, 4) three technologies were documented as demonstration projects which included reservoir management, permeability modification, and utilization of a liquid-level acoustic measuring device, 5) a bibliography of all literature utilized in the documents, and 6) a document which describes the KTTM. All workshops were conducted as part of the development of the KTTM. The selection of topics for the workshops and field demonstration documentation are examples only and are not intended as an all-inclusive list of activities that would be applicable in other regions. 
Table of Contents

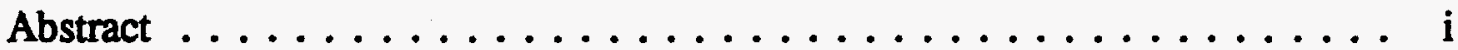

List of Tables $\ldots \ldots \ldots \ldots \ldots \ldots \ldots \ldots \ldots \ldots \ldots$

List of Figures $\ldots \ldots \ldots \ldots \ldots \ldots \ldots \ldots \ldots \ldots \ldots \ldots$

CHAPTER 1 - INTRODUCTION $\ldots \ldots \ldots \ldots \ldots \ldots \ldots \ldots \ldots$

Objective and Scope $\ldots \ldots \ldots \ldots \ldots \ldots \ldots \ldots \ldots$

Organizational Structure $\ldots \ldots \ldots \ldots \ldots \ldots \ldots \ldots \ldots \ldots$

Background .................... 5

Type of Technology Transfer Emphasized in this Program . . . . . 12

Technology Transfer Requirements and Impediments . . . . . . . 13

Current Situation in Technology Transfer $\ldots \ldots \ldots \ldots \ldots \ldots . . \ldots 15$

TORP Model for Technology Transfer . . . . . . . . . 16

Components of the TORP Technology Transfer Model . . . . 17

Kansas Geological Survey (KGS) . . . . . . . . . . . 20

Bartlesville Project Office (BPO) Technology Transfer . . . . 21

TIPRO Model . . . . . . . . . . . . . . 23

PRRC Model $\ldots \ldots \ldots \ldots \ldots \ldots \ldots \ldots \ldots \ldots 24$

PTTC Proposal . . . . . . . . . . . . . . 24

CHAPTER 2 - THE KANSAS TECHNOLOGY TRANSFER MODEL

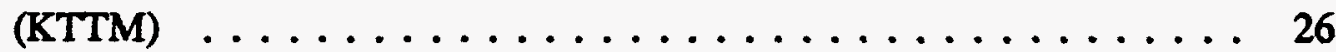

Purpose and Design of the KTTM ............. 26

KTTM Description . . . . . . . . . . . . . . . . 27

Problem Identification (PI) Workshops . . . . . . . . . . . . 30

Organizing a PI Workshop ............ 31

Conducting a PI Workshop ............... 33

Practical Considerations in Designing and Developing the

Problem Identification Workshop Format . . . . . . . 34

Technology Workshops ................... 35

Demonstration Projects - Operation and Documentation . . . . . . . 37

Expansion of Technology Transfer Activities to Include a

Interdisciplinary Team and Resources to Complete Tasks . . . . 39

Program Evaluation $\ldots \ldots \ldots \ldots \ldots \ldots \ldots \ldots \ldots$ 
Table of Contents (Cont.)

CHAPTER 3 - IMPLEMENTATION OF THE KANSAS TECHNOLOGY TRANSFER MODEL $\ldots \ldots \ldots \ldots \ldots \ldots \ldots \ldots \ldots$

Management Style ...................... 44

Responsibilities of Various Entities In Regional Program . . . . . 48

Problem Identification Workshops . . . . . . . . . . . . . . 48

Organizing the Six Problem Identification (PI) Workshops ... 49

Conducting the Six Problem Identification (PI) Workshops . . 51

Summary of Results in Problem Identification Workshops ... 52

Technology Workshops . . . . . . . . . . . . . . . . . 61

Document and Develop Demonstration Projects . . . . . . . . 65

Reservoir Management .............. 66

Permeability Modification . . . . . . . . . . 66

Acoustic Liquid-Level Measuring Device . . . . . . . . 67

Expand Technology Transfer Activities . . . . . . . . . . . 68

Program Evaluation of the KTTM Test . . . . . . . . 70

Near-Term Program Evaluation . . . . . . . . . . . . 70

Problem Identification Workshops - Evaluation from

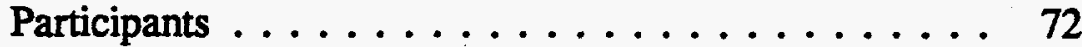

Technology Workshops - Survey Results . . . . . . . 74

Long-term Program Evaluation . . . . . . . . . . . . . . 81

CHAPTER 4 - LITERATURE REVIEW $\ldots \ldots \ldots \ldots \ldots \ldots \ldots \ldots$

Technology Transfer Models . . . . . . . . . . . . . . . 84

Technology Transfer Modes and the End-Users Involvement . . . . 85

The Importance of Creativity in the Technology Transfer Process . . . 86

Problem Solving Utilizing Project Teams . . . . . . . . . 88

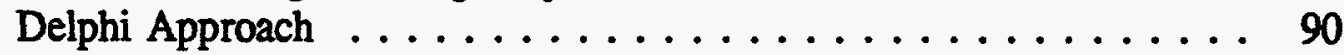

Program Evaluation $\ldots \ldots \ldots \ldots \ldots \ldots \ldots \ldots \ldots \ldots$

The Discrepancy Evaluation Model . . . . . . . . . . . . . 95

The Discrepancy Evaluation Model Modified for a Technology

Transfer Program . . . . . . . . . . . . . 96

CHAPTER 5 - THE NATIONAL TECHNOLOGY TRANSFER PROGRAM

Components of the Central Coordinating Program . . . . . . . 100

Technology Transfer Training . . . . . . . . . . . . 101

Distribution of Computer Software . . . . . . . . . . 101

Development of a National Database . . . . . . . . . . 102

Coordination With Applicable National Lab Activities . . . . 102

House Petroleum Publications . . . . . . . . . . . . . . 102

Conduct Class Meetings on Demonstration Projects . . . . . 102

Delegation of Responsibility and Identification of Roles . . . . . . 103 
Table of Contents (Cont.)

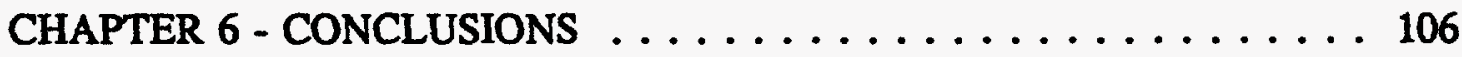

CHAPTER 7 - RECOMMENDATIONS $\ldots \ldots \ldots \ldots \ldots \ldots \ldots$

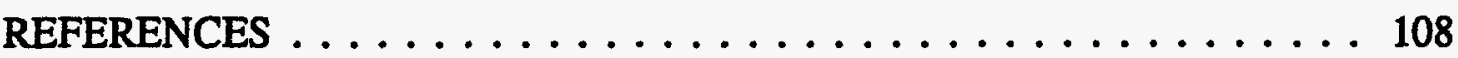

APPENDIX A - Problem Identification Workshop Invitation and Evaluation

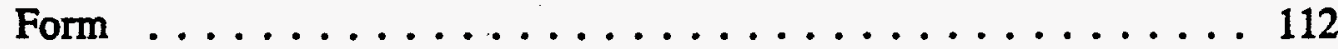

APPENDIX B - Data Sheet for Operators $\ldots \ldots \ldots \ldots \ldots \ldots \ldots$

APPENDIX C - Cover Sheets for Deliverables $\ldots \ldots \ldots \ldots \ldots \ldots$ 
List of Tables

Table $3-1$ - Schedule $\ldots \ldots \ldots \ldots \ldots \ldots \ldots \ldots \ldots \ldots$ 


\section{List of Figures}

Figure 1-1. Integration of disciplines for technology transfer activities. . . . 2

Figure 1-2. Organizational structure for project investigators. $\ldots \ldots \ldots 3$

Figure 1-3. Organizational structure of the technology transfer team. . . . 4 4

Figure 1-4. Capital spending for the largest 25 companies. (IPAA, 1992) . . 5

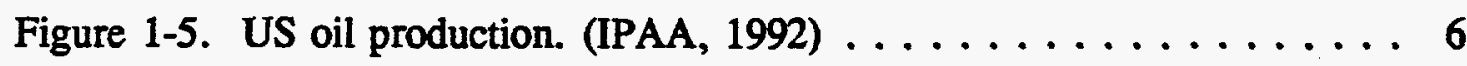

Figure 1-6. Number of abandoned wells in the United States (DOE, 1989). . . 7

Figure 1-7. Domestic oil resource (DOE, 1990). . . . . . . . . . 8

Figure 1-8. Mobile oil-in-place in the United States in billions of barrels. (DOE, 1990) . . . . . . . . . . . . . . . . . . 9

Figure 1-9. Employment in the extraction of oil and gas in the United States. (IPAA, 1992) $\ldots \ldots \ldots \ldots \ldots \ldots \ldots \ldots \ldots \ldots \ldots \ldots$

Figure 1-10. Distribution of the number of employees in independent oil companies. (IPAA, 1992) . . . . . . . . . . . . . 11

Figure 1-11. Flow diagram of TORP's screening process. $\ldots \ldots \ldots \ldots 18$

Figure 2-1. Developmental stages of program design. . . . . . . 27

Figure 2-2. Organizational structure of the Kansas Technology Transfer Model (KTTM) . . . . . . . . . . . . . . . . . 29

Figure 2-3. Flowsheet of the screening process for the regional resource center. $\ldots \ldots \ldots \ldots \ldots \ldots \ldots \ldots \ldots \ldots \ldots \ldots \ldots$

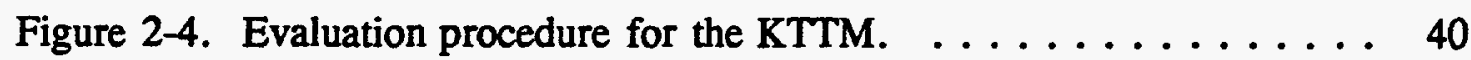

Figure 3-1. Organization structure in implementing KTTM. . . . . . 44 


\section{List of Figures (Cont.)}

Figure 3-2. Problem identification workshop locations $\ldots \ldots \ldots \ldots$

Figure 3-3. Locations of the technology workshops. . . . . . . . . 63

Figure 3-4. Program design for the Kansas Technology Transfer Model $(\mathrm{KTTM}) \ldots \ldots \ldots \ldots \ldots \ldots \ldots \ldots \ldots \ldots \ldots \ldots$

Figure 3-5. Participant's ratings on the quality of presentations in the technology workshops. . . . . . . . . . . . . 74

Figure 3-6. Participant's ratings on the expectations met as advertised. . . 75

Figure 3-7. Participant's ratings on organizing each technology workshop. . 76

Figure 4-1. Three tiers of technology transfer. $\ldots \ldots \ldots \ldots \ldots \ldots$

Figure 4-2. Two subsystems influencing each other. . . . . . . 87

Figure 5-1. The national technology transfer model. . . . . . . . . 99

Figure 5-2. Diagram of flow of information from the Central Coordinating Program. . . . . . . . . . . . . . . 100 


\section{CHAPTER 1 \\ INTRODUCTION}

\section{Objective and Scope}

The purpose of this document is to describe the development and implementation of the Kansas Technology Transfer Model (KTTM) which is to be utilized as a regional model for the development of other technology transfer programs for independent operators throughout oil-producing regions in the United States. The document contains: 1) background on the current problems in the oil industry that have created the need for domestic technology transfer programs, 2) information on current technology transfer programs, 3) a literature survey on technology transfer and related subjects, 4) a description of the KTTM and the methodology utilized which makes it adaptable on a regional basis, 5) a description of the testing of the KTTM model, and 6) the method by which the model can be linked to a national program. Components of the KTTM include: 1) problem identification workshops, 2) technology workshops/seminars, 3) documentation and development of field demonstration projects, and 4) expansion of technology transfer activities to include geological elements in Kansas. The principal organizational features that will be needed to implement the KTTM in a typical region include: 1) a regional resource center, 2) a regional coordinating committee, and 3) a working industry infrastructure.

\section{Organizational Structure}

The project team was organized under the Energy Research Center at the University of Kansas (KUERC). Staff at the KUERC and participating staff in TORP and KGS represent various disciplines including geology, geophysics, and engineering. This was ideal, since the goal of the KUERC is to be an umbrella organization through which departments of multi-disciplines can work together. This type of entity assists in breaking down the mind sets and operational differences that exist between such scientific disciplines. Figure 1-1 presents the concept of the integrated team approach. 


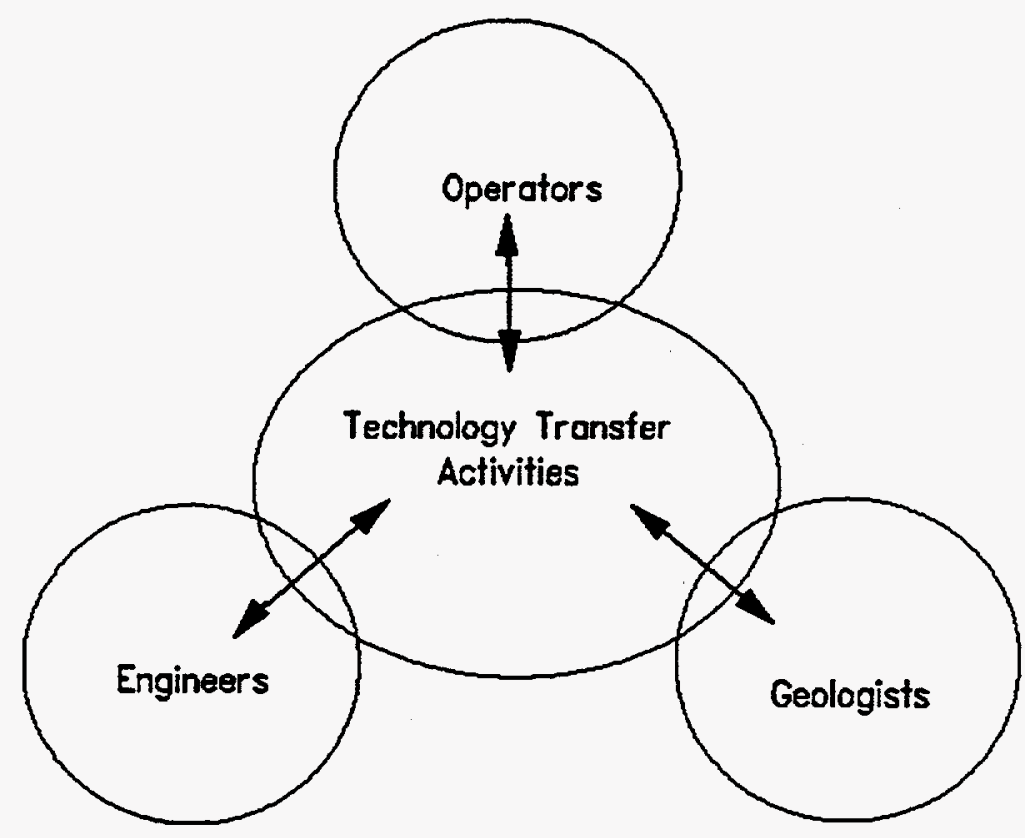

Figure 1-1. Integration of disciplines for technology transfer activities.

Project investigators from TORP and KGS working under ERC were responsible for overall goal setting, approving, and reviewing work for the technology transfer team. They worked together in initial proposal writing and budgeting in the

- project. They attended periodic technology transfer meetings and were involved in organizing the first two problem identification workshops. Figure 1-2 presents the organizational structure.

The technology transfer team was responsible in carrying out the day-to-day activities which included 1) organizing and conducting workshops, 2) writing participant and instructor manuals, 3) documenting technologies, and 4) conducting demonstration projects. In developing the technology transfer team, three additional engineers, and two additional geologists were hired as ERC personnel to work through TORP and KGS facilities. The entire technology transfer team consisted of six engineers, and four geologists. KGS and TORP personnel participated on a cost 


\section{ENERGY RESEARCH CENTER \\ TECHNOLOGY TRANSFER PROJECT}

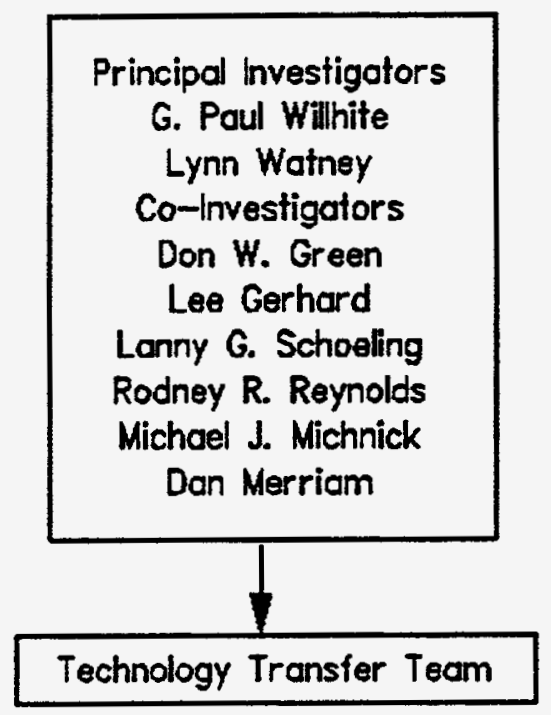

Figure 1-2. Organizational structure for project investigators.

sharing basis. Figure 1-3 presents the organizational structure.

The technology transfer team had frequent meetings for discussion. Each team member is briefly acknowledged for his responsibility in the deliverables on the title page. The management style is discussed in Chapter 4 . The project manager administered the technology transfer team as a partial fulfillment of his doctorate in engineering degree.

The following documents were developed and presented as deliverables to the Department of Energy (DOE). The deliverables have been made into a series. The cover sheets for the each deliverable are presented in Appendix C.

Advanced Waterflooding Workshop Manual

Advanced Waterflooding Workshop Instructor's Manual

Reservoir Description Workshop Manual

Reservoir Description Workshop Instructor's Guide 


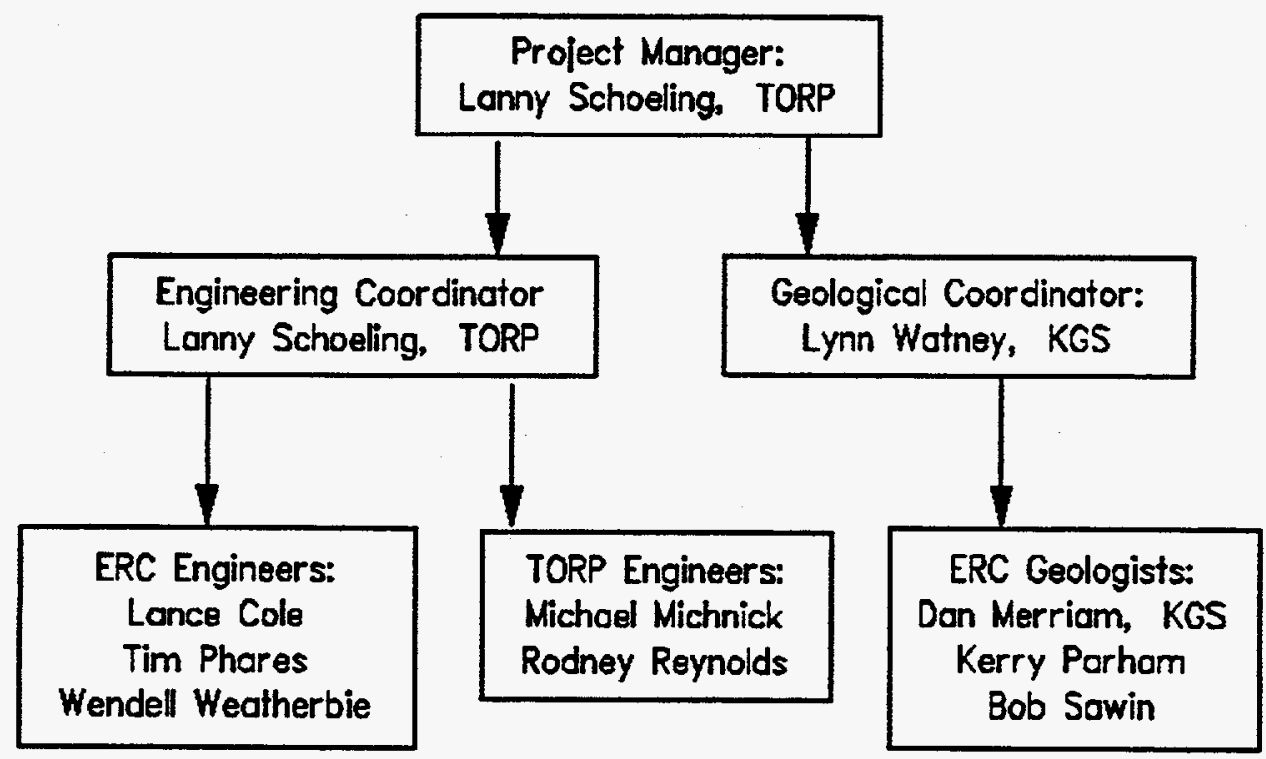

Figure 1-3. Organizational structure of the technology transfer team.

Computer Application Workshop Manual

93-3

Computer Application Workshop Instructor's Manual

Reservoir Management Demonstration Project

93-5

Echometer Demonstration Project

Permeability Modification Demonstration Project

Bibliography

93-8

Problem Identification Manual

Kansas Technology Transfer Model Document 


\section{Background}

The domestic oil resource base is mature and characterized by high operating costs, increased costs of regulatory compliance, low oil production rates, and concerns with environmental liabilities. This situation has caused the major oil operators to leave many of their domestic operations for more profitable foreign

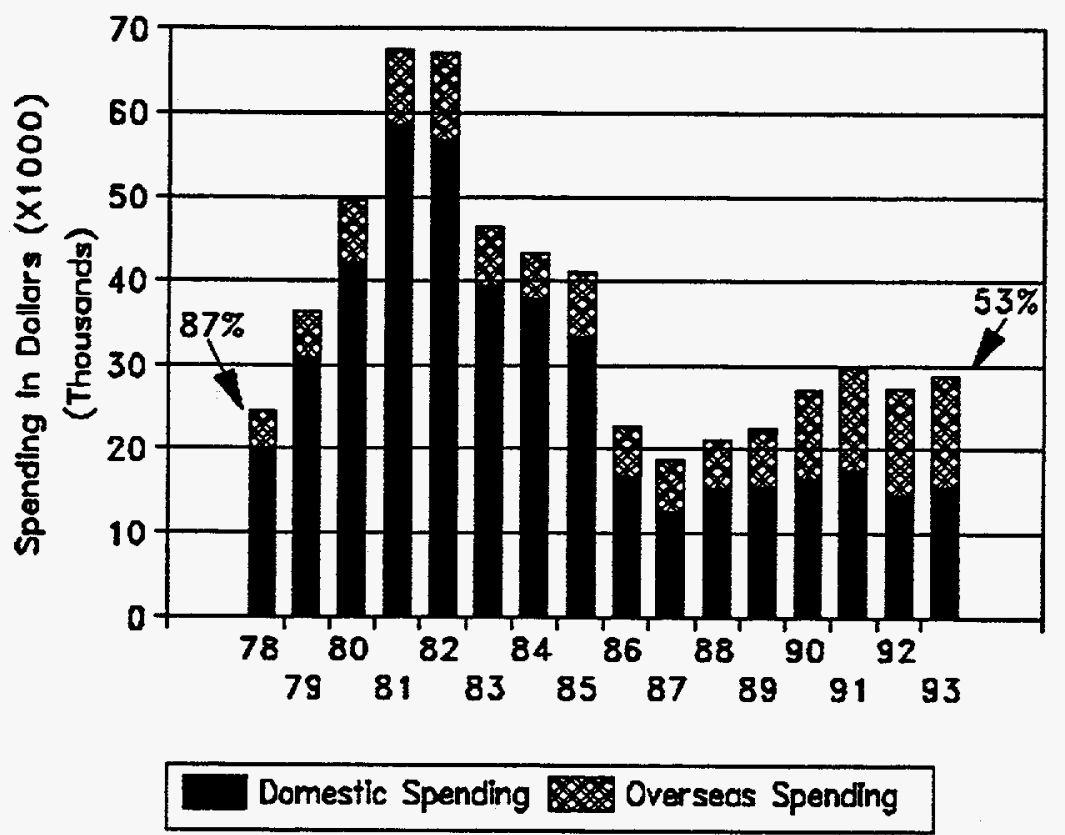

Figure 1-4. Capital spending for the largest 25 companies. (IPAA, 1992)

operations. Figure 1-4 is a graph presenting capital expenditures of the top 25 oil companies in the United States for overseas and domestic operations since 1978. In the past 11 years, capital spending has been reduced from more than 65 billion dollars to less than 30 billion dollars annually with the domestic share falling from $87 \%$ to $53 \%$.

In the past, independent operators would generally find the oil through exploration and then sell the reserves to major oil companies who had the technical 


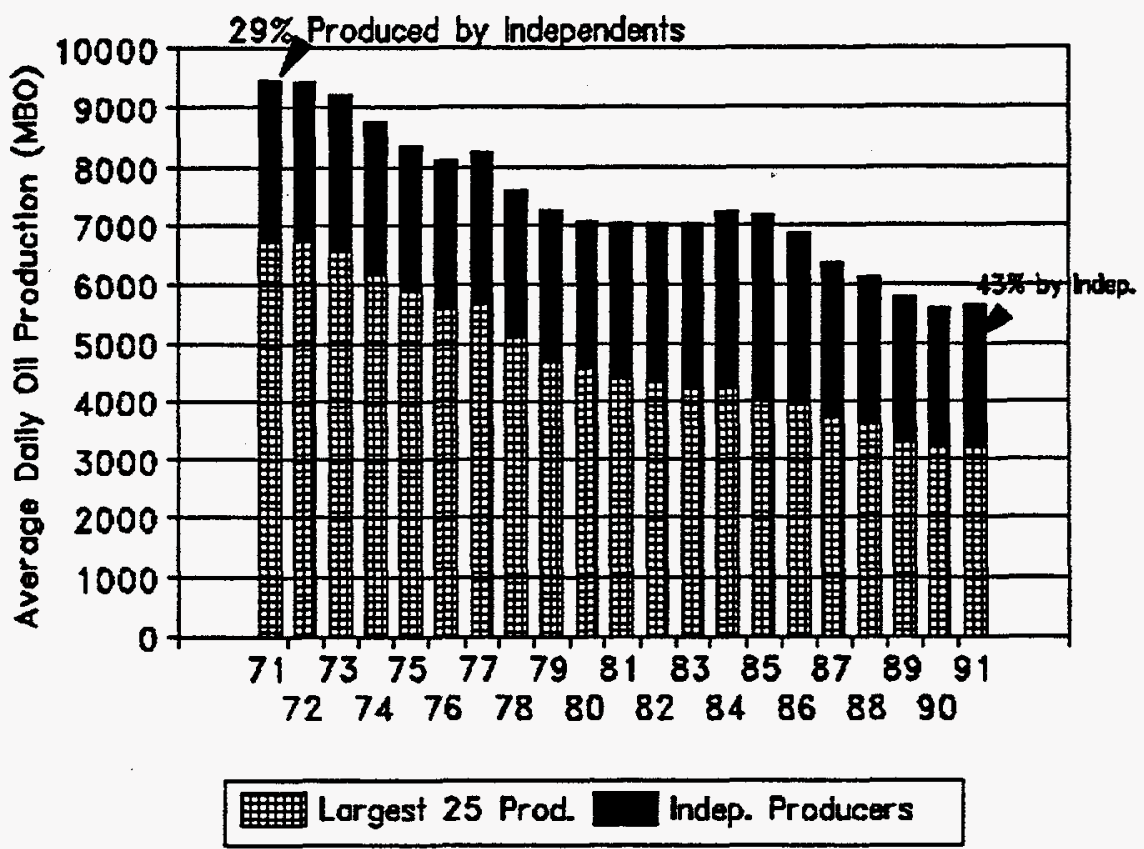

Figure 1-5. US oil production. (IPAA, 1992)

and financial resources to continue development and production. Now major oil companies are selling their domestic reserves to independent oil producers. The result is that the percentage of US production operated by independent operators (operators smaller than the largest 25) has risen from $29 \%$ in 1970 to $43 \%$ in 1990 , as presented in Figure 1-5. This figure also presents the decline in oil production which reflects the decreased capital expenditures of the major oil companies.

Almost one-third of the oil originally-in-place (OOIP) in the domestic United States (lower 48) has been produced. By 1987, actual reported well pluggings showed that access to $40 \%$ of the remaining oil-in-place (OIP) had been abandoned, with the rate of abandonment accelerating in recent years from $1 \%$ to $2 \%$ per year (DOE, 1990). It is estimated that over $75 \%$ of the remaining resource could be abandoned early in the twenty-first century. The options after abandonment, if fields 
are to be reactivated, are infill drilling or reentering plugged wells. Both options require substantial investment and may be uneconomical.

Stripper production, i.e., 10 BOPD or less, has become an increasingly important component of domestic production. From 1971 to 1991, production from stripper wells rose as did the percentage of total production contributed by these wells. This stripper production is price sensitive because these low-production wells have relatively high operating costs. Figure 1-6 presents the total number of

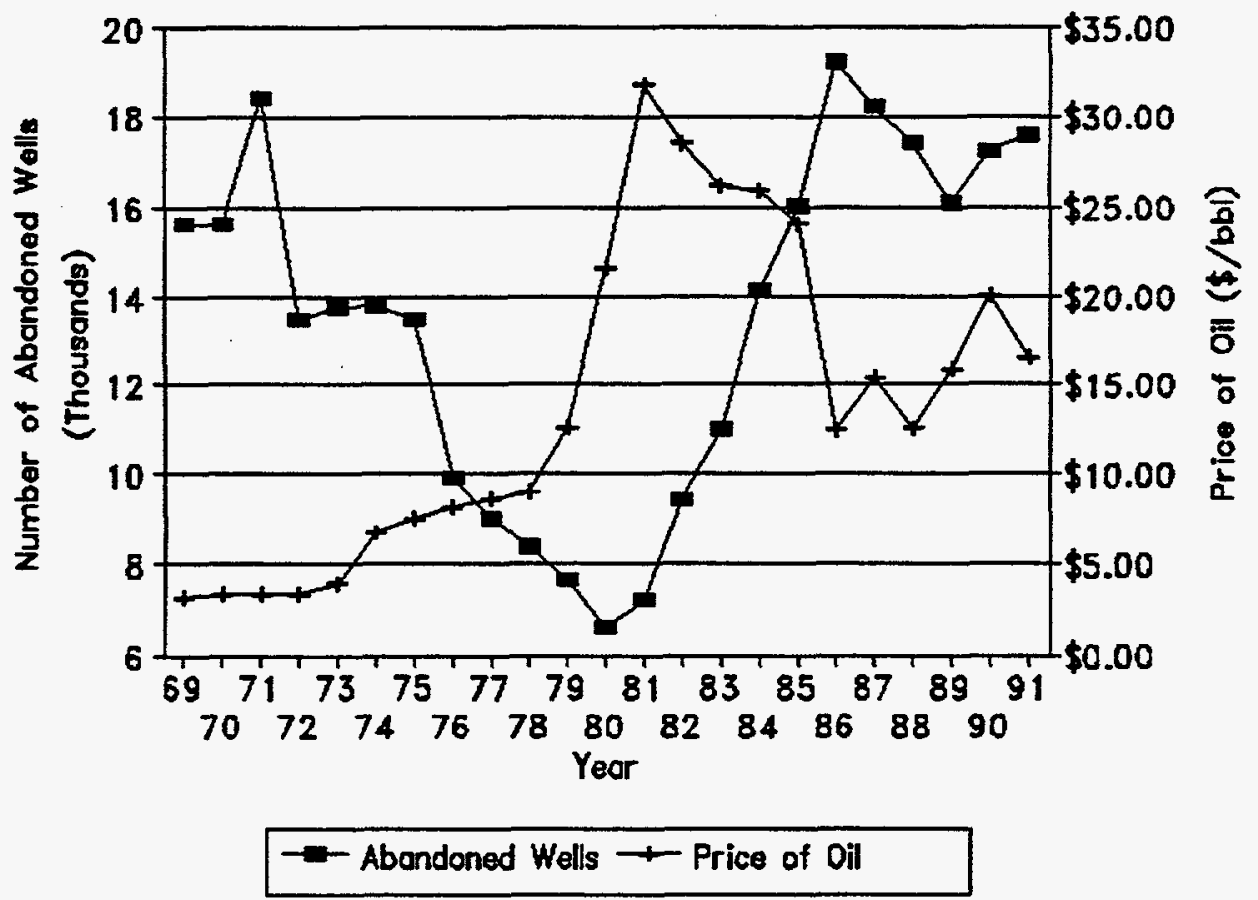

Figure 1-6. Number of abandoned wells in the United States (DOE, 1989).

abandoned wells and the oil price from 1969 to 1991 in the United States. Many stripper wells are operating at or near the economic limit and, without application of currently available technologies for improved operation, these wells are candidates for abandonment. 


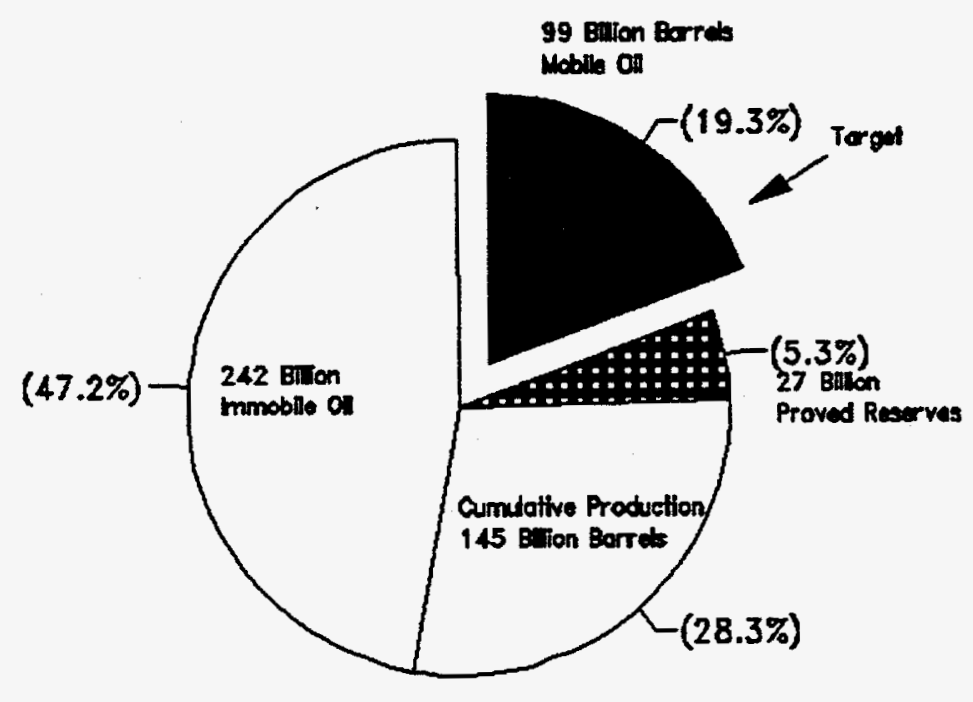

Figure 1-7. Domestic oil resource (DOE, 1990).

It is estimated that over $\mathbf{3 0 0}$ billion barrels of oil remain in known domestic reservoirs. Figure 1-7 presents an overall breakdown for original oil-in-place for the nation. Still to be recovered are proven reserves of 27 billion barrels (5\% of the OOIP) which can be produced utilizing conventional technology and with current economic conditions. Remaining mobile oil-in-place after proved reserves are produced is approximately 97 billion barrels (19\% of the OOIP). This mobile oil is the target for infill drilling and improved sweep efficiency technology. In many regions orreservoir significant oil can be recovered uting expanded recovery processes such as cyclic steam injection and steam flooding. Mobile oil is oil which is hydraulically connected between pore throats and can be easily mobilized if a displacement process such as waterflooding is imposed. The largest technical problem with recovering the mobile oil is the lack of understanding of reservoir 
architecture and how it affects fluid flow. Typically, the reservoirs are heterogeneous with variations in permeability, porosity, and fluid characteristics. These variations control fluid flow and can determine the degree of oil recovery. Immobile oil, the target for carbon dioxide, miscible, or low interfacial tension technologies, is the oil remaining after waterflooding. It is present in the pore spaces as oil droplets which are not hydraulically connected and will not move unless they are remobilized by a miscible technology. Figure 1-8 presents the mobile oil resource for the nation, distributed by state. In addition to these known resources, additional oil reserves are believed to be undiscovered in new fields.

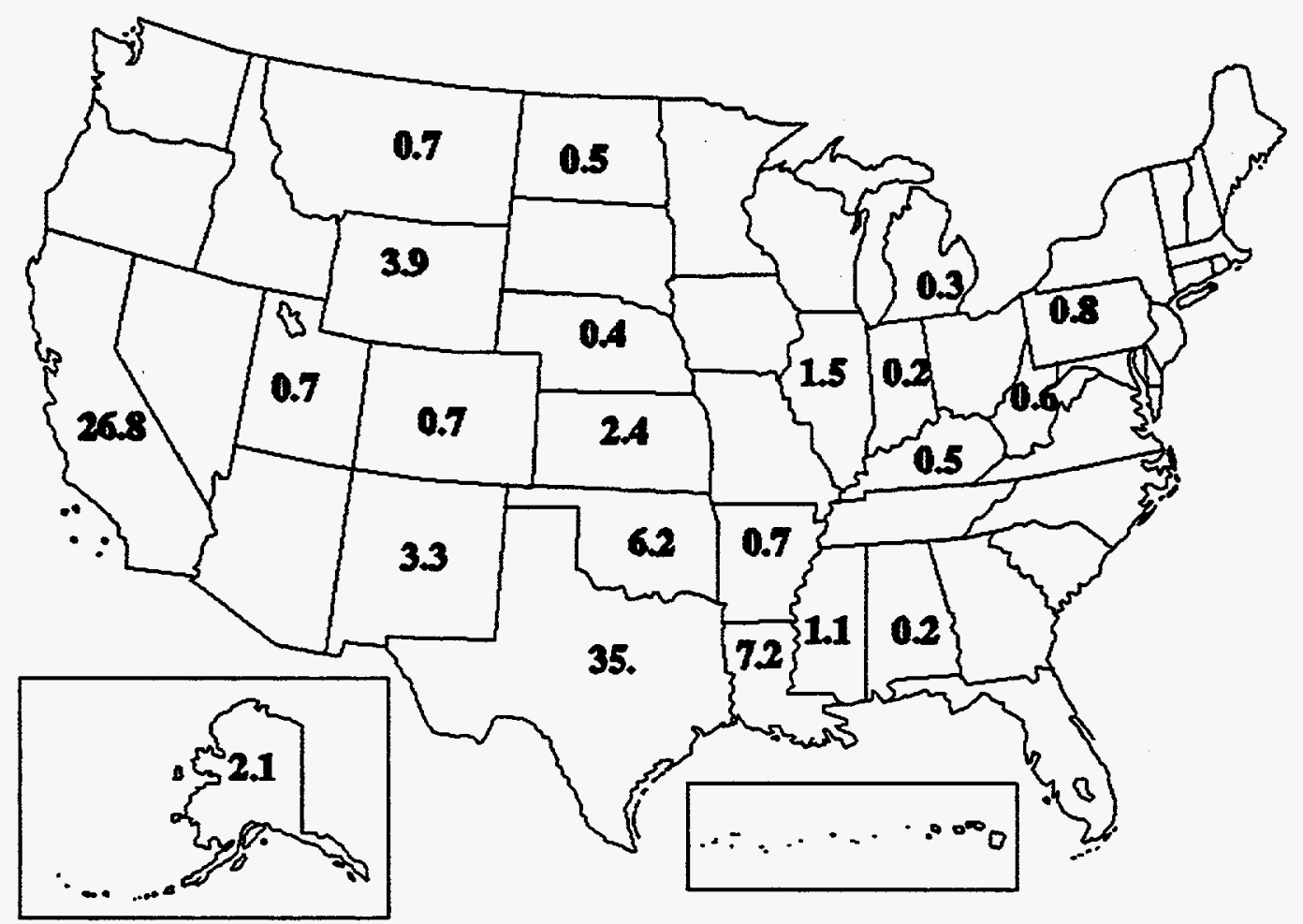

Figure 1-8. Mobile oil-in-place in the United States in billions of barrels. (DOE, 1990)

This oil reserve potential creates significant opportunities and challenges for independent operators. They must be able to characterize the reservoirs and develop the optimum reservoir depletion plan. They must have access to current and innovative technologies and the ability to apply the technologies. Such technological 
topics include 1) reservoir management, 2) reservoir characterization, 3) sweep improvement processes, and 4) advanced recovery techniques.

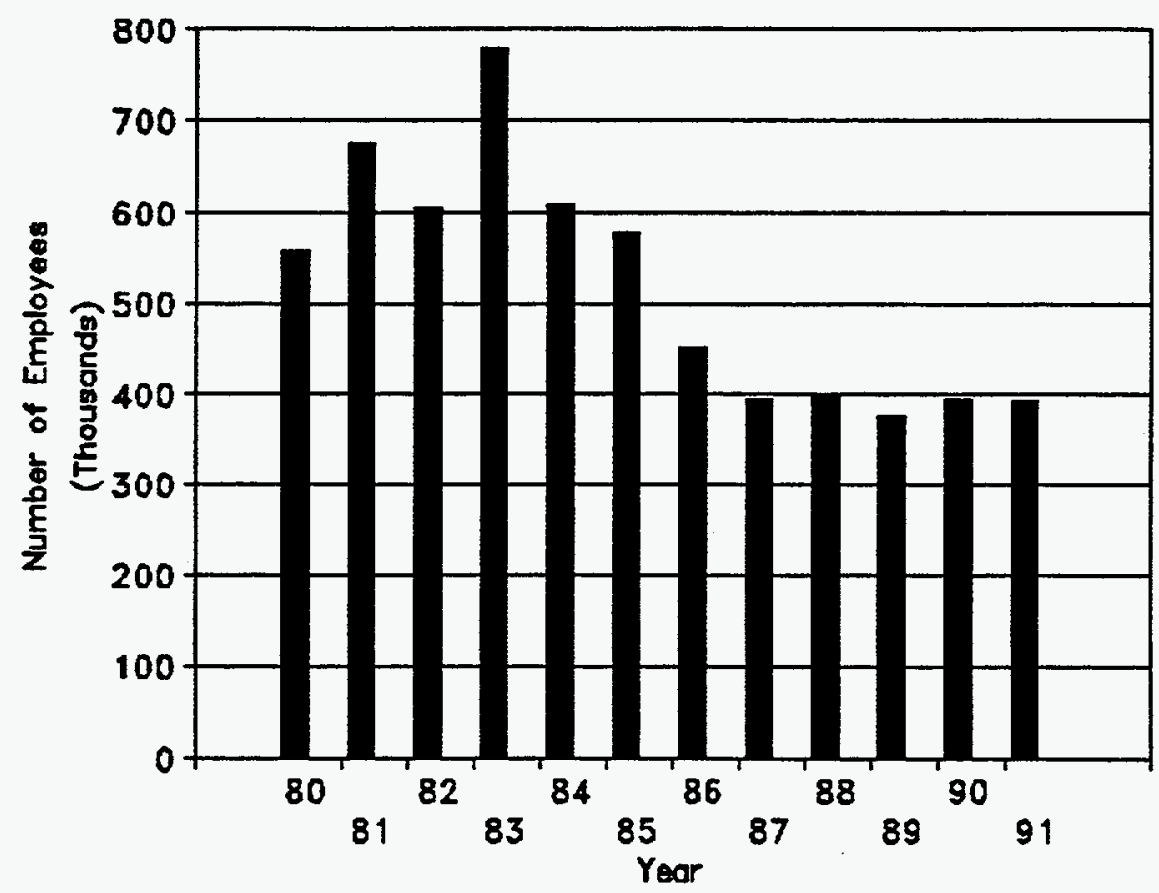

Figure 1-9. Employment in the extraction of oil and gas in the United States. (IPAA, 1992)

The current infrastructure to assist the independent operator includes field personnel within the independent companies, service companies, consultants, and research entities. This infrastructure has been collapsing with the drop in capital spending and price of oil. Figure 1-9 presents employment in the oil and gas extraction industry for the past 12 years (IPAA, 1992). If this decline is not reduced by some stimulus, then the infrastructure will not be available to produce the oil when economic times are better.

Independent operators have a variety of constraints relative to implementing conventional and newly developed technology including a lack of technical personnel, lack of capital, unavailable reservoir data, limited equipment resources and a lack of confidence in the successful application of technology. The independent operators are characterized as follows: 1) eighty percent of them have less than 50 employees, 2) 


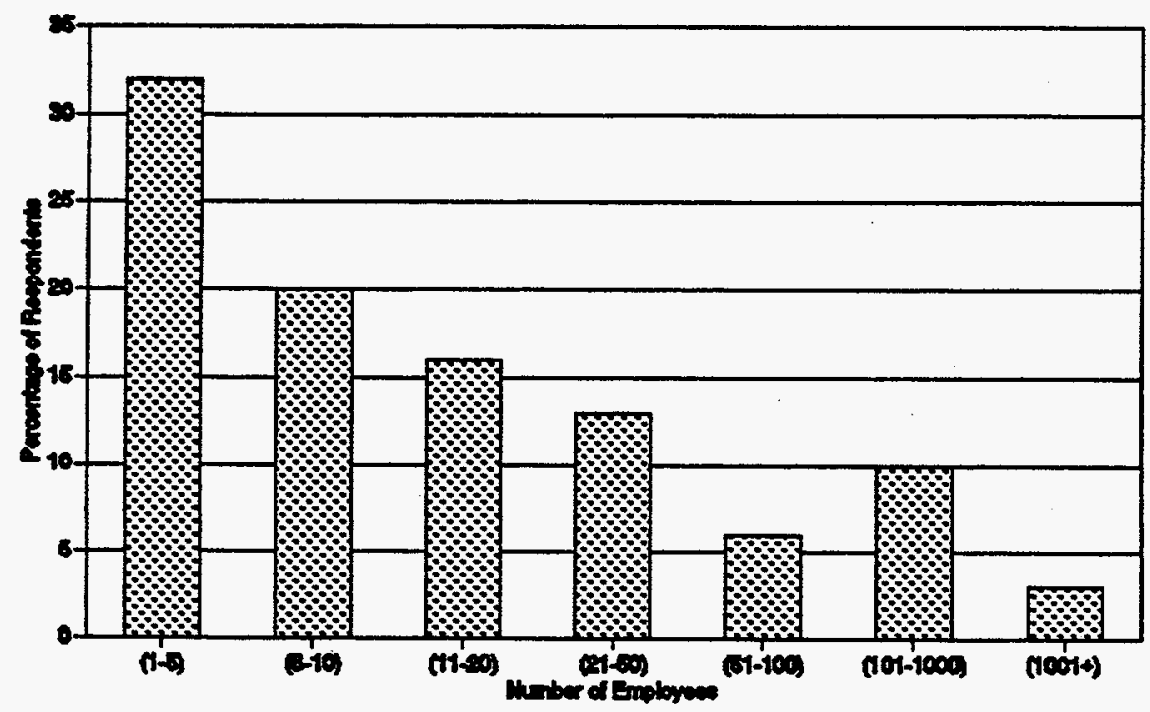

Figure 1-10. Distribution of the number of employees in independent oil companies. (IPAA, 1992)

sixty-one percent of the wells they operate are stripper wells, and 3) thirty percent of them operate only in one state. Distribution of the number of employees per company owned by independents is shown in Figure 1-10. This figure indicates that the majority of the independent oil companies in the United States operate with a as few of employees as possible. In most cases, technical staff are not employed on a regular basis.

The challenge to produce the nation's oil resource can be made manageable for independents with assistance of an effective technology transfer program developed to ensure that they are aware of and have access to potential technologies through education and demonstration. An effective technology transfer program should 1) be market driven or targeted to the independent's needs on a regional basis, 2) have channels of communication to the current infrastructure such as service 
companies, consultants, and research organizations, 3) be coordinated at a national technology transfer level, 4) be interdisciplinary, and 5) be implemented in the near future before access to reservoirs is eliminated.

\section{Type of Technology Transfer Emphasized in this Program}

There are different types of technology transfer. One way to consider technology transfer is to divide the process into three levels; technology development, technology acceptance, and technology application. "Technology development" centers on the scientist who is conducting the research in the laboratory or field, and who makes the results available in publications in professional journals. "Technology acceptance" centers on the technology user accepting and understanding the technology. The technology user must be someone who has the knowledge and the resources to apply and/or use the technology. "Technology application" centers on the technology user applying the technology and showing a profit in the marketplace. Both technology acceptance and technology application require a shared responsibility between development and application (user) personnel.

Each of these three levels of technology transfer is important. First, technology must be developed. However the developed technology may never be applied without the higher levels of technology transfer. The key is to develop a program which is efficient in networking the technology developers (researchers) with the technology users. To facilitate this goal, technology users must be linked more directly to developers of technology, and at the same time, researchers must gain a better understanding of and appreciation for the method the technology is applied. In other words, developers must have an understanding of the real problems that exist in the oil fields before they can effectively develop solutions.

The type of technology transfer emphasized in this program concentrates on the technology acceptance and technology application types of transfer. It is assumed that adequate technology exists or can be modified to make a profit in the marketplace. This type of technology transfer requires "action-oriented" people as 
implementers and a high degree of communication in one-on-one meetings, seminars, technical sessions, workshops, and demonstration projects. Effective technology transfer of this type requires mutual respect for the credentials of the participants, who are the developers and users. Successful technology transfer happens when each participant sees the exchange to be of mutual benefit.

\section{Technology Transfer Requirements and Impediments}

Knowledgeable applied research entities, consultants, and service companies exist who are aware of applicable technology which is not being used by the independent oil operator. A significant fraction of this technology will not be widely utilized without an organized program to stimulate transfer of the technology from technical entities to domestic oil operators. A successful technology transfer program must provide the appropriate technical information, while at the same time minimize barriers and impediments. Requirements for technology transfer include management support, agreement on goals and responsibilities, and effective communication. Barriers which impede technology transfer are inadequate incentives, geographical separation, and the unjustified "sales pitch".

Management mandate is essential within the oil, service and consulting companies that work with the oil operators. Management must promote technical support and encourage dialogue with the current technical infrastructure. The technical entities must assign a high level of priority to the technology transfer process, and establish cooperation and teamwork as part of their work culture and that of the oil operator. Both parties must regard the technology as important; one party cannot force the technology or his viewpoints on the other.

All participants must agree on the goals of the project involving technology transfer and the responsibilities of each party involved. The oil operator's plan for operating the field should set the basic agenda for considering the range of technologies that might be transferred. The operator's long-range plans should be known in order to gauge the effect on the supplier's services. Similarly, the service supplier must identify its long- and short-range objectives so that the oil operator can 
anticipate the economic benefit from new technologies being provided. Goal setting is a dynamic interactive process that should reflect the ever-changing economic and technical environment.

Roles and responsibilities must be identified by both parties. Many of the roles to be played by technical and operating personnel are easily defined; however, some functions at the interfaces between these groups may be inherently unclear. For instance, the operating personnel are responsible for keeping systems operational and profitable, while technical personnel set priorities on the long-range issues. These dissimilar roles create different views of when a project should start or how long it should continue.

The interactions between technical and operating personnel requires effective communication to facilitate technology transfer. Communication styles, operational methods and vocabularies are different for technical and operating personnel. Operating personnel produce brief summary documents, whereas technical personnel tend to produce highly detailed reports. Often this causes technical people to address the wrong problems and ask the wrong questions in the eyes of the operator. Effective communication is obtained when both parties attempt to speak each other's language. For instance, the technical person must use lay terms and active questioning techniques to get an idea across. The operating personnel must, through questioning, strive to understand why details are important.

Usually the technical entities are located far from the operating sites, preventing easy contact between people and impeding technology transfer. People tend to be most comfortable in surroundings to which they are accustomed. The technical person must become accustomed to visiting the site and meeting with field personnel.

A primary impediment to technology transfer is inadequate incentive. People often tend to do those things that they believe to be in their own best interest. Too often, company incentive systems run counterproductive to technology transfer. Personnel, budget, and reward systems often inhibit technology transfer by creating competitive relationships between groups or by placing high priority on short-term 
outcomes rather than long-term results.

The "sales pitch" syndrome is a constant barrier which the service companies and consultants must overcome. Many times operators tend to feel victimized when they are approached by a technical person describing a new technology. The operator feels that the service company or consultant is acting only in their own interest and is not interested in assisting the operator achieve his goal. This is seldom the case, because consultants and service companies know that if the operator can't make a profit, they are both out of business.

\section{Current Situation in Technology Transfer}

In the past, major oil companies, with large research organizations and internal technology transfer mechanisms, provided leadership within professional societies and stimulated industry-wide technology transfer through professional meetings, symposia, and the actions of consultants and service companies. These companies developed and introduced innovative technologies to domestic oil reservoirs because they could afford high-risk research and development costs. Independents operators seldom were involved in research and development of new technologies.

Following the downturn in the oil industry in the mid-1980s, the major oil companies are reducing expenditures for research, continuing to sell domestic production, and are moving to international operations. The independent operators are inheriting the responsibility to produce a significantly larger proportion of our domestic oil. Technology transfer mechanisms, such as international and national professional meetings, are not effective in transferring technology to many independents who have neither the technical staff and finances to attend national meetings nor the technical capability and capital to introduce new technologies. Also, for a variety of reasons, the independents have lacked confidence that technology would provide an adequate rate of return on investment.

Independent operators -will adopt and apply technologies that are proven effective in increasing production and/or reducing costs. What is needed is a technology transfer program that matches technology with the problem to be solved. 
Consultants and service companies currently have technology transfer programs which they use in providing technology to operators. In addition to TORP there are a number of entities conducting technology transfer activities which include 1) the state geological surveys such as Kansas Geological Survey and Illinois Geological Survey, 2) federal entities such as the Bartlesville Project Office (BPO), 3) regional entities such as the Texas Independent Producers and Royalties Owners Association (TIPRO), the New Mexico Petroleum Recovery Research Center (PRRC), and 4) the Independent Petroleum Association of America (IPAA) which has developed the Petroleum Technology Transfer Council (PTTC). Each of these programs utilize certain technology transfer models or have proposed models and these will be described in the remainder of this section.

\section{TORP Model for Technology Transfer}

The Tertiary Oil Recovery Project (TORP) at the University of Kansas was originally established in 1974 to provide a base of research and development in new technologies for the recovery of petroleum in Kansas and to disseminate information about these technologies to the Kansas petroleum industry. The specific objectives of TORP were and currently are to 1) evaluate the potential of oil recovery processes in Kansas, including tertiary oil recovery processes and more standard technologies such as waterflooding, 2) conduct research and development work on tertiary oil recovery processes which are applicable in the State, 3) disseminate information about tertiary oil recovery processes, waterflooding and reservoir management to the Kansas petroleum industry, 4) interact with representatives of the petroleum industry and provide technical assistance on selected field tests and demonstration projects, and 5) educate students and operators in the technology of tertiary oil recovery and efficient reservoir management.

In 1983, TORP initiated a technology transfer program to assist independent operators in Kansas. TORP's goal in this program is to transfer technology which has high potential for increasing oil recovery efficiency in the near-term. The technology is often conventional, but also includes newly developed technology 
available from applied research entities, consulting firms, and service companies. Technology transfer involves action and people communicating with people in numerous fashions: 1) one-on-one meetings, 2) seminars or technical sessions, 3) workshops, 4) newsletters, and 5) field demonstrations.

An advisory board made up of independent oil operators, consultants, service company personnel, and personnel from oil and gas associations was created when TORP was formed in 1974. This advisory board has been helpful in developing TORP's liaison program. As a result, the program immediately developed a rapport with a number of operators in Kansas and began assessing the problems that operators face.

\section{Components of the TORP Technology Transfer Model}

The TORP technology transfer program assists Kansas independent operators in determining oil field production problems through transfer of ideas, applications, methods, processes, and information about equipment. The program attempts to match the operator's needs with the proper technology, expertise, and oil industry services to solve the problem. Where appropriate, TORP strives to help an operator quickly enhance operations and cash flow to extend the economic limit of the property while more comprehensive measures are developed and applied.

TORP's technology transfer program has several important components: 1) field demonstration projects, 2) educational seminars, workshops, and conferences, 3) publications, including newsletters, and 4) individual meetings, all conducted with trained liaison personnel. Principles behind the model are 1) problem identification, 2) matching solutions to problems, 3) understanding the independent producer's position, 4) anticipating problems, 5) working cooperatively in implementing a project, and 6) not overselling the process being implemented.

Field projects provide a mechanism to demonstrate the manner in which a technology is implemented and the effectiveness of the technology in increasing oil recovery and/or improving production operations. These demonstration projects are done in a cooperative manner with operators. Demonstration projects also provide 


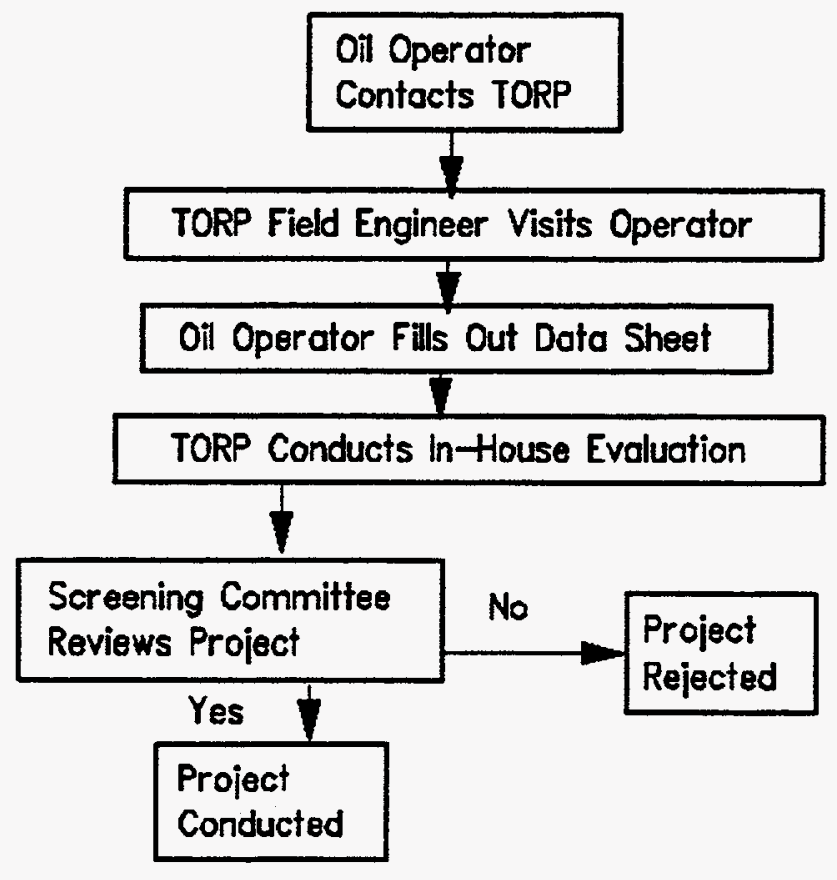

Figure 1-11. Flow diagram of TORP's screening process.

a mechanism to develop a working relationship between independent producers and liaison personnel. The interaction is two-fold: 1) liaison personnel become acquainted with field problems from the viewpoint of the independent operator, and 2) the independent operator obtains evidence that the technology can be implemented successfully in his/her field. When successfully done, this increases the overall confidence of both parties.

The ability of liaison personnel to listen to field operation staff is necessary for project success. Examples of this were when TORP field engineers conducted their first tracer tests and gel polymer treatments. Tracer breakthrough times were shorter than calculated. This indicated that the fractures were more severe than assumed in the calculations. The field operation staff, pumpers, could estimate tracer breakthrough times better using their knowledge of an individual well's daily injection 
and production rates. Injection rates on polymer gel treatments were much higher than initial injectivity calculations had predicted. This indicated that the initial assumptions utilized in the calculations were incorrect.

TORP established a screening committee to assist in the selection of demonstration projects. The objective was to select the demonstration projects that are most applicable to the overall needs of the industry and to avoid conducting services that service companies and consultants do. Selection is based on 1) how widespread the problem is, 2) the proposed method of solution, 3) TORP's capability to conduct or advise on the field test, 4) the need for additional field studies, 5) the economic effect of the solution, and 6) the availability of TORP personnel to work on the project. Figure 1-11 presents a flow diagram of the screening process. First, the oil operator contacts TORP's field liaison engineers. After a phone conversation, the field engineers schedule and conduct a field visit. After the field visit, the oil operator fills out a data sheet as presented in Appendix B. After the data sheet is filled out, TORP conducts an in-house evaluation, which the screening committee reviews. The project is accepted or rejected by the screening committee. In the past, TORP has conducted numerous demonstration projects in the permeability modification and reservoir management areas (Schoeling et. al, 1989).

Seminars, workshops, and conferences are important in a liaison program. Many independent operators want to become knowledgeable about new technology and will participate in these type of meetings. This activity is beneficial in two ways: 1) independent operators get a chance to meet liaison personnel and become acquainted with some of the technology and its application and 2) the liaison personnel have an opportunity to assess the needs of the operator. Independent operators want to understand how to assess reservoir potential and increase production on marginal or uneconomic leases. TORP has held nine biennial oil recovery conferences geared toward the independent operator to introduce new and current technologies. Also, TORP has conducted annual workshops at county community colleges in oil-producing areas. Topics covered have been 1) waterflooding, 2) oil field economics, and 3) use of personal computers in the oil industry. To simulate 
marketing of the current service infrastructure some of the workshop instructors are selected from service companies and consultants. This provides the workshop participants with an idea of the type of technology consultants and service companies currently have available.

Newsletters are an effective means of increasing an operator's awareness of demonstration projects utilizing new or current technology. The operator is made aware of technologies that have been implemented in reservoirs similar to their own. Newsletters are also helpful in advertising conferences, workshops, and seminars.

One-on-one meetings between operators and TORP liaison engineers are an effective way to communicate information about various technologies. While this is somewhat time consuming, a great deal of information can be transferred to an operator which is specific to that operator's problem. When individual one-on-one meetings are conducted properly, they are very beneficial in any technology transfer program. Trained liaison personnel must be able to generate two-way communication, making all parties feel that participation is to their benefit. This type of relationship flourishes when liaison personnel exercise a variety of communication skills including 1) listening without passing judgment, 2) maintaining one's position under stress, and 3) speaking out when the actions of the operator have caused a problem.

\section{Kansas Geological Survey (KGS)}

The Petroleum Research, Mathematical Geology, and Technical Information Services sections at the Kansas Geological Survey conduct regional framework investigations and oil field and outcrop analog studies including those done jointly with TORP; develop and disseminate oil and gas databases including production history, core, cuttings, well-log and geological publications through Lawrence facility and Wichita Well Sample Library and Information Office. Studies relating to improved reservoir description and prediction include refining knowledge and models of stratigraphic architecture and sedimentology, log analysis, automated mapping and computer display. KGS staff also provided data and technical expertise for state and 
national policy decisions. KGS's technology transfer effort includes a continuous series of publications, seminars and workshops covering a wide rage of geological topics, many offered jointly with the Kansas Geological Society, geology departments of universities in Kansas, and more recently with TORP (Carr and Schoeling, 1993).

\section{Bartlesville Project Office (BPO) Technology Transfer}

Technology transfer has been historically a prime function of BPO and its predecessor organizations. In the 1970s and 1980s, BPO's oil research program focused on long-term, high-risk research that industry preferred not to undertake. Projects were performed mostly by the petroleum engineering and chemistry departments of large universities, national laboratories, and the Bartlesville Energy Technology Center. The technology transfer activities accompanying that research were centered mainly on publication and distribution of the quarterly, annual, and final reports from those projects to interested researchers, mainly in academia and major oil industry companies, and sponsorship of symposia, including the biennial Society of Petroleum Engineers/DOE Enhanced oil Recovery (EOR) Symposium and the biennial Reservoir Characterization Symposium (Tiedemann, 1993).

In the wake of the turbulent events in the oil industry throughout the 1970s and 1980s and the resultant Energy Policy Act of 1992, BPO is expanding its technology transfer activities to include an outreach to the smaller independent oil producers who are responsible for an increasingly larger share of the U.S. domestic oil production. This outreach is designed to provide technology developed in the near term (1-5 years) that can be used directly in the oil field to assist in maintaining and increasing production from marginal fields.

The BPO Technology Transfer Program includes 1) publication of Quarterly Progress Reviews containing summary results for EOR projects, 2) distribution of scientific and technical oil recovery reports and reservoir simulation software to researchers and operators in the petroleum community, 3) offering of tutorial workshops involving hands-on experience with reservoir simulation software, conducted by BPO in cooperation with Society of Petroleum Engineers (SPE), and 
4) other educational activities. Additionally, BPO maintains ongoing outreach efforts with the Interstate Oil and Gas Compact Commission (IOGCC) to assess optimal technology transfer methods, and with the University of Kansas Tertiary Oil Recovery Program (TORP), the Kansas Geological Survey, and the Department of Geology, operating under the KU Energy Research Center. In 1992-1993 BPO supported technology transfer seminars conducted in eight Texas regions by the Texas Independent Operators and Royalty Owners Association (TIPRO) and the Texas Bureau of Economic Geology (BEG). This last series of seminars represents the basis of the TIPRO technology transfer model.

BPO is also implementing, as part of the Energy Policy Act of 1992 (EPACT), program technology transfer through research targeted to specific reservoirs. The program has near-term, 1-5 years; mid-term, 5-10 years; and longterm, $10+$ years strategies. In this program, DOE is funding research and demonstration projects in technologies targeted to the specific needs to be met in producing specific reservoir classes. Priority in targeting the reservoir classes is based on potential production and rate of abandonment of wells.

The near-term program involves stimulating the transfer of currently available technologies to domestic operators to reduce the rate of abandonment of wells and increase domestic oil production in the near term. Each demonstration project in the EPACT Reservoir Class program includes a task to transfer its successful technology to operators in reservoirs where the technology is applicable. BPO will assist in coordinating the transfer of these near-term results, with emphasis on reaching small independent producers, and concentrating on those regions having the highest-priority reservoirs in order to preserve access to the reservoirs. The program goals are to:

1) Transfer specific information on successful technologies that are immediately applicable to potential users active in recovering oil in high-priority reservoir class projects.

2) Transfer the results from cost-shared demonstrations of emerging technologies to operators in other areas where the technologies are applicable. 
3) Promote, and coordinate the interaction of service companies and equipment suppliers with operators to maximize efficiency of recovery.

The mid-term program will emphasize on maintaining contacts established in the near term with operators, service companies, consultants, researchers and others to sustain production in high-priority reservoirs through continued application of proven technologies, while monitoring, evaluating and applying emerging advanced technologies resulting from field tests and demonstrations. The effect of the new technologies on production and abandonment rate will determine the extent to which each technology is emphasized in the technology transfer activities.

Field projects and demonstrations will be monitored for predictable, costeffective technical and economic performance, and rated for routine applicability, extrapolation to other reservoirs, and effective methods of presentation to potential users. Technology will be transferred for application to other reservoirs in the same or similar classes.

The principal activity under the long-term program will be the dissemination of research results, primarily in geoscience and extraction technology, from universities and National Laboratories, much as in the 1970-1980s period of high-risk, long-term research projects.

\section{TIPRO Model}

The Texas Independent Producers and Royalty Owners Association (TIPRO) and the Texas Bureau of Economic Geology have developed a three-phase program to identify and address the technology transfer needs of Texas independent operators. The first phase, which was completed in the fall of 1991, consisted of a series of technology forums that identified and prioritized independent operators' technology needs on a regional basis. The second phase, carried out in late 1992 and early 1993 , consisted of a series of technology workshops that addressed the needs identified by producers during the first-phase technology forums. To sustain this technology transfer effort on a long-term basis, the third phase of the program is proposed to focus on developing long-term technical support through regional information centers. 
According to input received from forum participants, the five highest priority areas for technology transfer are 1) improved exploration strategies for discovering remaining oil and gas resources, 2) advanced formation evaluation techniques for improved assessment and development of oil and gas reservoirs, 3) completion technologies to improve reservoir stimulation and wellbore cleanup, 4) cost-effective access to advanced seismic imaging techniques to reduce exploration risk and optimize field development, and 5) improved characterization of oil and gas reservoirs so that uncontacted and bypassed resources can be recognized and developed. In addition to these high-priority areas, other identified areas related to reservoir performance prediction, oil and gas data bases, production wellbore mechanics, advanced EOR extraction processes, environmental regulations, drilling design, and production operations.

\section{PRRC Model}

The New Mexico Petroleum Recovery Research Center (PRRC) was formed in 1975 with one of the goals involving dissemination of petroleum recovery information to the public. Technology transfer is conducted both through traditional and innovative mechanisms. Methods include written reports, technical papers, presentation of results at various conferences, meetings, seminars, and newsletters. Other methods involve field demonstration projects and one-on-one meetings between industry personnel and staff at PRRC.

The PRRC has developed two short courses, one in reservoir characterization and the other wastewater management approaches and techniques. They have a field engineer who assists operators with advice on production problems. A number of field trials designed to improve oil and gas production have been conducted in joint efforts between the PRRC and the oil operators (IOGCC, Vol 1, 1993).

\section{PTTC Proposal}

In January 1993, the Independent Petroleum Association of America (IPAA) formed the Petroleum Technology Transfer Council (PTTC) to address the technology 
needs of the oil and gas producing community and to identify the best mechanisms for improving the transfer and communication of technology to domestic producers. The PTTC includes representatives from the major companies as well as independents, academia, state geological surveys, professional societies, service companies, the research community, and other groups involved in the technology transfer process. After the organizational meeting, a conclusion was to recommend forming a national "umbrella" technology transfer organization to facilitate and encourage broader awareness, dissemination and application of exploration and production technologies to oil and gas operators.

As a result, a report was written and submitted to DOE recommending that such a technology transfer organization be formed and supported. The program goals are to 1) assure the availability and accessibility of current technologies to independent oil and gas operators, 2) establish an on-going organization to assure future effective technology transfer to the industry, and 3) provide mechanisms for communicating operators' technology needs back to the research community. The program as proposed is to be funded for five years or until it becomes self-sustaining.

The proposed program has three primary tasks: 1) planning and managing the national technology transfer organization, 2) conducting problem identification workshops, and 3) developing regional resource centers. The problem identification workshops would be used to identify and prioritize the problems faced by operators in specific oil-producing regions. The regional resource centers would be established in approximately 14 locations across the country. They would provide operators with access to a library, technical and referral assistance, and computer workstations with data covering project histories, field and reservoir data, and analytical software. It is proposed that locations would be at institutions with operating technology transfer organizations (PTTC, 1993). 


\section{CHAPTER 2}

\section{THE KANSAS TECHNOLOGY TRANSFER MODEL (KTTM)}

\section{Purpose and Design of the KTTM}

In August 1992, the Energy Research Center (ERC) at the University of Kansas was awarded a contract by the United States Department of Energy to develop a technology transfer model which could be utilized throughout the United States. As a result, the KTTM was developed by joint efforts of an interdisciplinary group. It is an expansion and adaptation of the KU TORP model, which was started in 1983 and has been quite successful through the years. This chapter describes the KTTM, with detailed descriptions of each component, the integration of disciplines, the working entities implementing each component, and a possible evaluation program to improve and assess the model.

The focus and goal of the KTTM is to transfer technology to oil operators who, in turn, can apply the technology to reduce the rate of well abandonment in the near term and increase oil recovery. The emphasis is on technology awareness and application of current and newly developed technology. The model is documented so that it can be applied in a similar manner in other oil-producing states.

One of the major reasons the TORP model has been successful is the industry participation component involving problem identification, which results in the model emphasizing a market-driven approach, as opposed to a product-driven approach. In the past TORP conducted problem identification through informal one-on-one meetings, technology workshops, and advisory board meetings. It was obvious that the KTTM had to have this special attribute to be successful and adaptable to other oil-producing regions. It required methods to formalize problem identification, ensure technical reliability, and ensure interdisciplinary activities. On this premise the scope of the model was limited so that it could be developed, tested, and documented in one year.

The flowsheet of steps conducted in designing the program is presented in Figure 2-1. The design approach followed six steps: 1) development of program goals, 2) breakdown of goals into manageable objectives, 3) development of tasks 


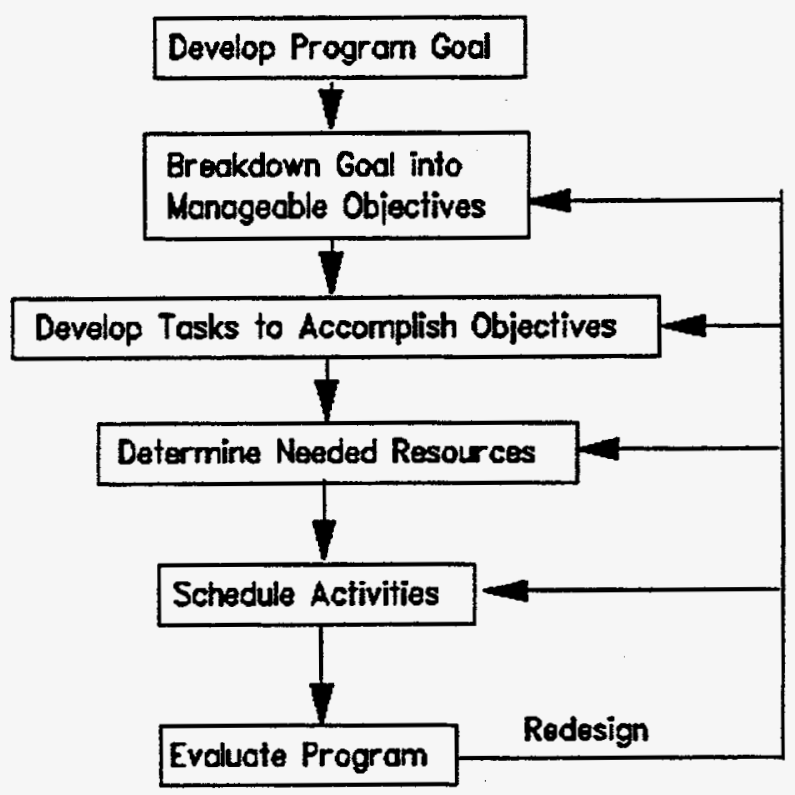

Figure 2-1. Developmental stages of program design.

based on the manageable objectives, 4) determination of resources to conduct the tasks, 5) development of a schedule of activities, and 6) development of an evaluation program. Although the flowsheet presents the steps in sequence, many of the steps were conducted in parallel. As the program is evaluated, it should be redesigned based on the discrepancies found in the evaluation. This procedure in development of the program design should be utilized in adapting the KTTM to other regions.

\section{KTTM Description}

An important point is that the program have clearly defined goals. Since this program is part of a DOE initiative, the goals are developed to complement the DOE's oil implementation program and achieve regional objectives in parallel. For that reason, the overall goal is to transfer current and newly developed technologies 
to oil operators who can apply the technology to reduce the rate of well abandonment in the near term and increase oil recovery. The overall goal is then broken down into manageable objectives which a region can implement in a reasonable period of time. As a result, the objectives of the KTTM are to 1) identify regional problems, 2) identify technologies that are possible solutions, and 3) identify methods to transfer the technologies to the oil operators.

The model is composed of the following major tasks deemed necessary to fulfill the objectives of the program.

1) Identify operators and conduct problem identification workshops in various operating regions.

2) Conduct technology workshops and seminars for operators to evaluate data and technology identified as having potential to solve problems.

3) Conduct and document demonstration projects to show how a technology is implemented and the effectiveness of the technology in increasing oil recovery and/or production operations.

4) Conduct expanded technology transfer activities to include interdisciplinary activities in a given region. Developed activities such as database development, 3-D computer reservoir visualization, and current petroleum libraries are expanded to provide operators with assistance to solve technical problems. These are additional resources necessary to accomplish the overall goal of the project. This component involves hiring the appropriate number of engineers and geologists to conduct all tasks adequately and the purchasing of proper equipment to expand technology transfer activities.

The KTTM is designed with the following working entities; 1) a regional resource center which consists of technical interdisciplinary personnel, 2) a regional coordinating group which functions as an advisory board, and 3) a working industry infrastructure. The overall structure of the regional program is presented in Figure $2-2$. 


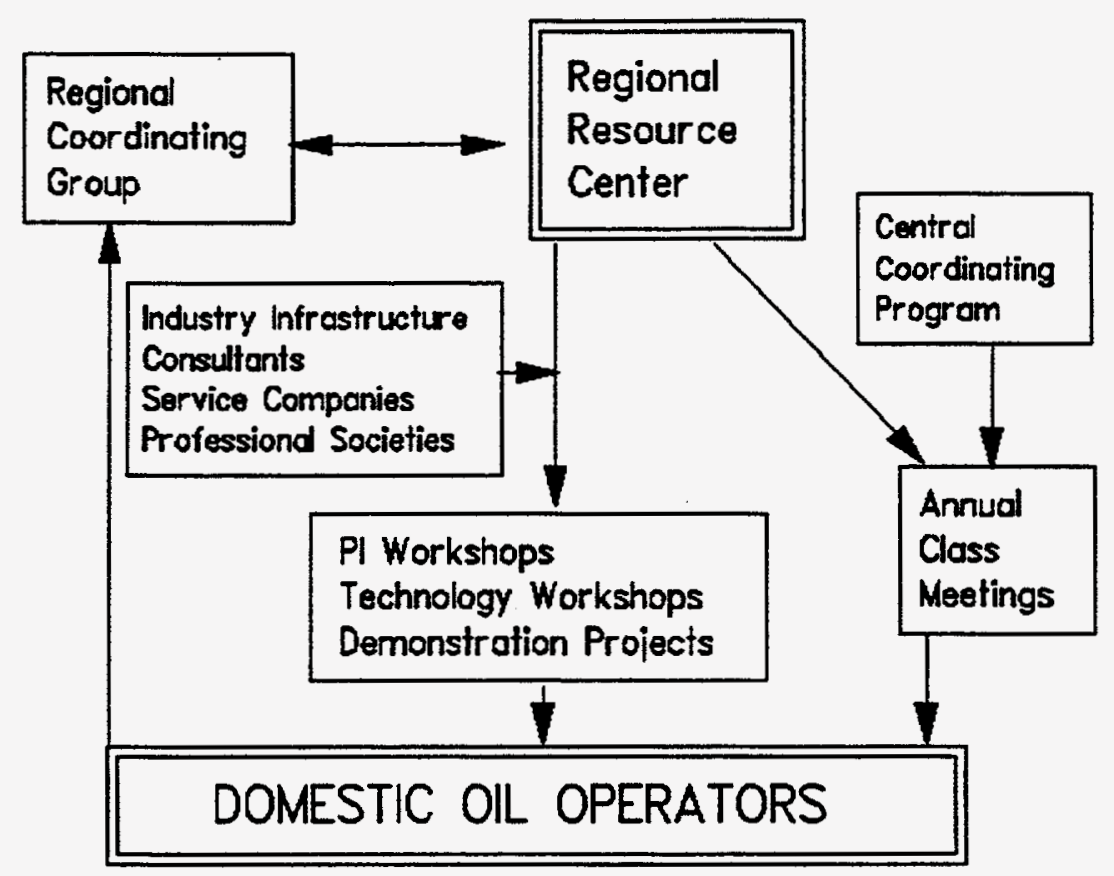

Figure 2-2. Organizational structure of the Kansas Technology Transfer Model (KTTM)

The resource center's function is seven-fold:

1) Organize and conduct problem identification and technology workshops.

2) Develop demonstration projects and assist DOE in conducting reservoir class meetings in support of the Federal Oil Research Program Implementation Plan (FORPIP).

3) Collect reservoir data for regional database development to be transferred to the Tertiary Oil Recovery Information System (TORIS) database at BPO and utilized in determining the impact the technology transfer program has had on industry; this is one of the long-term evaluation techniques to be utilized in the program evaluation.

4) Provide a library of petroleum literature for the local domestic operator.

5) Provide an unbiased referral assistance (i.e., consultants, service companies). 
6) Provide computer workstations that will be used for 3-D modeling, computer training, and access to databases.

7) Act as a clearing house for information and publish a newsletter.

To carry out these functions the resource center requires the following resources: 1) qualified technical and liaison technology transfer staff, 2) computer hardware and software, 3) space to conduct operator meetings and computer work, and 4) space for a library. The number and type of technical personnel depend on the region size and reservoir types. If the region is large and diverse, more technical personnel will be required since more workshops will be necessary. Resource center space will be dependent upon the number of technical staff and expected visits from operators.

The regional coordinating group consists of geological and engineering consultants, independent operators, and service company personnel. The functions of the group are the following:

1) Identify existing programs and capabilities.

2) Assist the resource center in the administration of technology. transfer activities.

3) Provide advice for problem identification and technology workshops.

4) Assist in program evaluation.

\section{Problem Identification (PI) Workshops}

A basic assumption in the KTTM is that problems related to petroleum production confronted by operators must be identified so that appropriate technology can be brought to bear on those problems. Operators should play a major role in identifying the problems. That is, while operators may not recognize or understand all the problems affecting production, their experience does provide important insight into most, if not all, of the significant problems.

Once the important problems related to petroleum production have been identified, action can be taken in a technology transfer program to address those problems. 
One useful approach to identify problems on a regional basis is the use of problem identification (PI) workshops. The use of PI workshops is a general approach which can be applied to identify critical problems oil operators face in any given oil region of the United States. Problem identification is necessary in identifying appropriate solutions, and therefore the technology needs, of a given region. Without adequate problem identification, the technical entity may develop solutions for perceived problems, which may or may not coincide with actual problems. In the past, TORP has conducted problem identification utilizing advisory boards and one-on-one meetings with individual operators. This has worked effectively in identifying local problems. However, in developing a generalized technology transfer model, it is important to implement a standard approach capable of identifying problems on a regional basis which can be utilized by other technology transfer entities in the United States. The PI workshop concept will help identify appropriate solutions on a regional basis. The workshops focus on both near- and long-term problems. However, emphasis is placed on near-term problems in the beginning of the project.

Dependent upon the types of problems to be identified, PI workshops can target specific groups, or industry people as a whole. For instance, field superintendents and field personnel are usually most knowledgeable about equipment and operating problems. Engineers and geologists are typically more interested in reservoir problems and well completions. If reservoir problems are of priority, engineers and geologists are targeted to participate in the workshops. If industry-wide problems are of priority, all types of industry personnel should be asked to participate. In testing the KTTM, industry-wide problems were the priority and all types of industry personnel were invited.

\section{Organizing a PI Workshop}

In organizing a problem identification workshop the following steps are taken: 1) divide the geographical region into subregions, 2) identify potential participants with expertise covering the spectrum of anticipated problems, 3) set the location and 
time for the workshop, 4) send invitations to potential participants, and 5) conduct the workshop.

The workshops are held in various locations or subregions throughout the resource center's geographical area of responsibility. Subregions are categorized by type of reservoir classifications and operator size/type. Oil is produced differently on a regional or subregional basis because of the reservoir type, surface conditions, size of the companies, and local environmental and statutory requirements. This leads to different prioritization of problems by operators.

Workshop participants are identified by state operator associations and technical societies such as the Society of Petroleum Engineers (SPE), the American Association of Petroleum Geologists (AAPG), and local petroleum-related associations. Experience with the model suggests that the total number of participants be no larger than 25 per workshop, and that the participants be broken up into approximately four groups. This is an ideal workshop size and is easily accommodated. Sometimes specific individuals are identified in a company and asked to attend; in other instances, companies are contacted and asked to send any appropriate representative. This is dependent upon the type of audience targeted for the workshop. This method of selection results in a diverse group of participants, ranging from pumpers, geologists, and engineers to presidents of companies, which will provide diverse opinions. As previously mentioned, the target audience should be selected based on the type of results needed from the workshop. Service companies, consultants, and other petroleum-related personnel should also be represented.

The workshop is held at a facility where a meal can be served. The room is large enough that four separate groups can have discussion without interference. The layout of the room influences the response of the participants. An ideal time to start the workshop is mid morning, allowing the participants a chance to go to their offices and take care of business before the workshop. The workshop is no longer than four hours including lunch. 
An invitation is sent to each prospective participant designating the time and location of the workshop, an overview of the objective of the workshop and specifying an RSVP date a week prior to the workshop. In the overview of the objective of the workshop, it is very important to stress that identified problems will not be associated with individuals. This gives the potential participants a feeling of confidentiality, and the response to the invitation will be higher. An example of an invitation is presented in Appendix A.

To ensure attendance, the technology transfer staff must personally contact potential participants who do not RSVP. The personal contact reinforces the importance of the PI workshop.

\section{Conducting a PI Workshop}

A workshop should be started on time and a comfortable atmosphere generated so that operators feel they can say what they want without criticism. The facilitator should stress the confidentiality of the meeting in that identified problems will not be associated with participants and that they will be acknowledged for their participation only on a group basis.

Questions are open ended to generate free thinking and not influence the answers. The following two questions are suggested in the initial problem identification workshops:

1) What are the problems that must be addressed to sustain production from existing reservoirs in the next 12 months to 5 years?

2) What technology would you wish for to sustain or increase production?

The first question is broken down into categories. Examples of some good categories are regulatory problems, production problems, and reservoir problems. The regulatory category is very helpful in getting participants to talk because of the high level of concern and emotion that this topic generates. The production category includes topics such as completion practices, wellbore problems and surface problems. The reservoir category focuses on reservoir recovery problems. The facilitator encourages participants to respond with answers and discussion. Once answers to 
each question are listed on a flipchart, participants prioritize the answers by category on a piece of paper. If the facilitator feels that the group wants discussion, the facilitator does not discourage it. However, the facilitator keeps the group discussion focused on the question. After the problems are prioritized by category, the participants are asked to prioritize problems from all the categories to develop a list of "overall problems." On the participant's prioritization lists, they are asked to identify themselves by job type, e.g., field superintendent, engineer, geologist, or pumper. The second question is asked in order to generate discussion on the technologies needed to solve the problems. The facilitator should ensure that the group focuses on technologies and not other factors such as regulations as a method of solving the problem.

In the last 30 minutes of the workshop, ask the participants, "How can this problem identification workshop be improved?" This question is asked to generate discussion on improving the format of the workshops. Each of these answers should also be prioritized. After this discussion the participants are requested to complete an evaluation form which is also presented in Appendix A.

\section{Practical Considerations in Designing and Developing the Problem Identification Workshop Format}

In designing the PI workshop format, four distinct phases are identified and utilized. The first phase explains the workshop objective, provides an explanation of the subject manner, and explains the importance that each individual contribute any information they feel is pertinent to the issue. As a result an introduction should be developed and specific questions identified which can be utilized in the workshops. This introduction is then presented to the entire group at the beginning of the workshop.

The second phase is to get an understanding of how the group viewed the issue. To encourage participants to speak up and provide their viewpoints, the large group is divided into smaller groups (4-6 participants per group). Each small-group facilitator is provided some open-ended questioning techniques to generate discussion, 
and a flipchart to list all possible answers to each question that the entire group can see and consider.

The third phase is to bring out the underlying reasons for the differences in opinion. This is done by asking participants to prioritize the answers or problems listed on the flipchart. This technique will bring the group to a discussion phase.

The fourth phase is to gather information and analyze the results after the workshop. The results are analyzed by using the participants' priority lists. Problems are prioritized first by category and then on an overall basis. The results are then sent to each participant.

\section{Technology Workshops}

The function of technology workshops is to provide operators with information about technologies which might be solutions to identified problems in their region. This is the technology awareness and acceptance stage. Technologies are matched with identified problems as possible solutions by technical personnel from the industry infrastructure. Workshops are taught by the same technical infrastructure, consultants, service companies, and university personnel. The workshops are conducted in given regions to increase technical awareness of the oil operators.

The technology workshops are low-cost, hands-on workshops or seminars in which currently available technologies that have potential to solve priority problems identified in the PI workshops can be introduced. The workshop instructors can include both university and industry personnel knowledgeable in the technology and who can relate well to the practical needs of operators and other participants.

Organization of technology workshops involves 1) selecting topics, 2) selecting a suitable time and location for the workshop, 3) selecting instructors, 4) publicizing the workshop to oil operators, and 5) writing and editing workshop participant's and instructor's manuals.

To select the workshop topics, utilize the results from the problem identification workshops. The identified problems from the PI workshops are communicated to a technical team who can identify respective technologies. This 
technical team's responsibility is two fold: 1) to identify possible technologies which can solve the identified problems, and 2) to identify instructors for the technology workshop. The technical team consists of personnel from the resource center, academia, service companies in the area, technical societies (SPE or AAPG), or experienced oil operators.

Technology workshops are conducted with different formats which include a hands-on workshop format or a seminar format. The format utilized is chosen based on the needs of industry. The workshop format involves the participants in a problem solving environment. Problems are worked by the participants and the participants leave with the ability to utilize the technology. The advantage of this format over the seminar format is that the participant leaves the workshop with a skill and can implement the technology more readily. In the seminar format, the objective is to increase the participants' awareness of the technology, but not actually have them become skilled in the technology in a "hands-on" sense. The advantage of the seminar format is that more material can be presented in a shorter period of time. This seminar format is used when a variety of technologies can be utilized to solve an identified problem that has high priority. The participant is given an awareness of each technology and how to become more familiar with it. The technology transfer team should determine the format prior to the workshop/seminar and act accordingly.

Technology workshops are located in the region of interest, ideally at a college or in a location where proper facilities can be made available. They are located where the majority of participants can be there in less than two hours one way. Oneday workshops tend to be better attended than multi-day workshops. It is essential to provide lunch as part of the workshop to encourage social interaction.

Workshops are widely publicized to enhance attendance. A brochure used for this purpose should be of professional quality and contain 1) a brief outline of the topics of discussion, 2) a biography of each instructor, 3) a description of the audience being targeted, and 4) time and location of the workshop. It is best to send the brochure two months prior to the workshops and again two weeks prior to the 
workshop if the preregistration is not nearly full. The brochure is sent on the following mailing list types: 1) resource center, 2) technical societies, and 3) operator organizations.

For each workshop, written material is prepared for the participants. The written material is usually a proceedings volume containing papers, a workbook, or a manual. This requires that each instructor develop written material. Sometimes it is difficult to get written material from service company, consultant, or industry personnel. When this situation occurs, it is usually necessary to have a resource center technical person or academic person coauthor the presentation. Also, it is possible to tape the presentations so they may be transcribed later, if written material cannot be prepared ahead of time.

\section{Demonstration Projects - Operation and Documentation}

The function of field demonstration projects is to show operators in a given region that a technology can be implemented economically. This provides the operator with a sense of confidence that a technology is feasible in their reservoir type. This is a very important component in technology transfer which assists in getting technology accepted throughout industry. This section describes the method of developing and documenting a demonstration project.

A demonstration project is conducted in a cooperative manner with the operator. Demonstration projects provide a mechanism to develop a working relationship between independent producers and resource center technical/liaison personnel. The interaction is two-fold: 1) liaison personnel become acquainted with field problems from the viewpoint of the independent operator and 2) the independent operator obtains evidence that the technology can be implemented successfully in his/her field.

A screening committee is selected from industry with the assistance of the regional coordinating group and assists in the selection of demonstration projects. The screening committee is made up of service company personnel, consultants, and oil operators. The purpose of the screening committee is to select the demonstration 


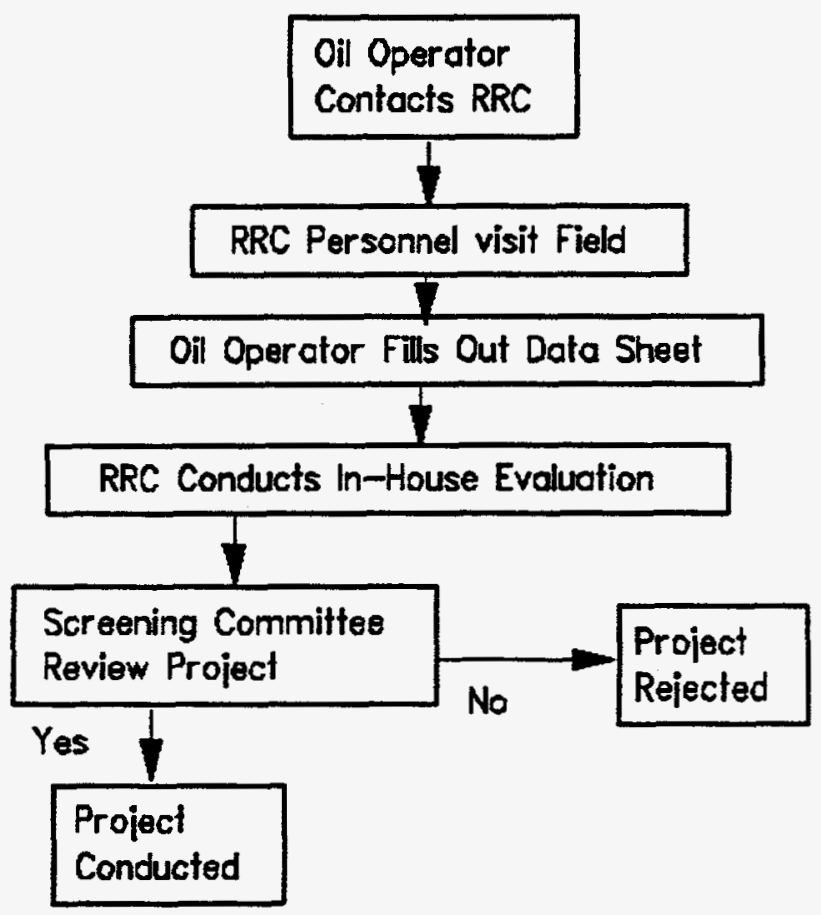

Figure 2-3. Flowsheet of the screening process for the regional resource center.

projects that are most applicable to the overall needs of the industry. Utilizing results from the problem identification workshops, selection is based on 1) how widespread the problem is, 2) the proposed method of solution, 3) the capability of conducting the field demonstration project, 4) the need for additional field studies, and 5) the economic effect of the solution. Figure 2-3 presents a flowsheet of the screening process. First, the oil operator contacts the regional resource center's (RRC) field liaison personnel. After a phone conversation, the field engineers and geologists schedule and conduct a field visit. After the field visit, the oil operator fills out a data sheet as presented in Appendix B.

The regional resource center is involved in demonstration projects, either by direct interaction in field implementation, or in an advisory capacity. Direct interaction involves the RRC having primary responsibility for the design of the 
project, in cooperation with the operator, and assisting in field implementation. The Operator provides supplies, field, manpower, and equipment. In the advisory capacity, the RRC serves to assist in the design by advising the operator and will be an observer in field implementation. The operator or his designated representative will have direct responsibility for field implementation.

In documenting a demonstration project, the document describes 1) an introduction to the technology, 2) a generic method of application or design method, and 3) an example of the technology being utilized in the demonstration project. It is written in language that oil industry personnel can understand. The introduction includes some background on the technology, and related technologies. The method of application describes 1) candidate screening methods, 2) equipment requirements, 3) procedure of design, and 4) the method to evaluate economic potential. The demonstration section contains 1) a description of the problem, 2) a description of the design, 3) results, and 4) a description of problems encountered.

Expansion of Technology Transfer Activities to Include a Interdisciplinary Team and Resources to Complete Tasks

The expanded technology transfer activities must include many disciplines such as engineering, geology, and geophysics. This interdisciplinary team is necessary to assist in conducting workshops, and in developing demonstration projects. Possible expanded technology transfer resources and activities include making available the following: 1) an extensive bibliography of pertinent literature 2) user-friendly PC freeware which can be demonstrated in workshops and one-on-one meetings, 3) workstations which are capable of 3-D visual displays of reservoir architecture and reservoir simulations, 4) electronic connection with campus facilities to enhance computational, data transfer and graphics capabilities throughout the industry, and 5) field equipment to assist in testing. A technology transfer program can also provide resources such as a core research facility, well core samples repository, and production and petroleum geological data bases. Licensed resources such as licensed software are used only for demonstrating successful application of the technology, not 
for commercial applications. A regional reservoir database is utilized in the program evaluation to determine the impact that technology can have on increasing oil production in the region.

\section{Program Evaluation}

The evaluation procedure utilized in evaluating the KTTM is modeled after the "Discrepancy Evaluation Model" (DEM) developed by (Provus, 1971). Modifications were conducted to the evaluation procedure utilizing ideas taken from IOGCC's framework for evaluation of technology transfer programs. The selection of the DEM serves two purposes. It provides information for program improvement and program assessment. It is particularly appropriate for use with new and innovative projects like the KTTM. The model is based on the primary assumption that evaluation must involve the comparison of performance against a standard.

In the model, five stages of evaluation allow the staff and manager opportunity to establish controls, when results do not meet standards. The stages include 1) design evaluation, 2) resource evaluation, 3) process evaluation, 4) output evaluation, and 5) impact analysis. The stages of evaluation correspond to the natural development of programs; planning, installation, early operation, and cyclical replanning. Figure $2-4$ is a flow sheet describing the evaluation process. The first four stages conducted are a near-term evaluation program which can be conducted after one year, while the impact analysis is a long-term evaluation performed after three to five years.

First, a set of standards must be developed, which is a program design. The initial program design procedure is presented in Figure 2-1. This six step process is cyclical in nature. All information generated from the evaluation program is then used in the program redesign, which leads to recommendations for the future.

In the design evaluation, the initial design is evaluated. The initial design is the standard to which the other evaluations will be compared for discrepancies. The following concerns are addressed: 1) was the program goal clearly defined? 2) was the program goal competitive with another program? 3) were the developed tasks 


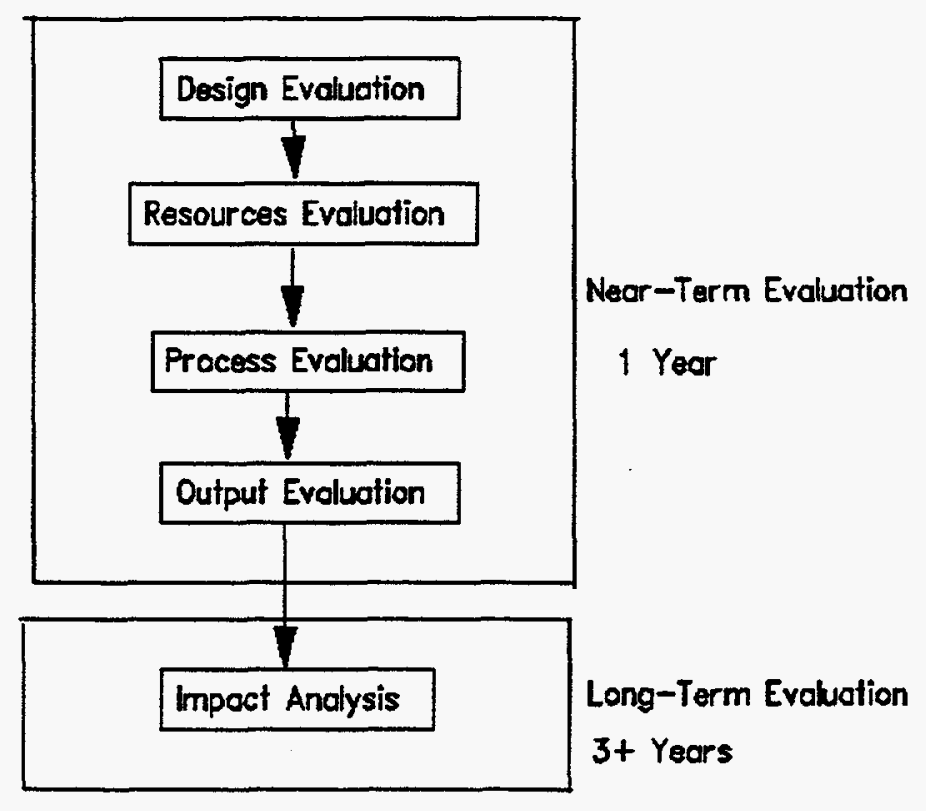

Figure 2-4. Evaluation procedure for the KTTM.

capable of achieving the program goal? 4) were the resources in the design adequate to conduct the tasks? 5) were the tasks scheduled appropriately? and 6) are there any undesirable impacts likely to be produced by program tasks?

The resource evaluation involves a comparison of the actual program resources utilized in conducting the tasks to the resources recommended in the program design. The following concerns are addressed: 1) were the technical personnel hired as qualified as the program proposal recommended? 2) were adequate computer hardware and software purchased as proposed? 3) were the locations of the workshops adequate as proposed? and 4) did the technical personnel have proper facilities at the resource center to complete the identified tasks?

The process evaluation involves a comparison of the tasks implemented in the program to the tasks proposed in the program design. The following concerns are 
addressed: 1) was the developed format for the problem identification workshops appropriate to accomplish the tasks of identifying regional problems? 2) was the workshop format developed appropriate in transferring technology to independent operators as proposed? and 3) were the documented demonstration projects appropriate in describing a technology and demonstrating it as proposed? Techniques used to evaluate the processes include 1) workshop evaluation forms completed by participants, 2) verbal communication from participants, and 3) critiques from instructors.

The output evaluation involves a comparison of results from processes with intended results in the proposal or initial design. This is the part of the evaluation which assesses the program. Categories to evaluate are 1) problems identified in the PI workshops, 2) technologies actually transferred to the independents, and 3) technologies transferred to the independents as a result of the documented demonstration projects. Techniques to evaluate the output are 1) workshop evaluations, 2) the number of participants in the workshops, 3) the number of demonstration projects, 4) the number of demonstration project documents requested, and 5) verbal communication from participants and industry.

The impact analysis is the stage in the evaluation which compares the impact the overall program has on the environment. Did the technology transfer program reduce the abandonment rate of wells in the region? Did any incremental oil result from the program? Were there any technologies transferred to the domestic operator in the region? Effective impact evaluation requires a carefully constructed prediction of the environment with and without the program. This can be a problem because it is difficult to predict what would have happened without the program. Techniques suggested are 1) workshop participant surveys conducted one to two years after technology workshops asking if, after the workshop, technologies presented were being applied and 2) modeling reservoirs in which new technologies were applied to estimate whether incremental oil had been produced. 


\section{CHAPTER 3}

\section{IMPLEMENTATION OF THE}

\section{KANSAS TECHNOLOGY TRANSFER MODEL}

As part of the development of the KTTM under the DOE grant, it was important to document, test, and evaluate the model in Kansas. Since the grant had a limit of one year, the scope of the objectives was limited to a manageable size which could be tested in one year. Figure 2-1 presents the methodology used in designing the program. The program goal was broken down into specific objectives for which a near-term evaluation could be conducted. The objectives were to 1) identify regional problems, 2) identify technologies that were possible solutions, and 3) identify methods to transfer the technologies to the oil operators. The tasks or activities designed to accomplish these objectives were the following: (The schedule for these activities is presented in Table 3-1).

1) Operators were identified and seven problem identification workshops were conducted in various operating regions in Kansas. A problem identification manual was written which describes the method of conducting the workshops and the problems identified.

2) Three technology workshops were conducted for operators to evaluate data and technology identified as having potential to solve problems. Instructor and participant manuals were written for material presented in each workshop.

3) Three demonstration projects were documented to illustrate how demonstration projects are conducted and to indicate the effectiveness of demonstrated technologies.

4) As an additional component, current technology transfer activities were expanded to include the disciplines of geology and geophysics. Resources were expanded to include database development, 3-D computer reservoir visualization, and current petroleum libraries were expanded to provide operators in Kansas with assistance to solve technical problems. These additional resources were necessary to complete the tasks. 
5) Finally, a document was written describing the development and testing of the KTTM. This document is designed to be utilized in the development of other technology transfer programs throughout the domestic industry.

All documents developed were deliverables as a part of the DOE project grant.

\section{Management Style}

In an organized technology transfer program, responsibilities must be defined to streamline the flow of information. Organizations must be developed which have a specific role and responsibilities. The members of each organization must view themselves as an essential, contributing members of the program. Figure 3-1 presents

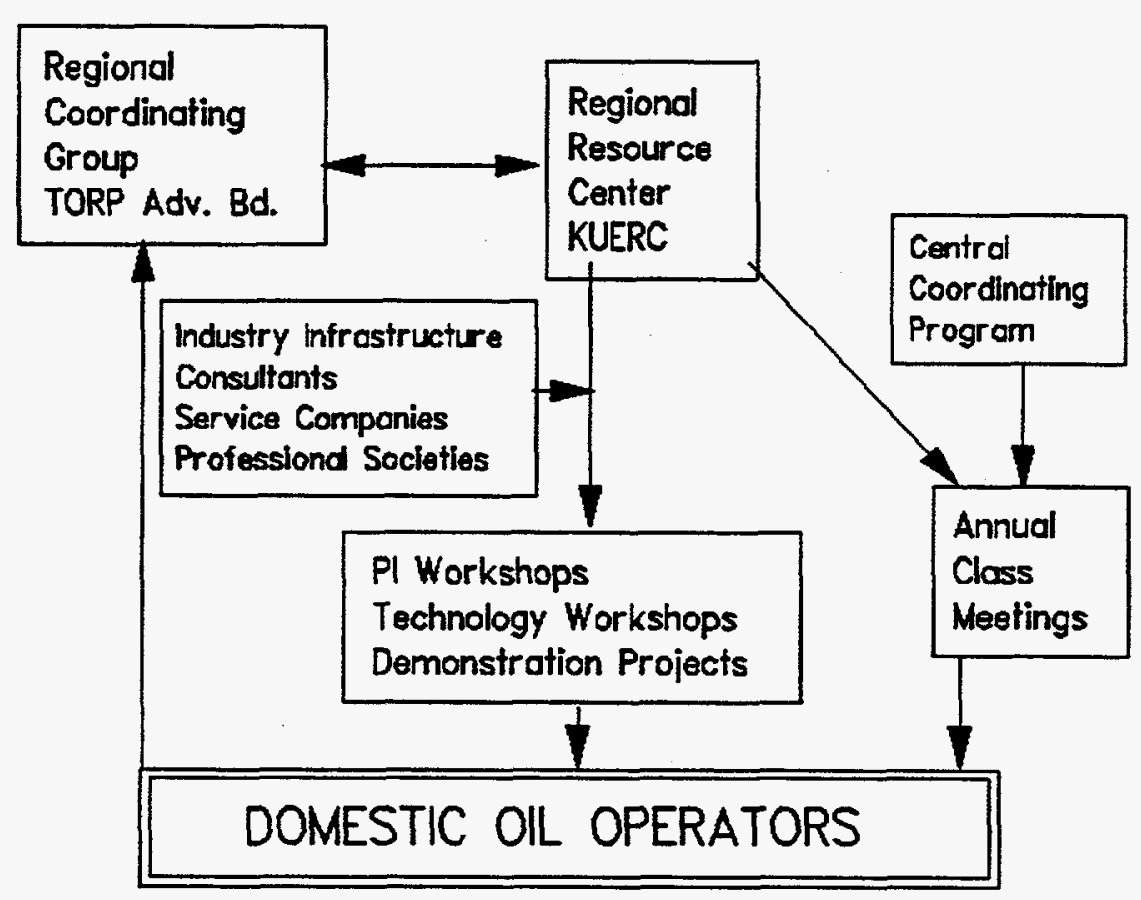

Figure 3-1. Organization structure in implementing KTTM.

the organizational structure used in testing the model. The structure consists of 1) a regional resource center, 2) a regional coordinating group or committee, 3 ) industry's 
infrastructure of consultants, service companies, and professional societies, and 4) the technology transfer process of workshops and demonstration projects to conduct technology transfer. The Central Coordinating Program (CCP) is part of the linkage of all the regional programs and it's function will be discussed in Chapter five. It is presented in this figure since annual class meetings in the national DOE program will be organized in cooperation with regional resource centers.

A resource center was developed within ERC for the technology transfer team to work within. The resource center embodied the technology transfer personnel, computer equipment, and field equipment required to complete the tasks involved in accomplishing the goals of the project. The organizational structure is described in Chapter one and presented in Figures 1-2 and 1-3.

To represent industry, a regional coordinating committee was developed. The regional coordinating group consisted of TORP's advisory board, which is made up of geological and engineering consultants, independent operators, and service company personnel. Kansas' consultants, service companies, and universities were utilized as the industry infrastructure. The overall structure of the regional program and how groups interacted are presented in Figure 3-1.

The management style used by the technology transfer team was called "Management by Objectives" (MBO) which is a well-known management technique used to manage professionals. It relies on goal setting to establish objectives for a project, and for each team member. In theory, objectives are established by having the team members do three things: 1) meet to agree on the their objectives during a given period, 2) develop plans on the method and the timeframe within which the objectives will be accomplished, and 3) agree on the method to determine if the objectives have been met.

An initial meeting was held to present the overall objectives and DOE deliverables to the technology transfer team. In the meeting, each team member agreed to accept certain responsibilities to complete the objectives and DOE deliverables in a certain timeframe. The schedule of activities was agreed upon by the entire technology transfer team. Periodic progress review meetings were held 
where each member presented his accomplishments and strategy for completing future responsibilities within deadlines. If deadlines were difficult to meet, other team members agreed to assist in completing tasks. The method utilized to determine if objectives were met, was a periodical reviewing process by the project investigators.

In the beginning of the project, the technology transfer team met every other week. After the team members felt comfortable with their roles and responsibilities, the meetings were held monthly with members having periodic one-on-one meetings when necessary.

The schedule developed to complete tasks within the specified overall timeframe is presented in Table 3-1. The timeframe of one year was extended a few months since the hiring of the technology transfer team was delayed a few months after project startup. 


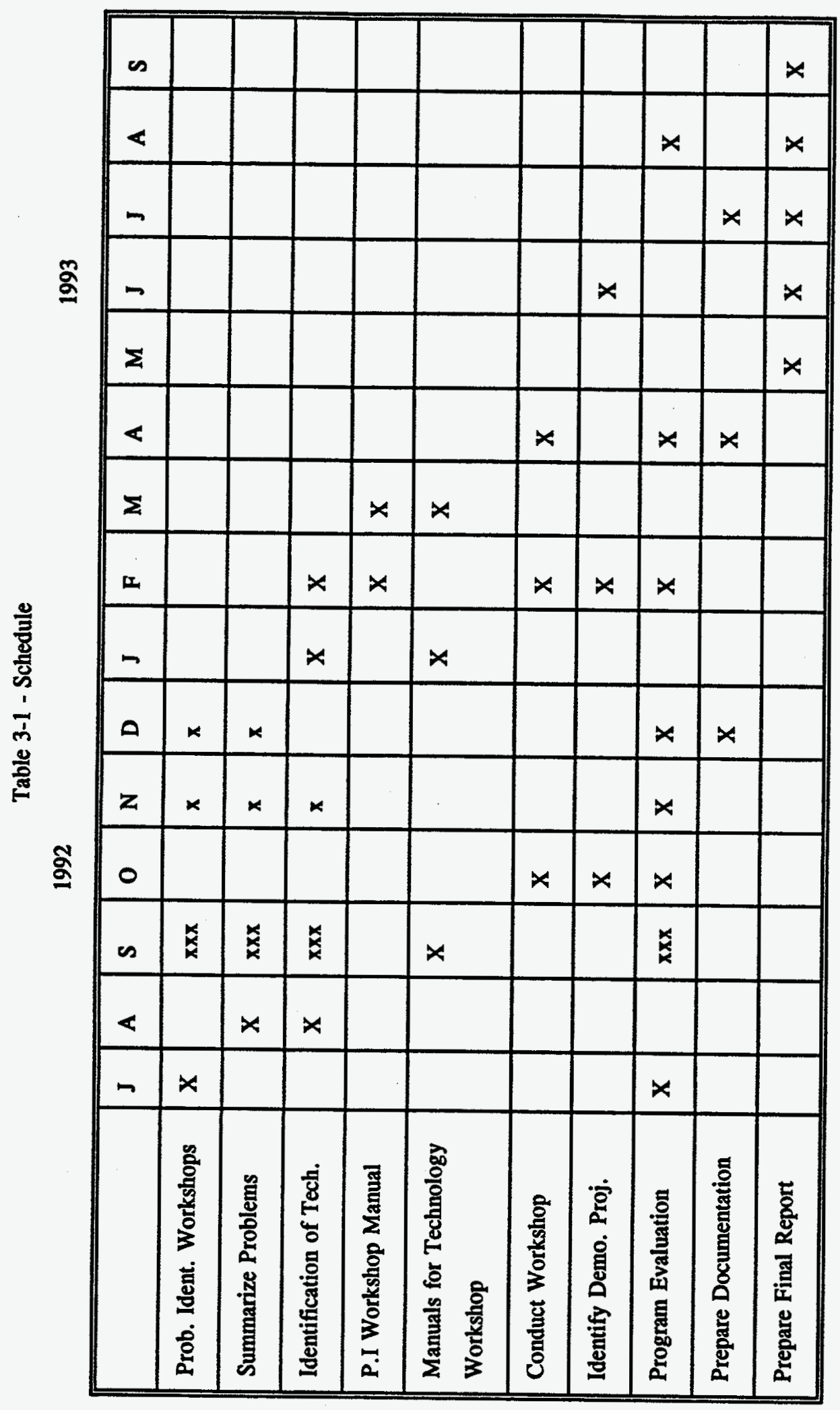




\section{Responsibilities of Various Entities In Regional Program}

The resource centers' (KUERC) function was seven-fold:

1) organize and conduct problem identification and technology workshops,

2) develop and document demonstration projects,

3) collect reservoir data for regional database development,

4) provide a library for local operators,

5) provide an unbiased referral assistance (i.e., consultants, service companies),

6) provide a computer workstation for modeling, training, and access to databases,

7) act as a clearing house for information and publish a newsletter.

The regional coordinating group (TORP's Advisory Board) had the following responsibilities:

1) assist by identifying existing programs and capabilities,

2) assist the resource center in the administration of technology transfer activities,

3) provide advice for problem identification and technology workshops.

\section{Problem Identification Workshops}

To develop and test the problem identification workshop (PI) concept, six regional workshops were scheduled in Kansas. The purpose of these workshops was to 1) develop a method for organizing the workshops, 2) develop a format for conducting the workshops, 3 ) develop a method for evaluating the raw results from the workshops, and 4) test the process.

The original proposal called for a seventh PI workshop. Instead of conducting this workshop in the workshop format at the regional level, it was decided that a summary of all problems identified in the preceding six regional workshops would be analyzed and reported to industry. Therefore, the problems identified in each workshop were analyzed on a regional as well as overall state basis. The results were presented at the seventh TORP conference in Wichita in March 1993. Attendance was over 120 people, including many who were PI workshop participants. The 
participants appreciated the opportunity to view the results of their work.

\section{Organizing the Six Problem Identification (PI) Workshops}

In organizing the six regional workshops, Kansas was divided into regions by size of operator and type of production. These were the initial categories used to determine appropriate regions in Kansas. Oil is produced differently on a regional basis because of the reservoir type, surface conditions, size of the company, and difference in environmental and statutory requirements. This was obvious from the different problems prioritized throughout the regions of Kansas.

Kansas has two basic types of reservoirs which vary in producing mechanism and applied recovery methods. In central and western Kansas, most reservoirs produce from carbonates with wells varying in depths from 3000 to $6000 \mathrm{ft}$. The Arbuckle formation is a large producing carbonate reservoir whose primary energy mechanism is waterdrive. The Lansing-Kansas City is another large producing carbonate reservoir whose primary energy mechanism is solution gas. Waterflooding is widely used as a secondary recovery technique in the Lansing-Kansas City reservoirs, but not in the Arbuckle. In comparison to eastern Kansas, larger independents typically produce in central and western Kansas.

Eastern Kansas reservoirs are typically sandstone with wells varying in depth from 150 to $3000 \mathrm{ft}$. These Cherokee Group reservoirs usually produce with a solution gas primary energy mechanism. In these reservoirs, waterflooding produces the major portion of the original oil-in-place, thus waterflooding technologies are of importance in this region.

Because of these differences, subregions were selected in central Kansas, eastern Kansas, and various portions of western Kansas. The locations of the workshops are presented in Figure 3-2. Two workshops were conducted in Wichita because of the large concentration of independent operators who have headquarters there.

After the subregions were identified, lists of potential participants for each location were assembled. The president of the Kansas Independent Oil and Gas 


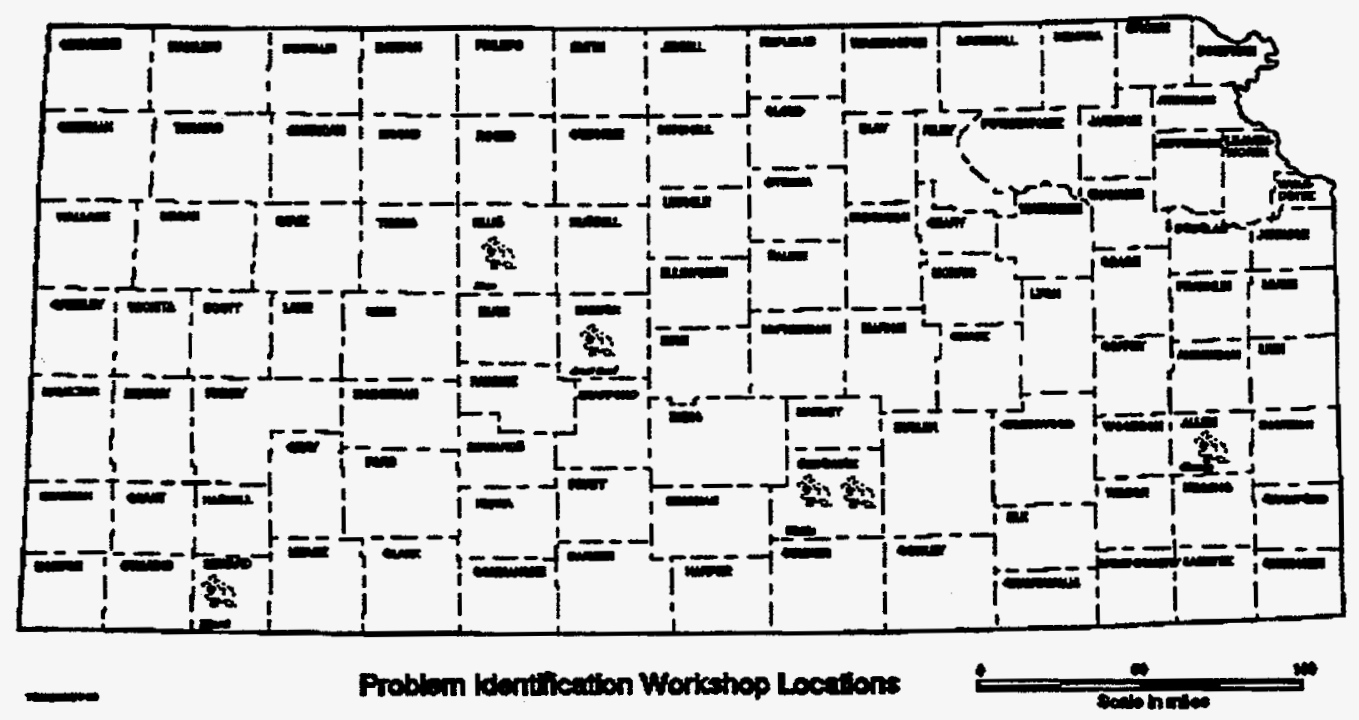

Figure 3-2. Problem identification workshop locations

Association (KIOGA) provided the list for the first workshop in Wichita. Service company personnel and past TORP-KGS associates provided lists for the workshops in Hayes, Great Bend, and Liberal. The president of the Eastern Kansas Oil and Gas Association (EKOGA) provided the list of names for the workshop in Chanute. In the second workshop in Wichita, the technical societies (Society of Petroleum Engineering (SPE), and the Kansas Geological Society, (KGS)) provided the names of potential participants. This method of selection resulted in a diverse group of participants, ranging from pumpers, geologists, and engineers to presidents of companies.

After the lists were assembled, an invitation was sent to each person. A sample of the typical letter is provided in Appendix A. The letter described 1) the purpose of the workshop, 2) time and location, 3) a sample of the type of questions to be asked, and 4) time of adjournment. Approximately 30 to $50 \%$ of those invited sent a positive RSVP to the initial letter, and after a follow-up phone call, another 20 to $30 \%$ agreed to attend. In total, approximately 50 to $60 \%$ of those invited attended a workshop. 


\section{Conducting the Six Problem Identification (PI) Workshops}

The format for the PI workshops changed as experience gained from the early workshops was incorporated into the later workshops. The first two workshops at Wichita and Hays, used a format which was different from the format outlined below. For that reason, the results are presented differently for the two earlier workshops. In those workshops, the problems were not categorized individually. All problems were listed on the flipchart, and instead of prioritizing by category they were ranked by a number 1 through 5 , with 5 being of highest priority. In the last four workshops, the problems were listed by category and then prioritized first by category and then on an overall basis.

The workshops were started on time and the operators were assured of the confidentiality of the meeting in that comments would not be recorded with their names, and that they would be acknowledged with other operators only on a group basis. The following questions were asked:

1) What are the problems that must be addressed to sustain production from existing reservoirs in the next 12 months to 5 years?

2) What technology would you wish for to sustain or increase production?

In the last four workshops the first question was broken down into three categories, i.e., regulatory problems, production problems, and reservoir problems. The regulatory category was very helpful in getting operators talking because of the high concern and emotional response this topic generates. The production category included problems from the wellbore perforations through the surface facilities. This category included wellbore perforations, wellbore, and surface problems. The reservoir category included problems outside the wellbore perforations, such as reservoir recovery problems. Once answers to each question were listed on a tablet, each participant was asked to prioritize the answers by category. After the problems were prioritized by category, the participants were asked to prioritize problems from all the categories to develop a list of "overall problems".

The second question was asked in order to generate discussion on the technologies needed to solve the problems. We had difficulty limiting answers to 
technology solutions; operators often tended to attribute problems to regulatory constraints and restrictions. The facilitator was also challenged with the task of preventing individual participants from dominating conversation while still keeping the discussion flowing.

\section{Summary of Results in Problem Identification Workshops}

The results are presented by question, category, and region. The procedure was to record all the problems the participants could think of, then prioritize the problems, first by category, and then on an overall basis. The results were analyzed on a statewide basis and by region.

\section{Question 1 (Overall)}

The question asked was "What are the problems that must be addressed to sustain production from existing reservoirs in the next 12 months to 5 years?"

\section{Statewide}

Industry personnel indicated their highest priority problem is complying with regulatory rules in the environmental area. They felt that the regulatory agencies need to simplify forms, reduce the number of unnecessary forms, and have knowledgeable personnel enforcing rules and regulations. Two other widespread problems were 1) lack of well information and 2) channeling and coning problems resulting in high water production. The problems are listed below in order of their priority.

1) Cost of compliance in environmental area - Regulatory.

2) Lack of well information - Production or Reservoir

3) Too much paperwork-need one standardized form and agency Regulatory

4) Inconsistencies in rules and regulations - Regulatory

5) Channeling problems and high water production - Reservoir 


\section{First Wichita Workshop}

The first workshop held in Wichita was in July 1992. The format was slightly different from the format in the final four workshops as a result of the development process. In this workshop, all problems were listed in all categories at the same time and the problems were prioritized as a group. The top priority problems are listed below in no priority order. Regulatory problems were not listed, because it was felt that they were unmanageable by the operator. Lack of well information and high water production are problems consistent with the statewide response. Note that the other problems listed are related to the problems of information and high water production.

1) Lack of information

2) Casing leaks

3) Water disposal

4) Water production and high lifting costs

5) Reservoir characterization

6) Presence of old unmarked plugged wells

7) Formation evaluation behind casing

8) Lack of control in injection profile

9) Converting producers to injectors (multiple zones)

\section{Liberal}

Oil production in Liberal is operated by larger independents $(25+$ people on staff) and major oil companies that have technical personnel on staff, therefore technical problems were not a high priority. Regulatory problems dominated the discussion. Since operators produce from all types of reservoirs, i.e., sandstones and carbonates, problems were not reservoir dependent. Listed below are the overall problems in the order of priority.

1) Cost to comply with regulations

2) Complying with the Resource Conservation and Recovery Act (RCRA)

3) Lack of reservoir information 
4) Inconsistencies in regulations

5) Fear of saltwater being classified as hazardous waste

\section{Great Bend}

The overall problems in this region were dominated by problems with Arbuckle production, i.e., strong waterdrive carbonate production. High water production and problems associated with it are listed below in order of priority.

1) Water production and high lifting costs

2) Cost to comply with regulations

3) Lack of experienced personnel

4) Casing leaks

5) Water disposal - number of sites and their ability to take enough volume

\section{Chanute}

Southeastern Kansas oil operators produce from shallow sandstone reservoirs which must be waterflooded to recover the majority of the reserves. Other than the concern for lack of information and the cost to comply with regulations, the problems are associated with waterflooding. Water quality is a major problem and causes wellbore plugging throughout Kansas. Poor sweep efficiency and channeling are two additional problems with waterfloods. Operators indicated that it was very difficult to find qualified field and technical personnel. Below are the problems listed in order of priority.

1) Cost to comply with regulations

2) Water quality

3) Sweep efficiency and channeling

4) Lack of information

5) Lack of education of field and technical personnel 
Hays

The overall problems in this region were dominated by problems with Arbuckle production, i.e., strong waterdrive carbonate production. High water production and problems associated with it are listed below in order of priority.

1) Cost to comply to regulations

2) Water production resulting in high lifting costs

3) The need for better economics utilizing polymer treatments

4) Casing leaks

5) Identifying infill potential through reservoir characterization

\section{Wichita}

The second workshop in Wichita indicated that lack of reservoir and well information was the top priority problem. Lack of qualified field and technical personnel was the second highest priority. The remaining problems were regulatory:

1) Lack of reservoir and well information

2) Education of field and technical personnel

3) Permanent liability on leases

4) Inappropriate and inconsistent regulations

5) Disposal of water

\section{Question 1 (Regulatory)}

The question asked was "What are the problems that must be addressed to sustain production from existing reservoirs in the next 12 months to 5 years?" It was requested that participants consider only regulatory problems in this category.

The top five regulatory problems are presented below for the state and for each region.

Statewide

1) Cost of compliance with regulations

2) Too much paperwork - need one standardized form and agency

3) Inconsistencies in rules and regulations, i.e., personnel unknowledgeable 

4) Liability
5) Lack of forced pooling

\section{Liberal}

1) Cost to comply with regulations

2) Regulatory laws are political and not scientific

3) Complying with the Resource Conservation and Recovery Act (RCRA)

4) Need for qualified personnel able to define problems

5) Fear of saltwater being classified as hazardous waste

\section{Great Bend}

1) Inconsistencies in rules and regulations

2) Cost to comply with regulations

3) Plugging well regulations

4) Lack of understanding regulations by the regulators and operators

5) Problems wells need to be looked at on a case-by-case basis

\section{Chanute}

1) Cost to comply with regulations

2) Inappropriate forms

3) Inconsistencies in rules and regulations

4) Injection well permits

5) Old plugged well regulations

\section{Wichita}

1) Confusion or inconsistencies in regulations

2) Liability of the operator

3) Right to know laws

4) Lack of unitization laws

5) Disposal or pit-pond regulations 


\section{Question 1 (Reservoir)}

The question asked was "What are the problems that must be addressed to sustain production from existing reservoirs in the next 12 months to 5 years?" It was requested that participants consider only reservoir problems in this category.

Reservoir problems varied throughout the State depending on the reservoir types. In western Kansas where the Arbuckle carbonate is the predominant producing reservoir, high water/oil ratios resulting from coning problems were indicated as a major concern. In southeastern Kansas, where the shallow Cherokee sands are the predominant producing reservoir, high water/oil ratios caused by channeling were the major problem. Problems common in all regions were lack of reservoir information, reservoir management, and affordable techniques to characterize reservoirs.

\section{Statewide}

1) Channeling and high water to oil ratios

2) Reservoir characterization, techniques used

3) Reservoir management

4) Lack of data

5) Injectivity problems caused by poor water quality

\section{Wichita}

1) Lack of reservoir information

2) Chemical problems and costs

3) Lack of knowledge of reservoir producing mechanisms and solutions

4) Communication between zones

5) Availability of logging tools

\section{Chanute}

1) Water quality

2) Reservoir characterization

3) Channeling and sweep efficiency 

4) Heterogeneities
5) Lack of information

\section{Great Bend}

1) Water production and high water to oil ratios

2) Lack of reservoir information

3) Reservoir characterization and identifying bypassed oil

4) Channeling behind pipe

5) Commingled production

\section{Liberal}

1) Reservoir characterization

2) Lack of information

3) Reservoir management

4) Skin damage

5) Pressure depletion

\section{Question 1 (Production)}

The question asked was "What are the problems that must be addressed to sustain production from existing reservoirs in the next 12 months to 5 years?" It was requested that participants consider only state production problems in this category.

Listed below are the top priority production problems on a Statewide and regional basis. Common problems in all regions were lack of well information, water quality, corrosion and scale problems, casing leaks, and water disposal problems. Production problems were similar in all regions.

\section{Statewide}

1) Well information

2) Water quality

3) Corrosion or scale - chemical problems 
4) Casing leaks

5) Disposal of water

Liberal

1) Lack of experienced personnel

2) Casing leaks

3) Problem identifying corrosion or scale

4) Water disposal

5) Chemical costs

Great Bend

1) Water disposal and lifting costs

2) Casing leaks on old wellbores

3) Bacteria and chemical problems

4) Landowner demands

5) Insurance

\section{Chanute}

1) Chemical problems

2) Water quality

3) Lack of efficient equipment

4) Poor quality workovers

5) Inexperienced personnel

Wichita

1) Lack of personnel experienced with production equipment

2) Casing leaks

3) Water disposal

4) Information on wells

5) Chemical treatments 


\section{Question 2}

The second question asked was "What technology would you wish for to sustain or increase production?"

The technology "wish lists" were prioritized by region only and reflect the type of problems in each region. Common technologies requested were technologies in 1) improved chemical treatment, 2) improved reservoir characterization, and 3) improved logging. In Liberal, where professional technical personnel are employed abundantly, technical tools such as reservoir simulators and 3-D seismic were on the wish list. In Great Bend and Hays, where Arbuckle production is predominant, participants wished for improved polymers to control water. In Chanute, where waterflooding is predominant, improved water quality techniques were listed.

\section{Liberal}

1) Access to reservoir simulators

2) Better 3-D seismic imaging

3) Improved completion techniques

4) Better logging techniques

5) Better drilling techniques

\section{Great Bend}

1) Improved polymer technology, i.e., without corrosion problems

2) Improved reservoir characterization techniques

3) Improved temporary plugging techniques

4) New casing repair techniques

5) Improved chemical treating technologies

\section{Chanute}

1) Improved sweep efficiency technology

2) Reservoir characterization technology

3) A better information base 
4) Improved water quality technology

5) Improved knowledge and technology in chemical treating

Hays

1) Effective water control technology, i.e., polymers, etc.

2) Equipment to reduce lifting costs

3) Education workshops and case studies

4) Horizontal well technology

5) Improved cased-hole logging

Wichita

1) Access to more reservoir and well information

2) Improved cementing technology

3) Improved logging technology

4) Access to reservoir simulators

5) Education in currently available technology

\section{Technology Workshops}

The function of technology workshops is to provide operators with information about possible technologies which might be solutions to identified problems in their region. In this part of the project, a method to organize and conduct the technology workshops had to be developed and tested. This required development of the following; 1) selection of topics or potential technologies, 2) selection of location, 3) publicizing of workshops, 4) development of workshop format and length, 5) selection of instructors, and 6) preparation of workshop material.

The three topics selected for the test workshops were 1) advanced waterflooding, 2) underutilized technologies in reservoir description, and 3) computer applications. In the selection of topics, we utilized the identified problems in the PI workshops and attempted to match technologies to problems. Although regulatory problems were given highest priority, it was decided that they would be best dealt 
with by the Kansas Corporation Commission, so regulatory issues were not selected as a workshop topic.

Waterflooding was selected for a technology workshop since water channeling, water quality, and improvement in polymer treatments were designated as having high priorities in the reservoir and overall prioritizations. Each of these topics were incorporated as subtopics of the seminar. The seminar covered 1) an introduction to waterflooding, 2) proper data collection to identify problems, 3) water quality, 4) case studies, and 5) remedial work such as gelled polymer treatments.

Reservoir description was selected for a technology workshop since it was identified as a high priority item in most of the subregions. Since lack of data was a major priority problem identified in nearly all PI workshops, it was decided that the theme of the workshop be underutilized technologies for reservoir characterization. The objective of the two-day seminar was to examine cost-effective, underutilized technologies that use reservoir descriptions to improve oil recovery. Some of the subtopics in the seminar were 1) a prologue to reservoir description, 2) new well logging techniques, 3) the role of 3-D seismic technology in reservoir description, 4) the use of core evaluation in reservoir description, 5) the use of transient testing in reservoir description, and 6) simulation which is a tool to improve and test a reservoir description. This workshop was presented in a seminar format because of the broad coverage required.

Computer applications was selected as a topic for a technology workshop because of the variety of problems that can be addressed. To better target this workshop, a questionnaire was sent out through the Kansas Geological Society to determine the type of computers used in industry and the degree of use. It was determined that the overwhelming majority of independent oil producers used DOS based PCs, with only $8 \%$ indicating that they used Macintosh. Approximately onethird of the respondents to the questionnaire indicated they were "heavy" computer users, while $11 \%$ indicated they did not use a computer for business purposes. The objective of the two-day workshop was to examine cost-effective PC-based computer technologies that can be utilized by oil and gas producers to improve efficiency of 
operations either through problem identification, problem solving or time saving applications. The ultimate goal was to improve efficiency of operations through significant time savings and greater breadth of utilization of problem solving techniques. Subtopics in the workshop were 1) database software, 2) wireline log analysis, 3) economic analysis, 4) computer mapping, 5) computer simulation, 6) transient testing software, and 7) Society of Petroleum Engineering (SPE) freeware.

The workshops were held at smaller colleges, seminar halls in bank buildings, or community colleges in the vicinity of the offices of the participants. The technology workshops were low-cost, hands-on workshops. The operators were introduced to those technologies which have potential to solve problems identified that were high priority. Locations were 1) Barton County Community College in Great Bend, Kansas for the advanced workshop on waterflooding, 2) Bank IV in Wichita, Kansas for the workshop on underutilized technologies for reservoir description, and 3) Wichita State University in Wichita, Kansas for the workshop on use of personal computers in the oil industry. Figure 3-3 shows the locations of the technology

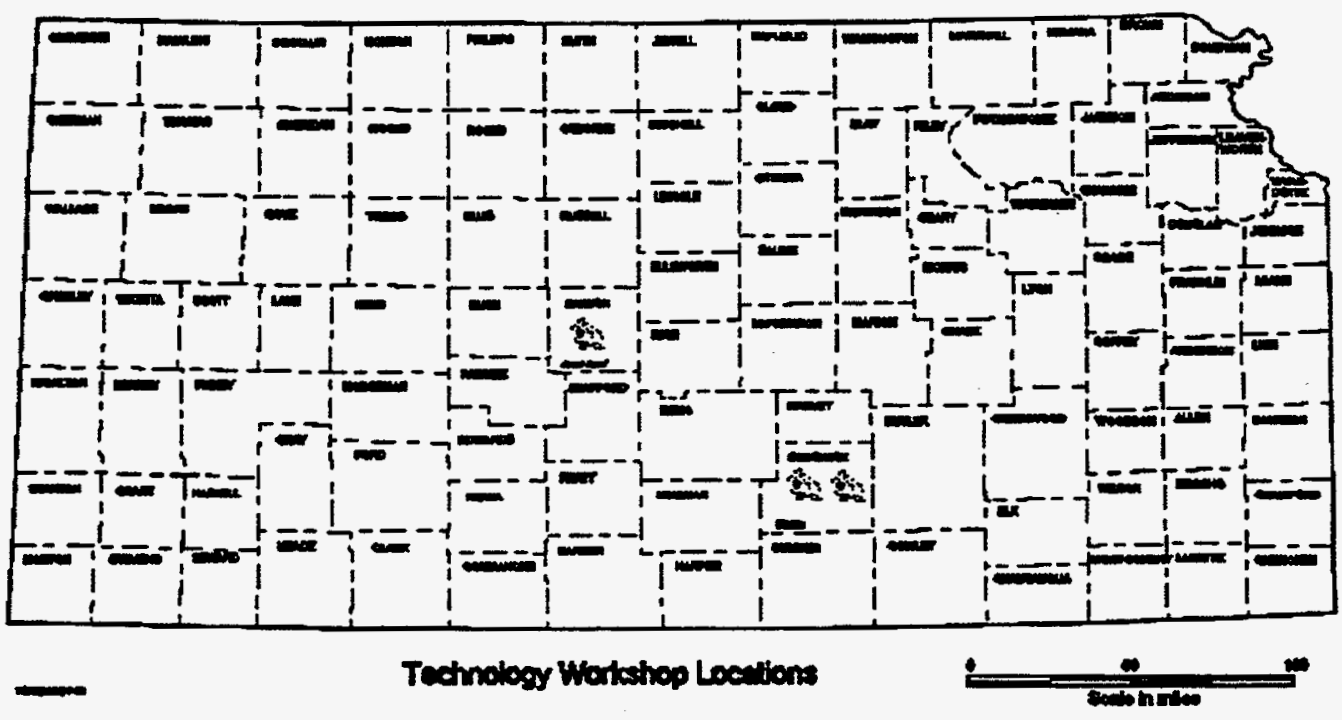

Figure 3-3. Locations of the technology workshops. 
workshops. These workshops were organized by the liaison technology transfer staff at the resource center, with cooperation of community colleges and the industry infrastructure.

Publicity was conducted using TORP's and the community college's mailing lists. Also the following organizational newsletters were utilized: 1) the Kansas Independent Oil and Gas Association (KIOGA) and the Eastern Kansas Oil and Gas Association (EKOGA), 2) Kansas Geological Society, 3) Kansas Geological Survey, 4) Tulsa Geological Society, and 5) Rocky Mountain Association of Geologists. The brochures contained 1) time and location of the workshop, 2) an overview of the workshop, 3) the intended audience, and 4) a preregistration form.

The waterflood workshop was a one-day workshop while the other two were for two days. If the scope of the topic permits, it was found that a one-day workshop was better attended. The computer applications workshop was conducted on a Friday and Saturday to gain access to a computer laboratory, which worked well in our case. In the two-day workshops, a social gathering was conducted on the evening of the first day. Vendors and speakers could demonstrate their technology in booths at this event. This was found to be very productive because of the additional informal interaction between speakers and participants.

Overall, it was determined that the workshop format had better results than the seminar format in getting technology to the user. It was found that the participants must involve themselves in using the technology to remember and become capable of using the technology after the workshop.

Selection of instructors was very important. Where possible the workshops were taught by representatives of the local technical infrastructure consisting of consultants, service companies, and university personnel. The regional coordinating committee, technical societies, and personal contacts of the organizers were the instructor resource base. In the waterflood workshop, the instructors were mainly university personnel with one industry consultant providing the case study section. One difficulty encountered was getting the industry instructors to document their presentations. With any industry or gratis speaker, the organizer has no real control 
to ensure that deadlines are met and illustrations are supplied. It was found that this can be overcome by having the resource center staff coauthor papers with industry persons, asking for documentation prior to presentation, and allowing plenty of time to meet deadlines. It is suggested that a week or two beyond the announced deadline be allowed for a firm publishing deadline, so that stragglers will get their papers, abstracts, and illustrations in by the absolute cutoff date.

\section{Document and Develop Demonstration Projects}

The function of field demonstration projects is to show operators in a given region that the technology can be implemented economically. It is important that the operator feel confident that a technology is feasible in his/her reservoir type. This is a very important component of technology transfer if the technology is to be accepted throughout industry.

As part of the development of the KTTM model, three demonstration projects were documented. The documentation was categorized by the type of technology used in the field studies. The documents include 1) an introduction to the technology, 2) a method of application, and 3) case studies utilizing the technologies. Technologies documented as demonstration projects covered 1) methods of reservoir management, 2) permeability modification, and 3) applications of the acoustic liquidlevel device. The case studies were for those fields which have been studied extensively by the Tertiary Oil Recovery Project (TORP), the Kansas Geological Survey (KGS), and the Kansas University Department of Geology (KUDG).

One new demonstration project was initiated in the Pen Field in Graham County, Kansas. The field produces from the Lansing and Kansas City groups (Upper Pennsylvanian) with the primary producing zones being the " $\mathrm{I}$ " and " $\mathrm{J}$ " zones. This project focuses on the use of the acoustic liquid level device which has the potential to be applied on a relatively wide basis by operators. This device has potential for relatively low-cost determination of downhole pump problems, wellbore skin problems, and the value of transmissibility around and between wells. 


\section{Reservoir Management}

Reservoir management was selected as a technology to be documented because it was identified as a priority problem in many of the problem identification workshops. Also reservoir management encompasses so many different technologies that it would be applicable in nearly all fields throughout Kansas. This document describes 1) organization of the reservoir management team, 2) geological techniques, 3) engineering analysis, and 4) two demonstration projects which have been demonstration projects conducted by TORP, KGS, and Kansas University Department of Geology (KUDOG) at the University of Kansas (Zenith and Pen Fields). The Zenith field in Stafford County, Kansas was extensively studied by TORP and KGS in 1990 . A result was that operating costs were reduced from $\$ 16.00 / \mathrm{bbl}$ to $\$ 9.50 / \mathrm{bbl}$. Personnel at the University of Kansas petroleum engineering and geology departments have been studying the Pen field for the past five years.

\section{Permeability Modification}

Permeability modification was selected to be documented because water channeling was identified as a high priority problem in the problem identification workshops. It was also determined that this technology was economically feasible for independents. Operators have a variety of constraints when implementing a technology, such as limited capital, unavailable reservoir data, and limited technical personnel. Permeability modification was identified as a possible solution to the water channeling problem for the following reasons listed below. These are guidelines which can be utilized in adapting technologies suitable for independent operators.

1) The technology can be scaled to any problem size. This increases the usage by smaller operators with smaller problems of channeling because of the lower up-front costs. Some technologies have been designed to be economical only when used in large fields where large problems exist. For instance, steam flooding technology requires a large capital investment in a steam generator which has a minimum size of requirement. 
2) The technology does not require a high degree of technical knowledge to implement, making it very feasible for independents to implement.

3) The technology does not require large amounts of reservoir data for design. In most cases, channeling problems can be located and quantified through use of tests that do not require extensive reservoir data. Calculations and tests that are applicable include material balance calculations between injection and production wells, water to oil ratio versus cumulative oil production curves, and tracer tests.

4) The technology does not require special high-cost equipment. The equipment can be built from everyday oil field equipment or from equipment easily obtainable by operators.

5) The technology lowers operating costs by reducing water production. Upon analyzing operating costs, it was found that four out of five categories were affected by high water production.

6) The technology has been demonstrated with a large degree of success. Operators need to see the technology successfully implemented in fields similar to their fields to increase confidence in the technology.

It is quite easily determined that permeability modification technology falls under these guidelines, which makes it a possible high potential technology for the independent.

The permeability modification document describes 1) the background on permeability modification, 2) a method of candidate selection, 3) a method to design treatments, and 4) two demonstration projects conducted by TORP in the New Albany and Savonburg Fields.

\section{Acoustic Liquid-Level Measuring Device}

The technology of the acoustic liquid-level measuring device was selected since it has potential for low-cost determination of downhole pump problems, wellbore skin problems, and transmissibility around and between wells. These topics were all identified as having a high priority. 
For many wells in the U.S., conventional well performance analysis and pressure transient tests using bottom-hole pressure recording equipment are too costly relative to the potential benefits. However, with the lower-cost acoustic fluid-level technology, these tests can be conducted to obtain needed data, which has the potential benefit of increasing recovery efficiency and oil production.

The document describes 1) background in the technology, 2) methods of utilizing the device, 3) the documentation of one past demonstration project utilizing the device in the Zenith Field, and 4) two additional demonstration projects which were initiated in the past year in the Savonburg and Pen Fields.

\section{Expand Technology Transfer Activities}

In development of the KTTM model, existing technology transfer activities have been increased by integrating and expanding the existing field liaison program developed by TORP to include participation by the Kansas Geological Survey (KGS) and the Department of Geology. This expanded technology transfer program assists oil operators in solving technical problems. Operated along the lines of the model developed by TORP, the program makes available an extensive bibliography of pertinent literature, user-friendly PC software, and visual displays of reservoir architecture utilizing computer workstations. Electronic connection with campus facilities is planned to enhance computational, data transfer and graphics capabilities. The technology transfer program utilizes, as appropriate, resources such as the core research facility, well core samples repository, and production and petroleum geological data bases maintained by the KGS.

A bibliography has been developed as a deliverable to DOE which describes the pertinent petroleum literature utilized in the technology transfer deliverables. A collection of user-friendly software has been collected and has been distributed to interested parties free of charge.

Computer capabilities have been expanded in the technology transfer program by obtaining the following equipment: 1) a Silicon Graphics workstation with VIP Western Atlas software, 2) a hard disk upgrade on a Silicon Graphics workstation 
with Stratamodel ${ }^{\oplus}, 3$ ) a Sun workstation with Landmark ${ }^{\oplus}$ software, and 4) a 486 PC with Paragon ${ }^{\oplus}$, Radian ${ }^{\oplus}$, F.A.S.T. ${ }^{\bullet}$, and Pan System ${ }^{\oplus}$ software.

The Silicon Graphics workstation with the VIP ${ }^{\oplus}$ 3-D software has the capability to simulate reservoirs of any shape and size within the limits of the 64 megabytes of random access memory. The simulator can model the following types of recovery processes: 1) polymer flooding, 2) gas injection, 3) thermal flooding, and 4) carbon dioxide flooding. It can model vertical, slant, and horizontal wells. Once the reservoir has been simulated, ideally an operator can visualize the fluid flow in the reservoir to determine remaining unrecovered oil and an optimum process of recovery.

The Silicon Graphics workstation with Stratamodel ${ }^{\oplus}$ has the capability of presenting a visual display of the architecture of a reservoir. Any known reservoir attribute such as porosity, permeability, and fluid saturations can be visualized. Stratamodel ${ }^{\oplus}$ is compatible with VIP ${ }^{\oplus}$ software in that geological attributes can be processed in Stratamodel ${ }^{\circledR}$ and transported to the simulator for modeling purposes. Landmark ${ }^{\oplus}$ is a 3-D seismic package which can utilize seismic data in the visualization process.

The Paragon software is a well management software package. Digitized well logs can be presented on the screen along with cross-sections of the reservoir. The Radian ${ }^{\oplus}$ software is a mapping software package which can map reservoir attributes. Radian ${ }^{\oplus}$ is compatible with the VIP ${ }^{\oplus}$ software on the Silicon Graphics workstation.

A Digital Well Analyzer unit was purchased to demonstrate its capabilities. The computerized acoustic bottom-hole pressure system includes a well sounder, pressure transducer, power source, and a portable computer. The computer-based data acquisition and analysis package allows automatic measurement of annular fluid level, calculation of producing bottom-hole pressure, measurement of polish rod dynamometer data and calculation of downhole pump dynamometers and includes the measurement of motor current and power. Data can be exported to well test analysis software, (F.A.S.T. ${ }^{\oplus}$, and Pan Systems ${ }^{\oplus}$ ). 


\section{Program Evaluation of the KTTM Test}

The proposed five stages of evaluation for the regional technology transfer model, presented in Figure 3-4, involve near- and long- term evaluation. The nearterm evaluation was conducted as part of the program; however, due to the short test period of one year, the long-term evaluation methodology will be described and included in the recommendations for further study.

\section{Near-Term Program Evaluation}

The first stage involves the program design evaluation, which is the standard to which the three latter stages will be compared. In this stage of evaluation, the standard is evaluated to determine if it was developed appropriately to accomplish the

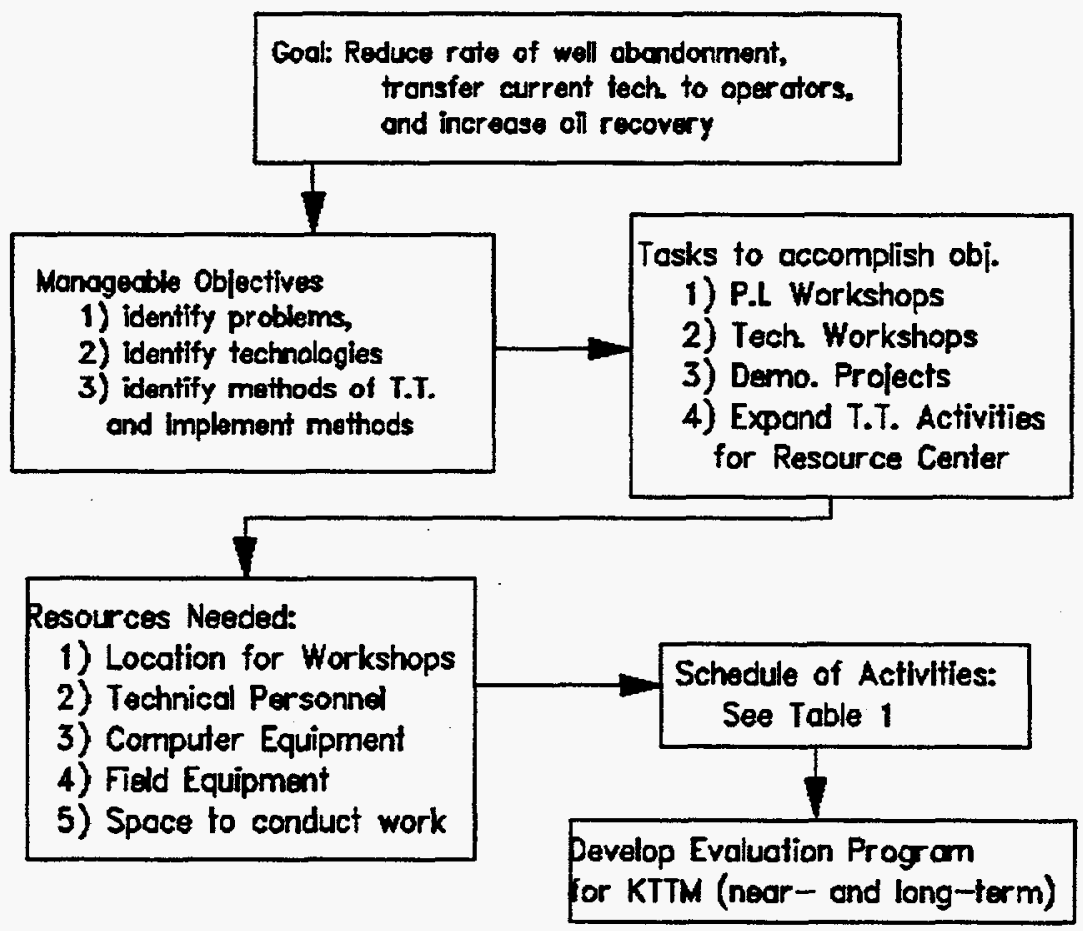

Figure 3-4. Program design for the Kansas Technology Transfer Model (KTTM)

goal of the program. Figure 3-4 presents the program design. The goal was clearly 
defined and not competitive with any other program. The goal complemented the proposed DOE national near-term program goals to reduce the rate of abandonment of wells and transfer current technology to domestic operators to increase oil production. The proposed manageable objectives developed were properly prioritized to reach the overall goal. First, problem identification was conducted, then technologies as solutions were identified, and methods to transfer the identified technologies were developed and tested. The tasks were sized appropriately so that they could be completed within a one-year period. The tasks were designed to achieve objectives in the near-term and, at the same time, be manageable by the technology transfer team. The proposed seven problem identification workshops were adequate for determining problems on a subregion basis in Kansas. The proposed three technology workshops and three demonstration projects to be documented were adequate if they were geographically located appropriately with topics broad enough to address the high priority problems. Required resources were determined by the number of workshops to be conducted, material and manpower needed in the workshops, and the labor required for writing of the manuals. Required additional equipment such as personal computers were determined by the number of technical personnel and the type of possible technologies to be transferred. The expanded activities were determined by a needs analysis of current technology transfer activities. The schedule was developed appropriately in the order of identifying problems, technologies as possible solutions, and methods of transferring the technologies. However, the schedule did not include the time needed to hire additional staff, and this resulted in expanding the timeframe by two extra months beyond the one year. The tasks were not scheduled sequentially in order to spread the individual tasks out and to reflect on experiences, i.e., the research and investigative process. No undesirable impacts were determined to be a result of the program design.

The resource evaluation involves comparing the actual resources needed to conduct the tasks and the proposed resources in the program design. The personal computers, workstations, and field equipment were adequate for conducting the 
designed tasks. Office space was a problem at times, and as a result, technical personnel doubled up in offices. Another impediment to technology transfer, which was due to lack of resources, was the problem of having the geologists and engineers in separate buildings. If the entire staff were located in one building, interdisciplinary interaction would have been greater.

The process evaluation involves comparing the actual process of conducting the tasks compared to the program design. All tasks were conducted as designed. The seventh problem identification workshop was replaced by presentation of a summary paper at a TORP conference. This provided feedback to the operators on the results of their participation. One of their requests was to see the overall analysis of the problems identified as a result of the grant. The technology workshops were conducted as designed.

The output evaluation involves comparing the actual output or product of the work as a result of the program to the intended results in the program design. Since the program processes were mainly workshops and documented demonstration projects, workshop evaluation was done by having participants fill out evaluation documents. The output evaluation was conducted relative to both the near- and longterm objectives. Since the program period was one year, only the near-term evaluation is presented; however suggested procedures are presented for conducting a long-term evaluation.

\section{Problem Identification Workshops - Evaluation from Participants}

The problem identification workshop results have been presented and have identified problems on a subregion basis. The problems identified were adequate for determining possible technologies to be transferred to operators. One hundred and one participants were involved in the six workshops. Below are the comments taken from the evaluation forms.

1) Good cross-section of people.

2) Explore further the idea of having a technology resource center.

3) Have more problem identification workshops. 
4) Send more material in advance.

5) Meet with service company personnel only.

6) Meet with field superintendents only.

7) Physically separate groups when brainstorming.

8) Involve the Kansas Corporation Commission.

9) Send questionnaires or surveys to a large number of operators.

10) Prior to the meeting have participants bring a list of major technical problems.

11) Utilize a mail survey.

12) Have one-on-one problem identification meetings.

13) Send the results of the problem identification workshops to the participants both on a regional and statewide basis)

These comments should be utilized in the redesign of future problem identification workshops. 


\section{Technology Workshops - Survey Results}

The three technology workshops attracted a cross-sections of industry participants. Figure 3-5 presents the participant's ratings on the quality of

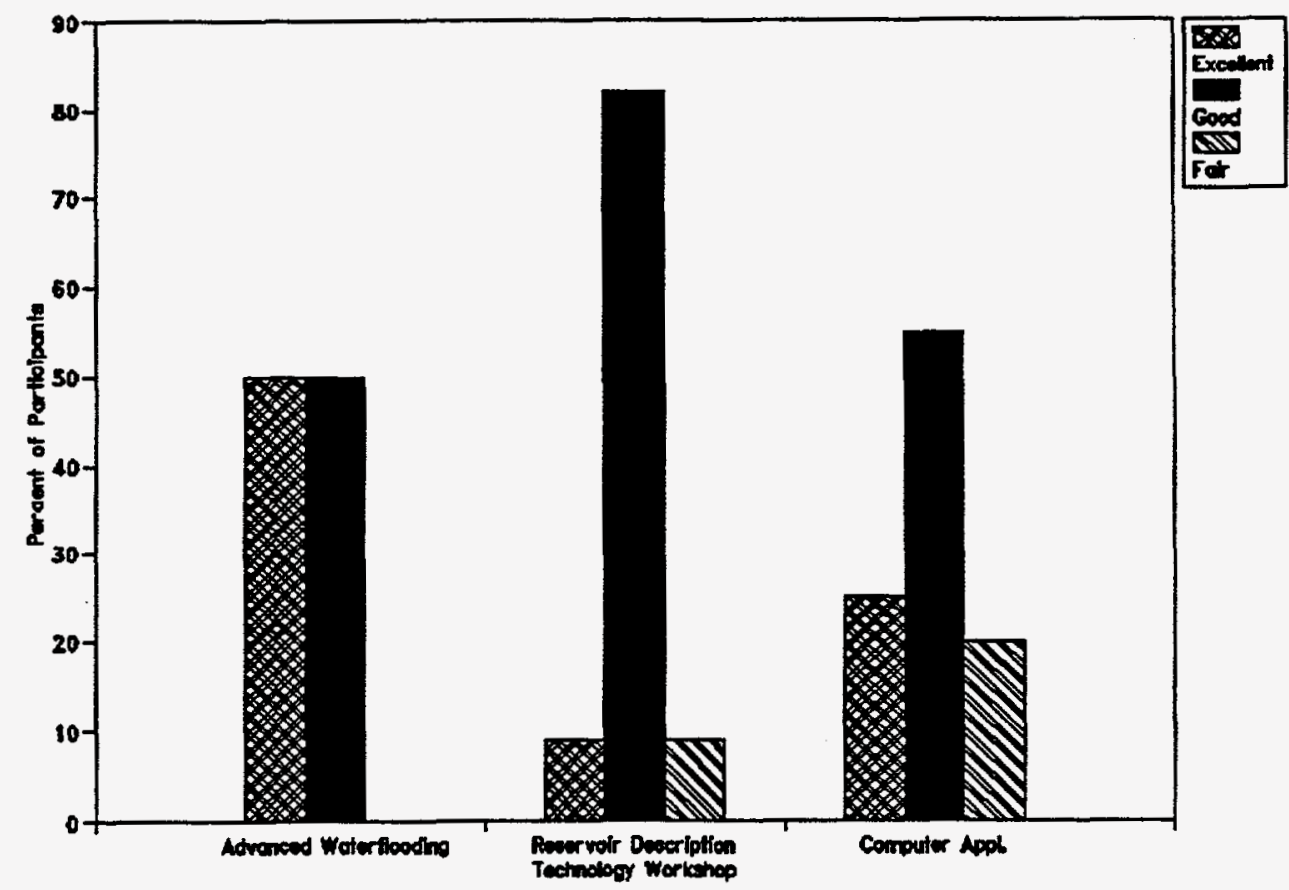

Figure 3-5. Participant's ratings on the quality of presentations in the technology workshops.

presentations in each workshop. When comparing the workshops, the advanced waterflood workshop had the highest ratings. This may be due to past TORP experience in conducting waterflood workshops. No poor ratings were given to any of the workshops on quality of presentations. This indicates that overall the instructors selected were good. Highest improvement is possible in the computer applications workshop, however the average rating is already above good.

Figure 3-6 presents the participant's ratings on how well advertised workshop expectations were met. The highest ratings were given to the advanced waterflood workshop. The computer workshop has the largest margin for improvement, however 


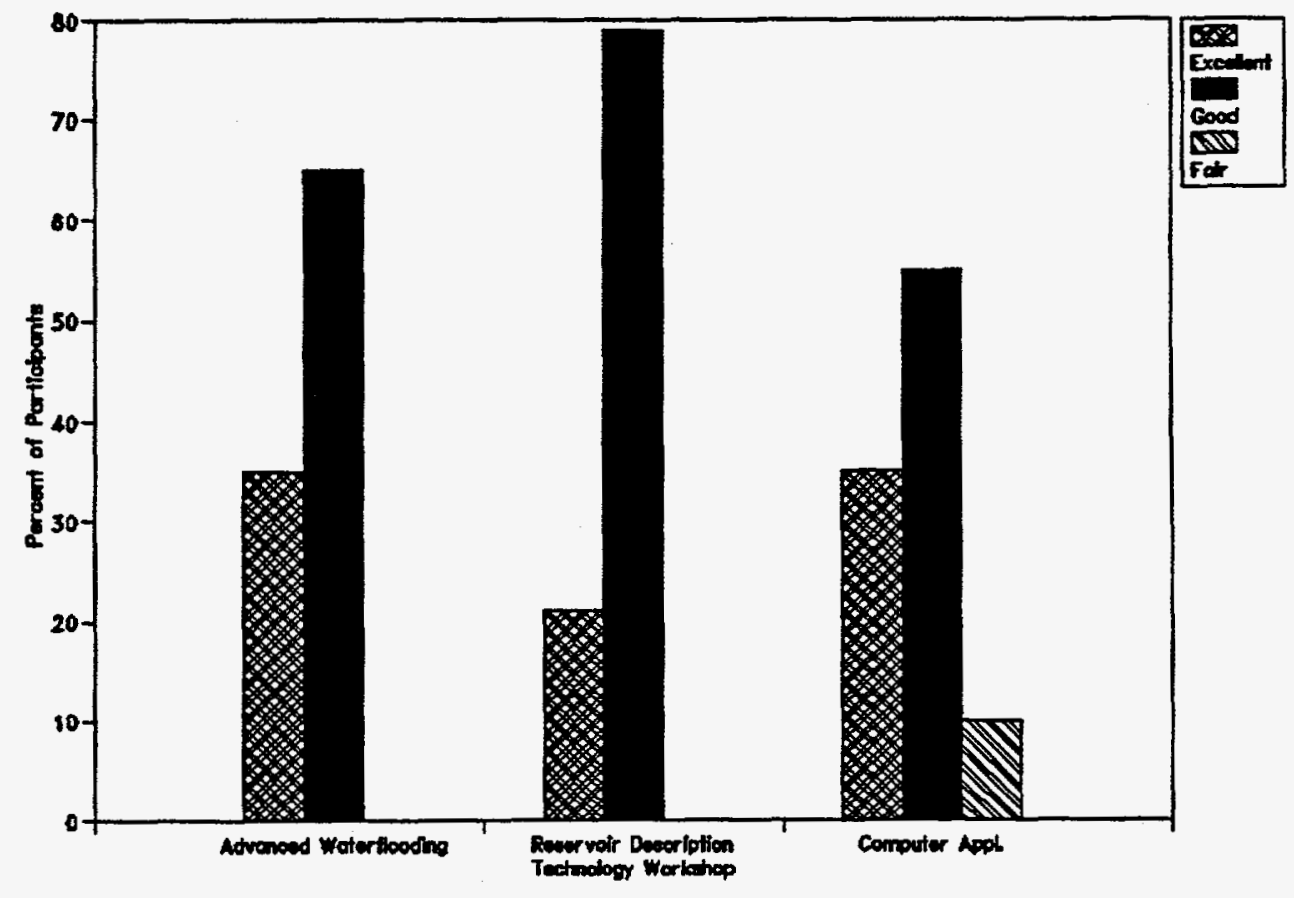

Figure 3-6. Participant's ratings on the expectations met as advertised.

no poor ratings were given.

Figure 3-7 presents the participants ratings on the organization of each workshop. The advanced waterflooding workshop rated the best, while the reservoir description workshop showed greatest margin for improvement. The reservoir description workshop was an initial attempt to bring together a variety of disciplins involving 38 participants over two full days with a mix of oral presentations, problems solving work sessions, and an evening poster session. Consultants, independents, and majors, were part of the program. Much was learned for future reference. Overall, the technology workshop ratings averaged from good to excellent, indicating that overall, the technology workshops were a success.

Below are compiled results of each workshop survey. The advanced waterflooding survey was slightly different than the other workshop surveys, therefore the percent of each profession and employment is not surveyed in the advanced 


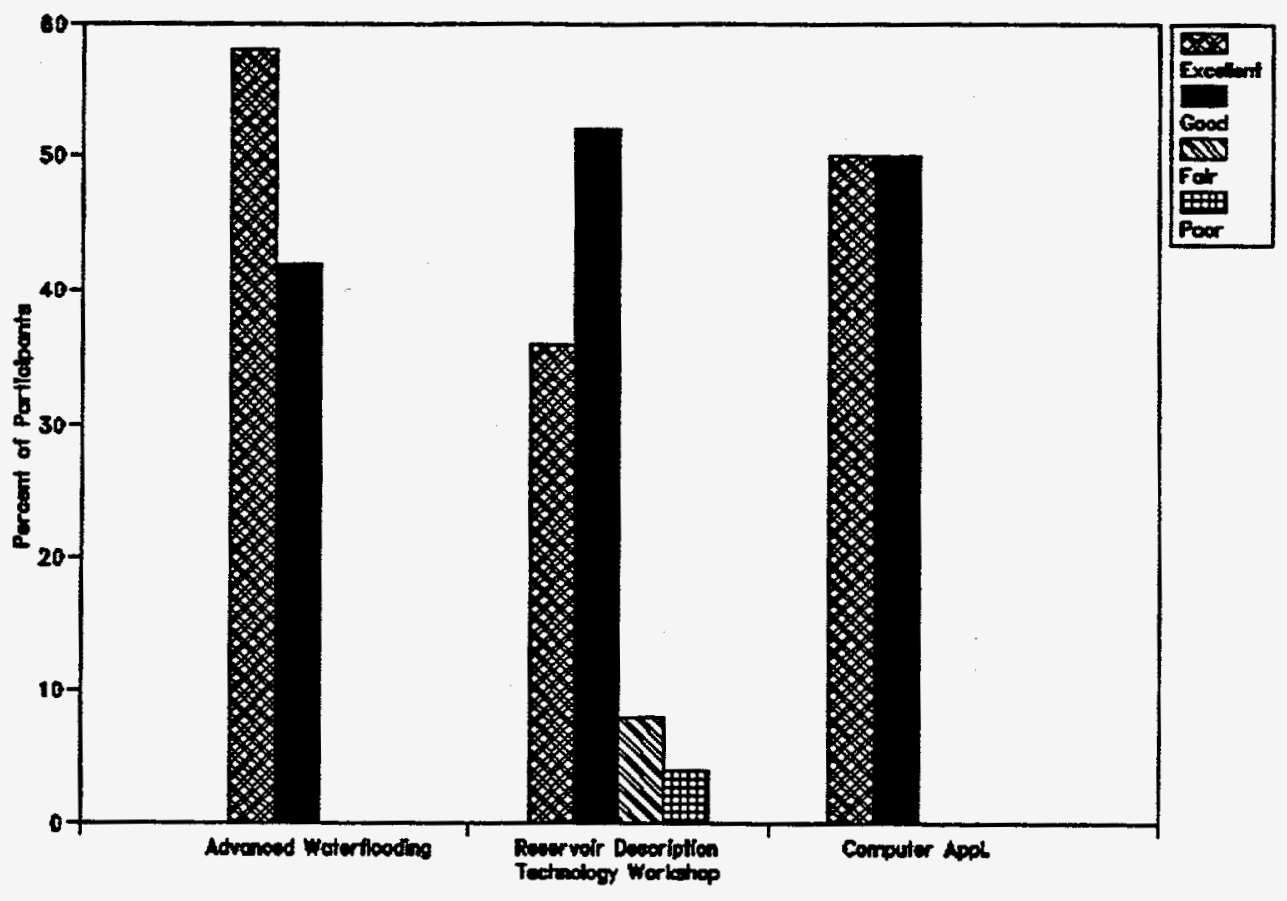

Figure 3-7. Participant's ratings on organizing each technology workshop.

waterflooding workshop.

Reservoir Description Seminar (Participant's Evaluation)

The seminar had 141 participants and maximum seating was 200 .

Profession:

$32 \%$ Engineers

$64 \%$ Geologists

4\% Geophysicists

Employment:

4\% Majors

$12 \%$ Large Independents

$52 \%$ Small Independents

$16 \%$ Consultants

$12 \%$ Academic/Research

$4 \%$ Environmental 
Ratings on the workshop were the following:

Organization: $\quad 36 \%$ Excellent $\quad 52 \%$ Good $\quad 8 \%$ Fair $4 \%$ Poor

Expectations as

Advertised: $\quad 21 \%$ Excellent $\quad 79 \%$ Good

Quality of

Talks:

9\% Excellent

$82 \%$ Good 9\% Fair

Method the participant was notified of the workshop

$56 \%$ Brochure

$20 \%$ Society Newsletter

$20 \%$ Colleague

$4 \%$ Other

Suggestions for improvement of the workshop were:

1) Have shorter presentations and use classroom setup for working problems.

2) Continue emphasis on independents with topics such as 3-D seismic imaging, geological aspects of capillary pressure analysis.

3) Screen vendor talks so technical content is improved.

4) Have more case studies.

5) Provide more hands-on problem sessions.

๑) Send out publicity earlier.

Topics the participants wanted expanded were:

1) information on sources.

2) methods of measuring reservoir properties.

3) reservoir characterization.

4) results of gel conformance treatments.

5) logging technology. 
6) transient testing.

7) characterizing waterflood performance.

8) directional drilling.

\section{Computer Application Workshop (Participant's Evaluation)}

The workshop had 40 participants, determined by the maximum possible number of computers with at the facilities.

Profession of participants:

$55 \%$ Engineer

$35 \%$ Geologist

$5 \%$ Geophysicists

Employment of participants:

$10 \%$ Large Independent

$55 \%$ Small Independent

$30 \%$ Consulting

$5 \%$ Banking

Ratings on the workshop were the following:

Organization: 50\% Excellent $\quad 50 \%$ Good

Expectations as

Advertised: $35 \%$ Excellent $\quad 55 \%$ Good $10 \%$ Fair

Quality of

Talks: $\quad 25 \%$ Excellent $\quad 55 \%$ Good 20\% Fair

Method participant was notified of the workshop

$50 \%$ Brochure

45\% Society Newsletter

$5 \%$ Other 
How would you rank your computer skills?

$5 \%$ Highly skilled

$20 \%$ Skilled

$65 \%$ Average

$10 \%$ Non-user

How would you rate the workshop presentation level?

$10 \%$ Too Advanced

74\% Just Right

$16 \%$ Too Simplistic

If you had the opportunity to attend another computer workshop, would you like more instruction or more computer usage?

$0 \%$ Instruction

74\% Combination

26\% Computer Usage

Recommended Topics for Future Workshops

1) More detail on BOAST.

2) Drillstem Test Software.

3) Seismic Software.

4) Data management software.

5) Mapping software.

6) Reservoir simulation.

7) Well Stimulation Software.

8) Economic software packages.

Participants suggestions on Workshop Improvement included:

1) Separate participants by skill level.

2) Include more detail on subjects and reduce number of subjects.

3) Have better computer hardware available to use. 


\section{Advanced Waterflood Workshop (Participant's Evaluation)}

facility.

The workshop had 61 participants which was the maximum seating in the

Ratings on the workshop were the following:

Organization: $\quad 58 \%$ Excellent $\quad 42 \%$ Good

Expectations as

Advertised: $\quad 35 \%$ Excellent $\quad 65 \%$ Good

Quality of

Talks: $\quad 50 \%$ Excellent $\quad 50 \%$ Good

Method of notification of the workshop

$55 \%$ BBBC Brochure

$45 \%$ TORP Newsletter

Suggested Improvements:

1) More on water quality.

2) More on case histories.

3) Stay practical in your talks, stay away from theory.

4) Extend to two days and explain in more detail.

5) More on well logging.

In summary, the evaluations from participants in the problem identification and technology workshop were quite favorable with some excellent suggestions. 


\section{Long-term Program Evaluation}

The long-term evaluation consists of two parts: 1) further investigation of output from the technology workshops and documented demonstration projects and 2) an impact analysis. This evaluation should be started in the second year and continued throughout the program.

It is suggested that participants in the technology workshops be contacted to determine if they have utilized any of the technologies presented in the workshops. The number of requests for information on demonstration projects should be documented and the requesters should be interviewed for an evaluation of the information periodically.

An impact analysis should be conducted utilizing the regional database and reservoir analysis. In the locations where technology has been implemented as a result of the program, incremental oil should be determined and a cost/benefit analysis conducted. 


\section{CHAPTER 4 \\ LITERATURE REVIEW}

This chapter includes a study of literature reviewed to supplement work conducted during the past ten years in development of the Tertiary Oil Recovery Project technology transfer model and work during the past year in the development of the KTTM. This material will be useful in training seminars for liaison technology transfer personnel, managers of technology transfer programs, and in the evaluation of technology transfer programs.

Technology transfer has various definitions in the literature, along with different models to support the ideas. This chapter discusses the types of technology transfer, modes of technology transfer, and the various models. Since technology transfer involves groups and creative thinking, a section on group dynamics and creativity is also presented, including a section on the Delphi process as part of the techniques for structured group-communication. A section on program evaluation is presented to determine a possible program evaluation technique for the KTTM.

In the literature, the term "technology" has been applied widely to everything from manufacturing hardware to skills possessed by people, and can be defined as any tool, technique, product or method of doing or making, by which human capability is extended (Williams and Gibson, 1990).

The term "transfer" refers to transformation of a technical concept of proven feasibility into a development state closer to the end use in the production of a service or goods. Transfer is successful when the transformation is complete and end-users find that the tool or technology enhances their process or output in some way. Therefore, technology transfer involves some source of technology, or personnel with specialized technical skills, which is transferred to a target group of end-users or application personnel who do not possess those specialized skills or who therefore cannot create the technology or tools themselves. Technology transfer is the movement of this applied knowledge through one or more communication channels with communicating or liaison personnel structured as groups or organizations. Given that the fundamental motive for communication among these agents is the transfer of 


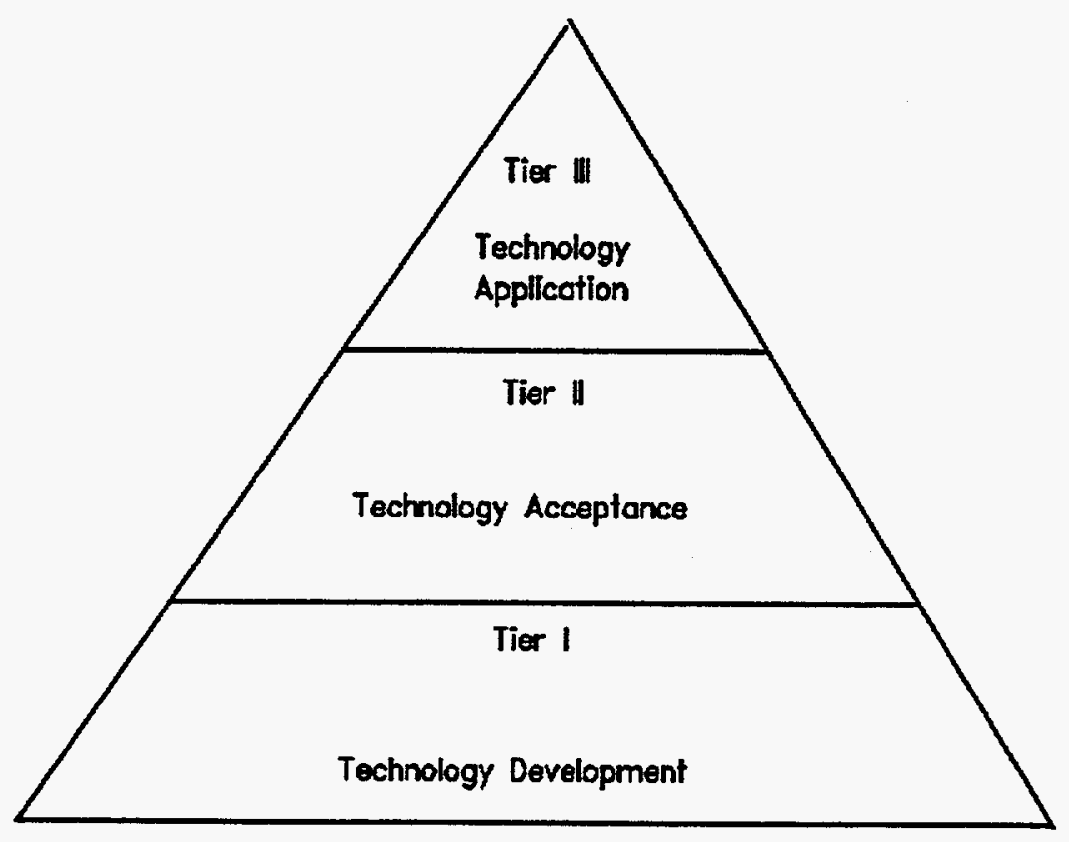

Technology Tronsfer of Three Levels of Involvement

Figure 4-1. Three tiers of technology transfer.

the respective information, one can propose different allocations of responsibility among agents for the transfer to be successful.

As described in chapter one, technology transfer can be divided into three levels which have different goals as presented in Figure 4-1. These are technology development, technology acceptance, and technology application. Each level of technology transfer is of a different type which has separate distinct goals. To achieve timely and efficient application of technology, different functions, tasks, and networks must be activated simultaneously to overcome obstacles and barriers to the transfer process. To facilitate this goal, technology users must be linked more directly to the development of the technology. At the same time, researchers must gain a better understanding of and appreciation for the application of the technology. 


\section{Technology Transfer Models}

Various models have been documented, including 1) the appropriability model (Devine, James, and Adams, 1987), 2) the dissemination model (Rogers and Kincaid, $1981), 3)$ the communication-based model (Williams and Gibson, 1990).

The appropriability model is based on the principle that "Good technologies sell themselves". An example would be a developer solving the fusion energy problem with no negative impacts on the environment. The model emphasizes the importance of the quality of research and competitive market pressures to promote the use of research findings. Deliberate transfer mechanisms are viewed as unnecessary. All the researcher needs to do is develop the right idea and the customer will beat a path to the inventor's door.

The dissemination model is based on the role where experts inform potential users of the technology. Once the linkages are established, the new technology will flow from the expert to the nonexpert. An example would be an SPE symposium where participants desire to obtain technical information.

The communication-based model involves an interactive process where individuals exchange ideas simultaneously and continuously. Feedback from the enduser is so pervasive that the end-users in the transfer process can be viewed as developers also, thereby blurring the distinction between the developer and end-user. Often the technology to be transferred is not a fully formed idea. Researchers, developers, or users are likely to have different perceptions about the technology, which affects how they interpret the information. As a result, technology transfer is often a chaotic, disorderly process involving groups and individuals who may hold different views about the value and potential use of the technology. Feedback helps participants reach convergence about the important dimensions of the technology. Both problems looking for solutions (market-driven) and technology solutions looking for problems (product-driven) are encountered. An example of the use of this type of technology transfer model would be when a fishing tool is continuously being changed on-site until the tool is retrieved. Both end-user and developer of the tool must work together to utilize the technology. 


\section{Technology Transfer Modes and the End-Users Involvement}

Understanding the type, or mode, of technology transfer is very important to properly manage a technology transfer project. Different types of technologies require different modes of technology transfer. The two modes of transfer discussed are point-to-point and diffusion. In the literature the modes are seldom compared or discussed together. Researchers tend to discuss person to person transfer from a single developer to a single end-user, whereas marketers concentrate on the diffusion mode, technology transfer from a single developer to multiple end-users (Williams and Gibson, 1990).

In general, both modes involve the same basic transfer process, the initiation and implementation stages. However it is important to distinguish between the modes in order to 1) establish user expectations, 2) allocate resources appropriately, and 3) choose transfer managers with the right skills. Each mode is complicated by the degree of diversity of the technology and possible applications the technology may have. In the person-to-person mode, all users apply the technology or tool to the same task, whereas in the diffusion mode, users with diverse jobs use the same technology or tool but apply it to very different tasks. The volume and physical dispersion of users determine the kind of user representation possible during the development of the new technology, the degree to which the technology can be customized, and the problems that implementation managers will most likely encounter.

An example of person-to-person transfer would be "fishing tool" technology in which the developer of the tool must go on a well location to modify the tool for the user to fish pipe or a drilling bit out of a well. In this case, a tool is used by few people in some central critical step in a process and is being deployed bilaterally through one person to one user.

Process tools that are intended for a large number of sites, users, and applications are likely to be disseminated through a process of diffusion (Rogers, 1983). An example would be reservoir simulation technology, which is applicable to a variety of applications, i.e., reservoir characterization, EOR processes, and 
reservoir management. Diffusion transfer must be oriented to the idea of the users adopting the technology before implementation.

In either transfer mode, two motives inspire technology developers to involve the intended users of a new technology in its development: 1) acquiring knowledge from the user needed in the development process so as to create a relative advantage over previous practices to ensure usability (Boland, 1978), and 2) attaining user acceptance of the innovation and commitment to use it (Ives and Olsen, 1984). The first motive rests on the assumption that the interaction between the technology developers and users during development creates a better design than either group could have generated alone. Market researchers have found that it is beneficial to use "lead users" to assist in the design of the next generation of a product (Hippel, 1988). The second motive for user involvement is increasing user acceptance which generates favorable information about the innovation and increases the user's tolerance of initial inadequacies because of their sense of ownership.

Managerial skills are important in managing these processes. The primary managerial skills required in person-to-person transfers are negotiating skills, understanding how to overcome the initial positions of various groups by translating them into interests so that common ground may be found. The more numerous the receiving groups, the more complex the person-to-person transfer is and the more interpersonal and negotiating skills the project manager needs. The primary managerial skills required in diffusion transfers is marketing skills and group leadership abilities. Marketing teams and developers must work as a team in the diffusion transfer process.

\section{The Importance of Creativity in the Technology Transfer Process}

Successful innovative firms tend to have a flexible approach to technology transfer which commits them to reorganize and deal with the unpredictable demands of the innovative process. This requires that the firm or entity become creative in problem solving. 
It has been found that the factors associated with commercial success are 1) understanding the user's needs, 2) paying attention to marketing, 3) conducting development work efficiently, and 4) effective use of outside technology and scientific advice (Rickards, 1985).

Today the question of "market-driven" versus "product-driven" has become

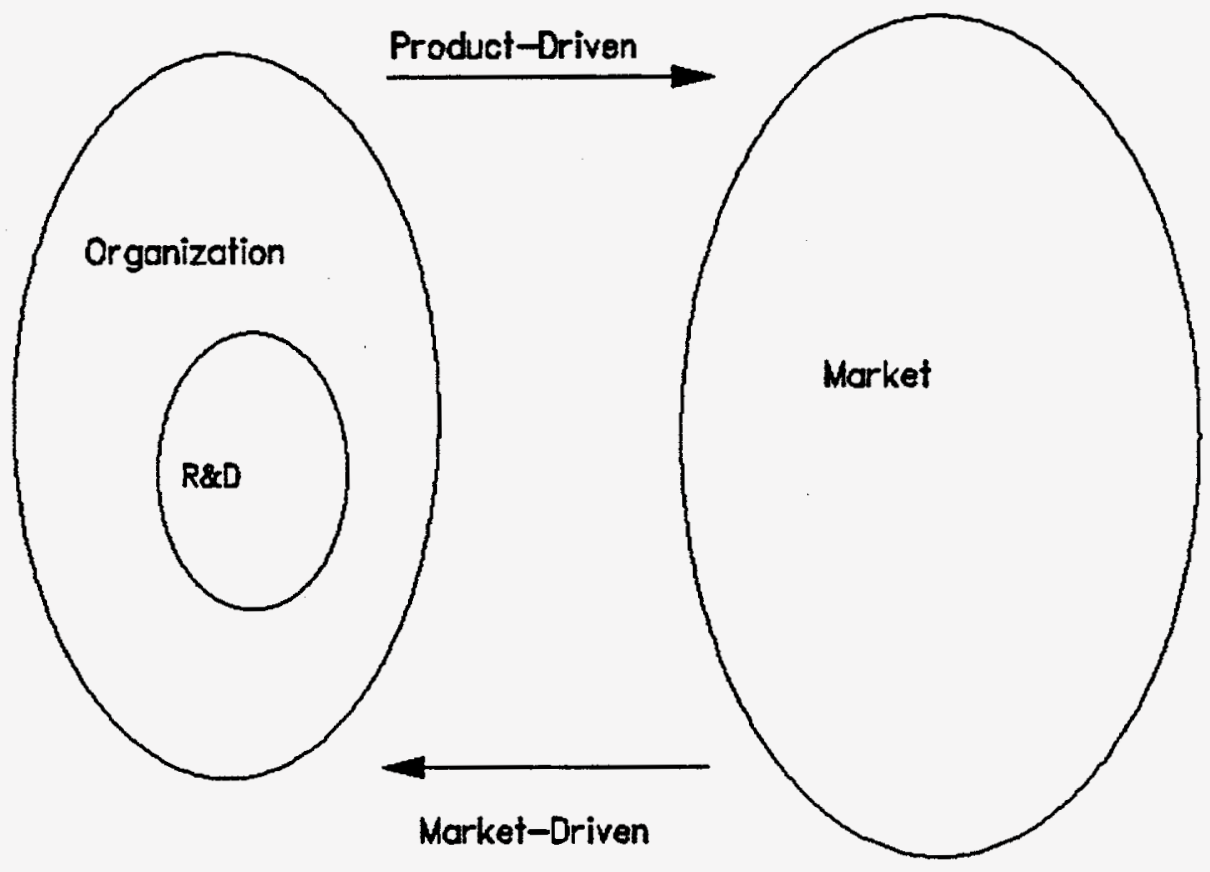

Figure 4-2. Two subsystems influencing each other.

less of a live research issue, as presented in Figure 4-2. What is important is that the major subsystems are communicative and do influence each other. Technical inventions and market needs do not occur in isolation, but are closely linked. In some circumstances the technology will perhaps be more visible and in others the market will appear to be the dominant influence; however, both will be present. Each technology is unique at the time of the discovery and introduction to the market. To resolve the specific problems within the unique and uncertain environment which is 
associated with each innovation, one must become skilled at creative problem-solving. Therefore, the ability of an entity to be creative is a major factor in the success of a technology transfer program. Rickards has identified seven blocks to creativity: 1) self imposed barriers, 2) unwarranted assumption, 3) one-correct-answer

thinking, 4) failing to challenge the obvious, 5) negativity, 6) pressures to conform, and 7) fear of looking foolish. Each of these blocks represents a mind set (Rickards, 1984). Mind sets inhibit creativity when a person looks for the dangers and weaknesses in a new idea before considering strengths.

Rickards also indicated that creativity can be stimulated through various methods: 1) reversals, 2) incubation and random input, 3) goal orientation, and 4) brain storming. Reversal involves reversing a setback into a powerful learning experience and using it in a rethinking process. Incubation involves the ability to escape from the mind set for a period of time and have random input, which works well for breaking conceptual blocks. In some idea-seeking situations it is more important to get away from overworked ideas, than to move towards some previously identified goals. Goal orientation is the method of stimulating creativity by examining and challenging targets and goals. Brainstorming involves deliberately generating ideas without evaluation or censorship of them. Brainstorming requires a skillful leader who encourages the team members to generate ideas and feel confident that they are not evaluated. In summary, to increase the overall creativity within innovation projects, attention has to be paid to fostering a creative environment both by example and thorough training. In this way many of the organizational resistances to new ideas and flexibility can be reduced.

\section{Problem Solving Utilizing Project Teams}

A good technology transfer program must be based on interdisciplinary team work. It must establish an optimum team environment which can be innovative and adaptable to any environmental situation. In the oil and gas industry, interdisciplinary teams must be developed to assist in technology transfer because of the variation in types of problems. This section provides a literature survey on group dynamics and 
team psychology.

In the 1950s formal studies of small groups expanded, particularly in the United States. Cartwright and Lippitt (1957) provided a summary of group dynamics. They indicated that leaders have been strongly influenced by the dynamic equilibrium in a working group, with various pressures and resistances maintaining the equilibrium.

Various studies have been made which follow the passage of a team through formation to effective operation. One well known model (Tuckman, 1965) suggests that there are four stages in this process: 1) formation stage, 2) adjustment stage, 3) norm-setting stage, and 4) performance stage. The formation stage is the period when members are inclined to seek resolution of their personal needs such as position in the team. In the adjustment stage, members attempt to find ways to accommodate their needs often causing conflict and personal attacks. This stage continues until the team members reach a consensus on who does what. The norm-setting stage sets the rules of play which develop around key issues on each team members behavior and the objectives of the team. In the performance stage, the dynamic equilibrium has been set and the team can act in ways that reveal routines that have been unconsciously set.

Other clues to the dynamics of groups have emerged in work on leadership, motivation, communication, and how people complement each other. Studies have been conducted to explain success and failure in management teams through identifying roles needed, and the consequences of a surplus or deficiency of occupancy of any roles. Belbin (1981) suggested that eight team roles exist in a group: 1) the shaper, 2) the chairman, 3) the plant, 4) the resource investigator, 5) the team worker, 6) the company worker, 7) the monitor-evaluator, and 8) the completer-finisher. The shaper plays the role of a task-oriented leader who is concerned to shape the course of events through getting his own way. The chairman is a leader who attempts to draw out the ideas of others, rather than imposing his own views. The plant role is taken by an individual who is known to have plenty of ideas that assist the team in imagination. The team worker has empathy and is sensitive to 
ways of keeping relationships in a team in harmony. The company worker's role is to always be aware of the corporate goals. The completer-finisher role is to see the project through to implementation. In innovative-seeking environments the role of completer-finisher is difficult to fill because individuals who are innovators do not like this position.

The study suggested that most people have one preferred role, and if they could not behave in such a fashion would turn to a fallback role. Teams were found to be repeatedly more effective if all eight team roles were likely to be effectively taken up. Teams with missing roles were less effective.

\section{Delphi Approach}

The format which evolved from experience in conducting problem identification workshops resembles a simplified version of the Delphi approach. A widely used model for reaching consensus in a group. As described in the literature, diverse approaches of the Delphi technique can be taken and the method can be modified for any specific purpose.

Delphi may be characterized as a method for structuring a group communication process so that the process is effective in allowing a group of individuals, as a whole, to deal with a complex problem or come to a consensus on a topic (Linstone and Turoff, 1975). The Delphi approach does not have to produce a single answer as its output. Instead of reaching a consensus, the Delphi approach will leave a spread of opinions for experts to consider. The objective is to reduce the spread of possible answers as much as possible without pressuring the respondents. It is a method of structured communication based on 1) feedback of individual contributions of information and knowledge and 2) assessment of the group judgement or view. It allows opportunity for individuals to revise their views and yields a degree of anonymity for the individual responses. In the literature there are many different views on the best and most useful procedures for accomplishing the various specific aspects of the Delphi approach. In this section two views of the Delphi approach will be reviewed: 1) the conventional Delphi approach and 2) the Delphi 
Conference approach. Also the basic phases of the process will be reviewed.

In the conventional Delphi approach, a small monitor team designs a questionnaire which is sent to a larger respondent group. After the questionnaire is returned, the monitor team summarizes the responses and, based upon the results, develops a new questionnaire for the respondent group. Before the group receives the new questionnaire, they are given at least one opportunity to reevaluate their original answers based upon examination of the group response. This form of the Delphi approach is a combination of a polling procedure and a conference procedure. It attempts to shift a significant portion of the effort needed for individuals to communicate from the larger respondent group to the smaller monitor team.

In a new form of the Delphi approach, called "Delphi Conference," the monitor team is replaced by a computer which has been programmed to carry out the compilation of the group results. This approach has the advantage of eliminating the delay caused in summarizing each round of questionnaires, thereby turning the process into a real-time communication system.

Usually the Delphi approach, whether it be conventional or real-time, undergoes four distinct phases. The first phase is characterized by explanation of the subject under discussion, wherein each individual contributes additional information they feel is pertinent to the issue. The second phase involves the process of reaching an understanding of how the group views the issue. If there is significant disagreement, then that disagreement is explored in the third phase to bring out the underlying reasons for the differences. The last phase is the final evaluation which occurs when all previously gathered information has been analyzed and the evaluations have been reexamined.

On the surface, the Delphi approach seems like a very simple concept that can easily be employed. Because of this, many individuals have attempted the procedure without carefully considering the problems involved in carrying out such an exercise. Linstone and Turoff (1975) have indicated that some of the common reasons for the failure of the Delphi approach are: 
1) Imposing the facilitator's views and preconceptions of a problem upon the respondent group by overspecifying the structure of the Delphi approach and not allowing for the contribution of other perspectives related to the problem.

2) Assuming that the Delphi approach can be a surrogate for all other human communications in a given situation.

3) Utilizing poor techniques of summarizing and presenting the group response and ensuring common interpretations of the evaluation scales utilized in the exercise.

4) Ignoring and not exploring disagreements, causing discouraged dissenters to drop out resulting in the generation of an artificial consensus.

5) Underestimating the demanding nature of the Delphi approach and the fact that the respondents should be recognized as consultants and properly compensated for their time if the Delphi approach is not an integral part of their job function.

In addition to the above problems associated with the Delphi approach, other criticisms are often raised in the literature (Cascio, 1992). The general complaints against it have been insufficient reliability, different results when different participants are used, and the impossibility of predicting the unexpected. These are the virtual problems that do not in themselves affect the utility of the technique. Typical of these is the question of how to choose a good respondent group, which is a problem when forming any group committees, panels, or study groups. This is a problem regardless of the communication mode used, therefore, while it is a real and significant problem, it is not a problem unique to the Delphi approach.

\section{Program Evaluation}

Evaluation involves a set of procedures to appraise a program's merit and to provide information about its goals, expectations, activities, outcomes, impact and costs. It is defined as the comparison of what is performance against an expectation of what should be standard. Evaluations are conducted because groups or individuals want to know about a program's progress and effectiveness. Evaluation is important 
in any program because it can serve many purposes if applied correctly. This section provides information on the purposes of program evaluation, evaluation methods and one evaluation model.

Anderson and Ball (1978) have described the capabilities of program evaluation in terms of six major purposes which are to 1) contribute to decisions about program installation, 2) contribute to decisions about program continuation, expansion, or certification, 3) contribute to decisions about program modification, 4) obtain evidence to rally support for a program, 5) obtain evidence to rally opposition to a program, and 6) contribute to the understanding of basic psychological, social, and other processes. Each of these purposes of evaluation are not mutually exclusive, and should provide a way to define evaluation. Each of these areas of involvement can be broken down into a number of components to be evaluated, depending on the purpose of the evaluation. For the purpose of this document, only the first three purposes will be discussed, because of the nature of the technology transfer program needs.

If the purpose of the evaluation is to make a decision to install a program, then a front-end analysis is needed. Precursors to decisions about whether to implement a program are 1) assessment of the needs for a program, 2) estimates of cost and operational feasibility, and 3) projections of demand and support. Even after the case has been made that a particular kind of program is needed, the priority for this program in the face of competing needs and limited resources must be assessed.

The program evaluation to decide to continue or expand a program, is sometimes called "impact" evaluation. After a program is in operation, it is frequently important to monitor the continuing needs of the program and the impact the program has had on the environment. The cost and demand need to be assessed against the projections made in the planning phase of the program. Each of these needs to have a short-term and long-term analysis, with any side effects investigated.

The program evaluation to decide on program modifications emphasizes description of program processes in contrast to program products. Improvement may be in the areas of program objectives, program content, and program methodology. 
In determining the evaluation method, the choice is dependent on the evaluation purpose and the nature of the program. Anderson and Ball describe seven useful methods which are not necessarily mutually exclusive: 1) experimental and quasi-experimental, 2) correlation methods, 3) surveys, 4) personnel or client assessment, 5) systematic expert judgment, 6) clinical or case studies, and 7) informal observation or testimony. The latter three methods will not be discussed in light of the purpose of evaluating the type of program considered in this work.

Experimental studies are essential if evaluators are seeking relatively decisive answers to certain questions about program or component effectiveness. However, experimental designs depend on being able to develop proper control groups in the study. In programs in different regions of the United States, this can be very difficult because of the variation in cultures, organization structures, and oil reservoirs throughout each region.

Correlation methods involve comparing programs, their input, cost, output, and the impact they have on the environment. Correlation methods have received a bad name in evaluation circles, because some hard-pressed program evaluators have been tempted to draw causal inferences about programs from simple correlational studies without examining the outside environment.

Surveys are a major tool of evaluation efforts directed toward needs assessments, cost estimates, operational feasibility, and program acceptability. Surveys can take a variety of forms such as telephone interviews, questionnaires, observations, and content analysis of records. The decision to use a survey and survey type depends on the purpose of the information-gathering effort and on the nature of units to be surveyed and the level of confidence the evaluator seeks in the results.

Personnel or client assessment is used in experimental designs for obtaining information about program and component effectiveness. Personnel can be assessed for competencies, attitudes, physical and psychological conditions, and other characteristics intrinsic to the content and purposes of the program, as opposed to attitudes and reactions about a program. For example, if a needs assessment was 
conducted to contribute to a decision of installing a petroleum technology transfer program, the participants of the program would be assessed regarding their knowledge on technologies applicable to their reservoirs and their abilities to acquire the technologies. If they were assessed as adequate, it might be recommended that the program not be installed or a limited version be installed.

\section{The Discrepancy Evaluation Model}

Provus (1975) suggests that there are two kinds of evaluation, summative and formative. The primary aim of summative evaluation is assessment, and the primary aim of formative evaluation is program improvement. Program improvement is designed to discover whether a program is operating as it was intended. Formative and summative evaluation complement each other, because formative evaluation provides the foundation both technically and politically to produce summative evaluation. Based on these types of evaluations, the discrepancy evaluation model was developed in 1966 by Provus (1975).

The "discrepancy evaluation model" (DEM) serves two purposes: 1) to provide information for program improvement, and 2) for program assessment. It is particularly appropriate for use with new and innovative projects. It is sensitive to the natural developmental stages experienced by such programs and provides evaluation activity appropriate to each stage. The stages involve planning, installation, early operation, and stabilization. Information obtained through evaluation is designed to help the administrator make decisions that improve programs in the initial stages of development and operation.

The model is based on the primary assumption that evaluation must involve the comparison of performance against a standard and uses any discrepancy between the two as a unit of measurement. The discrepancy evaluation model includes five major stages: 1) program design, 2) program installation, 3) program process, 4) program terminal products, and 5) program cost-benefit analysis or impact analysis. On the basis of the comparisons made at each stage, discrepancy information is provided to the program staff, giving them a rational basis on which to make 
adjustments in their program. In summary, the discrepancy evaluation model uses the first three stages of evaluation for program development and stabilization and the fourth and fifth stages for program assessment. It is important that the stages in this model do not all occur concurrently and that the object of evaluation under the model is to compare performance with a standard and provide feedback on discrepancies. This feedback permits decision makers to change either behavior or the standard and thus equalize the two.

The Discrepancy Evaluation Model Modified for a Technology Transfer Program The Interstate Oil and Gas Compact Commission (IOGCC) developed a framework for the evaluation of a technology transfer program under a contract from the Department of Energy. It is a systems approach based on the discrepancy evaluation model (DEM). The purpose of the selected methodology is to set standards, measure performance, and report on discrepancies between standard and performance. Inputs, processes, and outputs are regularly monitored, and impacts are frequently assessed (IOGCC, Vol. II, 1993).

The design evaluation is an assessment of the consistency of the design with the likelihood of achieving the desired impacts. Desired impacts might be increased oil recovery from domestic reservoirs as a result of technology utilization that would not have occurred had the program not been implemented. The input evaluation is the determination of whether the program has been installed as planned. The process evaluation is the monitoring of the sequential accomplishment of manageable objectives or tasks leading to achievement of program goals. The output evaluation is the determination of whether the specific products or services of the program have been delivered. The impact evaluation is an assessment of the extent to which the desired impacts of the program in industry have been obtained. 


\section{CHAPTER 5}

\section{THE NATIONAL TECHNOLOGY TRANSFER PROGRAM}

In the spring of 1992, Congress recommended that DOE develop a comprehensive five-year technology transfer plan to stimulate effective use of conventional technologies in U.S. domestic oil fields, utilizing the current industry infrastructure.

The FY 93 House Language is quoted as the following:

The Committee is aware of proposals for managing an expanded technology transfer program. The Committee believes the Department should analyze current technology transfer programs, including 1992 efforts at the University of Kansas, and also publish a request for qualifications $(R F Q)$ to assess interest and qualifications of organizations in this area. These results should be included in a report to the Committee on the needs for technology transfer, and methods of satisfying these needs, including alternatives such as increasing current efforts as well as competitive solicitation of expertise. No 1993 or carry-over funds should be expended on expanded efforts prior to such report being available to the Committee.

The FY93 Senate Language is quoted as the following:

The Committee is aware of the need to make technological advances available to the oil producing community through an effective technology transfer program. The urgency of this program is related to the need to preserve economic access to the Nation's aging oil fields. The Committee believes that it is critical that the Department's technology transfer efforts reach the broadest cross-section of the producing community and that one mechanism or approach is unlikely to meet the needs of every individual or organization. The Committee believes that the Department should develop a comprehensive 5-year technology transfer plan that incorporates and coordinates the existing efforts, including the 1992 efforts at the University of Kansas, and identifies additional requirements. Following Committee review, the Department should initiate a pilot effort in 1993 to demonstrate a national oil technology transfer program to implement this plan. 
From the language it is understood that the DOE five-year technology transfer plan include existing DOE technology transfer efforts and utilize, insofar as possible, the capabilities of on-going programs currently present in segments of the oil industry, including the TORP program. As a result, DOE is developing a draft of an overall national technology transfer program to be presented to Congress in late 1993. The goals of the program are to 1) expand and accelerate the awareness, acceptance, and the use of current and innovative oil technologies, 2) reduce perceptions of the risk related to the use of the technologies, 3) improve public perceptions of exploration and production, its importance to the nation, and its environmental consequences, and 4) improve the understanding of the situation and the needs of the oil operators.

As part of its activities under the DOE grant to expand the TORP concept, the University of Kansas has developed a proposed national technology transfer program containing several components: 1) a central coordinating program, 2) an industry coordinating committee, and 3) regional programs. It is understood that DOE will consider the elements of this proposed program for appropriate inclusion in its fiveyear technology transfer plan, along with elements of other on going and proposed programs as described in the introduction of this report.

The overall structure of the plan proposed in this effort is presented in Figure 5-1. The central coordinating program and the regional program are integrated by the DOE Fossil Energy HQ/BPO setting policies and direction. An industry coordinating committee, possibly the Petroleum Technology Transfer Council (PTTC), will develop and administer the regional program in cooperation with DOE. The design of the program is flexible in an attempt to address all the different types of regional infrastructures. It is built on the existing DOE technology transfer efforts such as the Energy Policy Act of 1992 (EPACT) Reservoir Class Program and the capabilities of on-going programs currently present in segments of the oil industry.

Since the major objective of the program is to stimulate activities in the current industry infrastructure, the "regional program" is the major technology transfer component. The regional program will be based at regional resource centers 


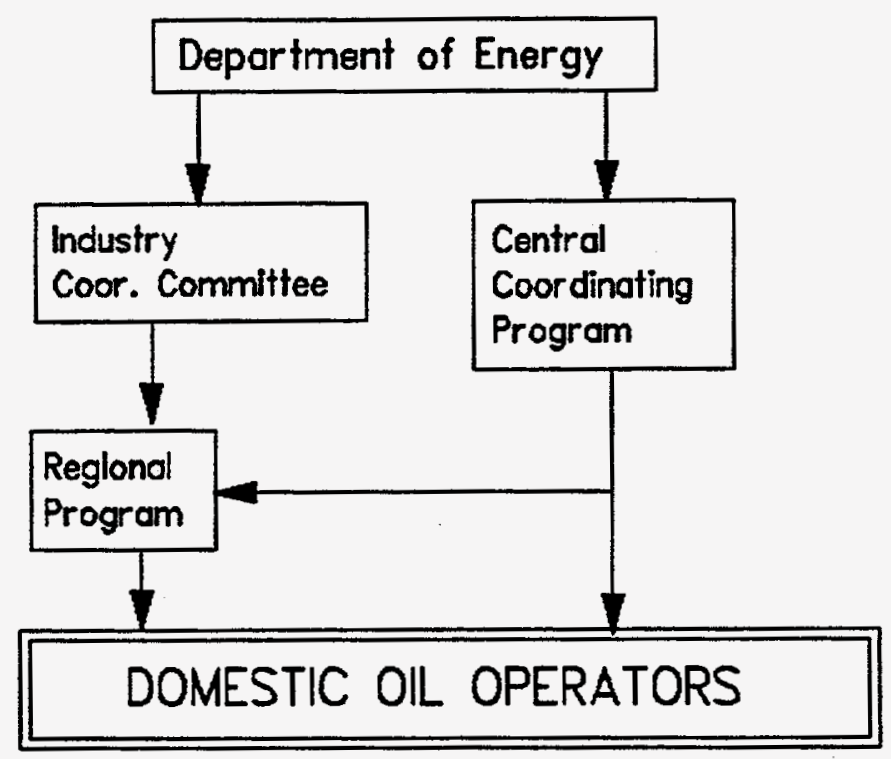

Figure 5-1. The national technology transfer model.

and will utilize the current infrastructure, including industry consultants and service companies, along with geological surveys, universities, bureaus, and professional societies. The regional model must have four important attributes before the program can be successful. The regional model has to 1) be adaptable to all the oil producing regions targeted, 2) complement the overall national program, 3) be interdisciplinary, and 4) work through industry's infrastructure. Technology transfer activities in the regional program will include problem identification workshops, technology workshops, field demonstration projects, and one-on-one activities at resource centers. The resource centers will be incorporated within existing organizations in each region, as described in the KTTM (Chapter 3). The remainder of this chapter describes how the regional program is linked to the national technology transfer program. 


\section{Components of the Central Coordinating Program}

A Central Coordinating Program (CCP) will be based at the Bartlesville Project Office. Figure 5-2 presents a flow diagram illustrating how information will flow to domestic oil operators. The CCP will have several functions, such as

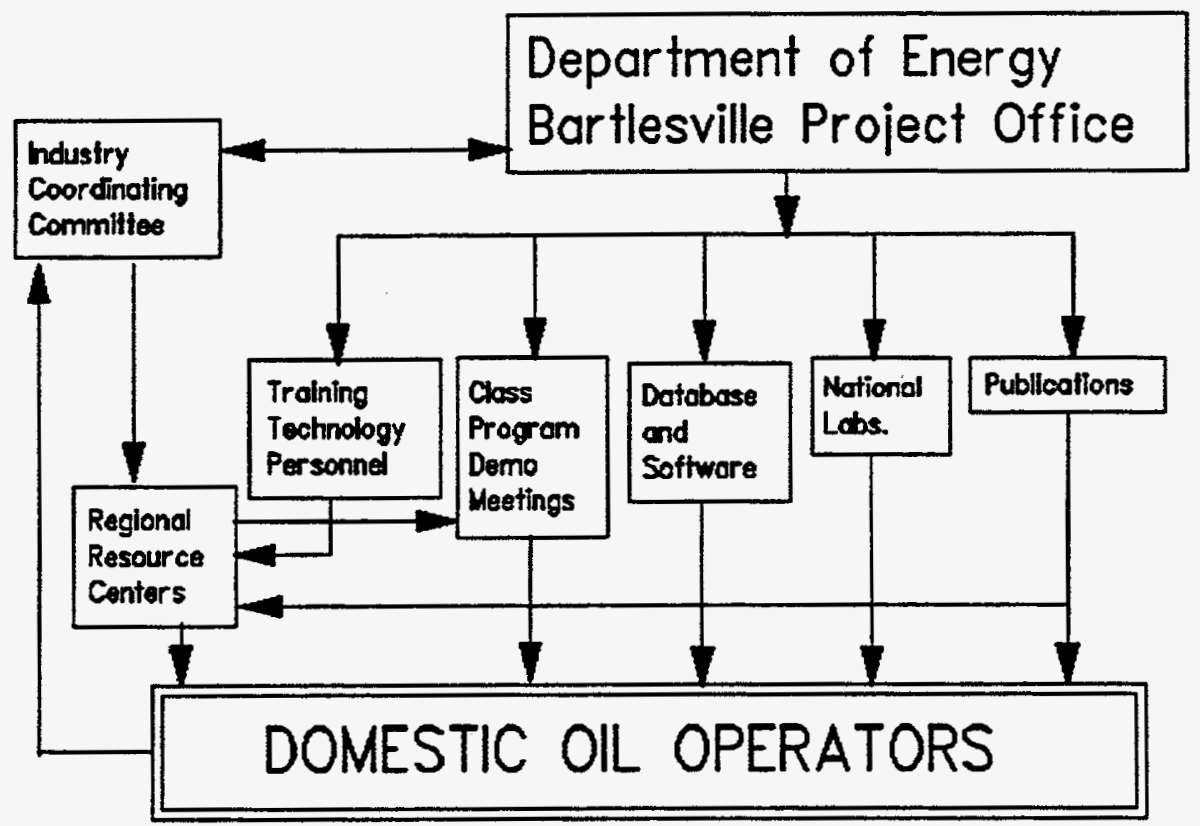

Figure 5-2. Diagram of flow of information from the Central Coordinating Program.

distribution of BPO publications and software, continued development of the "Tertiary Oil Recovery Information System" (TORIS) database, coordination of the National Labs Oil Recovery Technology Partnership programs, technology transfer training, and implementation of the Reservoir Class research, development, and demonstration program. The CCP will also serve as advisor for the hiring and training of liaison personnel in the regional resource centers and act as a facilitator for common problems throughout the oil-producing regions. The CCP will utilize the regional 
resource centers as their major distribution system to the operator, however operators will also have direct access to the $\mathrm{CCP}$ in Bartlesville, $\mathrm{OK}$.

\section{Technology Transfer Training}

Technology transfer seminars will be conducted to provide liaison personnel at the regional level with information on methods of technology transfer and common technologies useful in oil producing regions. Technology transfer specialists will be hired to inform and assist technology transfer personnel who are working at resource centers. These seminars will be used to disseminate information about common technologies useful in a variety of regions and will provide training in technology transfer concepts. These seminars will include training in 1) technology transfer methods, 2) methods of organizing problem identification workshops, 3) methods of organizing technology workshops, and 4) methods of organizing demonstration projects. Skills taught may involve training of 1) group dynamics, 2) stimulating creativity, 3) Delphi group methods, and 4) promotion or advertising methods.

As part of the program, technology transfer personnel from the CCP will periodically visit regional resource centers to 1 ) determine common needs of industry in different oil regions, 2) report on the regional resource center's progress in technology transfer, and 3) advise in technology transfer matters.

\section{Distribution of Computer Software}

Computer freeware to assist in reservoir management will be made available to domestic oil operators. Types of software included will be DOE's Predictive Models, BOAST-II, BOAST-VHS, and other available programs applicable to the domestic oil industry. This will be an extension of the current Bartlesville Project Office (BPO) technology transfer activities. Personnel from the CCP will assist in organizing and conducting computer software workshops, which will be conducted at the regional level. 


\section{Development of a National Database}

BPO's TORIS reservoir database will be expanded utilizing the additional data from the regional resource centers. Personnel from the CCP will assist the regional resource centers in developing regional reservoir databases that are not proprietary. These nonproprietary regional databases will assist operators in decision making in their fields by providing reservoir data, production histories, and recovery methods. The database will also be utilized to determine the impact of technologies implemented in domestic reservoirs.

\section{Coordination With Applicable National Lab Activities}

The CCP will assist the National Laboratories, through the Oil Recovery Technology Partnership, in focusing on high-priority technical problems and common problems identified by various regions of the domestic oil industry. The $\mathrm{CCP}$ will assist the laboratories in coordinating activities with regional resource centers, service companies, consultants, technical societies such as the Society of Petroleum Engineers (SPE) and the American Association of Petroleum Geologists (AAPG).

\section{House Petroleum Publications}

Publications responsive to the needs of the domestic oil industry will be made available as part of the CCP. These publications will include reports from the DOE Reservoir Class Demonstration Projects, supporting research projects at universities and laboratories, and progress reports at the regional resource centers.

\section{Conduct Class Meetings on Demonstration Projects}

Demonstration projects are part of any good technology transfer program. The CCP will be responsible for organizing and conducting meetings dealing with the results of the near- and mid-term projects being conducted in the various DOE reservoir classes. These meetings and the transfer of resulting technology will be coordinated with the regional resource centers. 


\section{Delegation of Responsibility and Identification of Roles}

In an organized technology transfer plan, responsibilities must be defined in an attempt to streamline the flow of information. Each entity must understand its role and responsibilities and view itself as an essential, contributing member of the team.

This plan assigns the responsibilities on the basis of strengths. The Maintenance and Operating (M\&O) contractor at the Bartlesville Project Office (BPO), with the assistance of the DOE staff, will act as overall coordinator of activities, while the state, local, and regional entities will perform the direct transfer of technology to operators.

The Bartlesville Project Office (BPO), in cooperation with DOE Headquarters, will have primary responsibility for developing technology transfer policy. BPO, as part of its responsibilities under the DOE Oil Research Program, will direct and oversee the activities of the M\&O contractor who operates the Bartlesville research facility and assists in implementing the DOE Oil Research Program.

The M\&O Contractor is in an excellent position to coordinate activities between all technology transfer entities. The M\&O Contractor will act as the facilitator and streamline the work, promoting efficiency and eliminating duplication of effort by the regional centers. The M\&O Contractor's responsibility will be to coordinate common activities, including the organization and implementation of technology transfer training seminars for regional resource centers staffs, and communicating the common information and technology transfer techniques to all entities.

BPO will direct the M\&O contractor to carry out the following responsibilities as part of the central coordinating program:

1) Coordinate the organizing and conducting of technology transfer seminars and the training of technology transfer personnel who will be working at resource centers; be a technology transfer information base for state, and regional entities.

2) Maintain and distribute DOE and other applicable petroleum industry software applicable to the domestic oil industry. 
3) Continue to expand the BPO national database of reservoir information and perform selected analyses addressing identified technology needs.

4) Coordinate activity between operators and the National Labs by providing technology transfer assistance.

5) Provide publications which complement all technology transfer activities.

6) Coordinate with the regional resource centers in conducting meetings for the various DOE reservoir classes, based on results of field tests (PON Projects).

The Industry Coordinating Committee, possibly the PTTC, will meet semiannually and provide input to the M\&O contractor on major program goals and direction. The committee will be made up of independent oil and gas producers representing various independent oil and gas associations, members from the academic community, professional societies, and members representing major service companies.

Primary responsibilities include:

1) Establishing standards and criteria for regional programs.

2) Assisting in organizing regional coordinating groups.

3) Assessing regional technology transfer proposals.

4) Providing a report to DOE on evaluation of the overall technology transfer regional program.

The Regional Coordinating Groups will be formed from members of local SPE and Geological Societies, independent operators, consultants and service companies. The groups will be responsible for:

1) Identifying existing programs and capabilities.

2) Assisting the resource center in the administration of technology transfer activities.

3) Providing advice for problem identification and technology workshops.

4) Evaluating the regional resource centers activities for further justification of funds. 
5) Selecting members to serve on screening committees which will determine the focus of demonstration projects.

Regional professional societies such as the Society of Petroleum Engineers (SPE) and the American Association of Petroleum Geologists (AAPG) will have the responsibility to assist in forming the regional coordinating groups and to provide input on instructors for focused technology workshops.

Service companies and industry consultants will participate in the problem identification workshops, and provide an inventory of instructors for the technology workshops. Along with operators, they will serve on screening committees in selecting demonstration projects and will provide input on the regional resource center activities. 


\section{CHAPTER 6 \\ CONCLUSIONS}

A plan for a national technology transfer program has been developed based on principles and experienced developed in the KTTM.

A regional technology transfer program has been developed which is designed to 1) be adaptable to all oil-producing regions, 2) complement the national program, 3) be interdisciplinary, and 4) stimulate the current industry infrastructure.

This regional technology transfer program must include 1) problem identification workshops, 2) technology workshops, 3) demonstration projects, 4) an adequate resource center, and 5) an evaluation program for assessing and improving the regional model.

The technology transfer model (KTTM) is effective in Kansas. Six problem identification workshops and three technology workshops were organized, conducted, and tested with a high degree of success according to the participants' evaluations. Also, three technologies were documented with case studies in Kansas.

Through use of problem identification workshops and annual evaluations, the model can be adapted to oil-producing regions throughout the nation.

It was found that problem identification workshops are very useful in determining problems in given regions. They must be properly facilitated to get unbiased results. A workshop format has been developed which can be utilized in any region. It was found that the facilitator must utilize open-ended questions and active listening skills, and categorize the questions to get adequate unbiased results. It was also found that asking a question of high emotional content, such as one concerning regulatory issues, was helpful in getting participants to open up. Analysis of the workshop responses indicated that the region was divided appropriately by reservoir size and type.

Resource centers must be, and should be perceived as, technical entities rather than only information service/library entities. Therefore, liaison personnel must be experienced technical people who have credibility with the operator community. Liaison personnel should have exposure to interdisciplinary (geology, engineering, and operations) efforts, demonstrated ability to learn new technology and technology transfer concepts, and excellent interpersonal communication skills. 


\section{CHAPTER 7 \\ RECOMMENDATIONS}

The proposed national technology transfer program should be implemented by the Department of Energy, in conjunction with its oil technology transfer program, within the earliest time frame possible. A principal component of the initial implementation of the program should be the testing of the KTTM in another oilproducing region to determine its adaptability.

The program should also be continued in Kansas to evaluate the long-term impact the program has on the industry in terms of transferring technologies, reducing the rate of well abandonment, and increasing oil production. If this occurs, office facilities should be made available for the liaison technology transfer team such that engineers and geologists could operate in proximity.

During development of the KTTM problem identification workshop, participants recommended that the workshops be continued on a normal basis in the future, and technology workshop participants recommended a number of additional topics they perceive to be needed in the future. 


\section{REFERENCES}

Adams, K.A., (1991) "Reservoir Simulation of Primary Production in the Zenith Field, Stafford and reno Counties in Kansas", Masters Thesis, 1991, University of Kansas.

Anderson, S.B., and Ball, S., (1978) "The Profession and Practice of Program Evaluation," Jossey-Bass Publishers, San Francisco, Washington, London.

Andrews, F.M. (1979), "Scientific Productivity," Cambridge University Press/Unesco, Cambridge.

Belvin, M. (1981), "Management Teams: Why They Succeed or Fail," Heinemann, London.

Boland, R.J. (1978). The processes and product of system design. Management Science, 24(9), 887-898.

Carr, T.R., and Schoeling L.S., (1993) "Kansas: A model of Technology Transfer for the United States," Interstate Oil and Gas Compact Commission Mid-year Meeting, June 25, 1993, Tulsa, OK.

Cartwright, D., and Lippitt, R., (1957), "Group Dynamics and the Individual," International Journal of Group Psychotherapy, 7, No. 1, pp. 86-102 (reprinted in Leavitt (1974), op. cit)

Cascio, W.F., "Managing Human Resources - Productivity, Quality of Work Life, Profits," McGraw-Hill, Inc. Third Edition, 1992.

Chang, M.M., Sarathi, P., Heemstra, R.J., Cheng A.M., and Pautz, J.F., "User's Guide and Documentation Manual for BOAST-VHS for the PC," January 1992, NIPER-542, (DE92001021), Bartlesville Project Office, U.S. Department of Energy, Bartlesville, Oklahoma.

Devine, M.D., James, T.E., Jr., \& Adams, I.T. (1987, fall) "Government supported industry-research centers: Issues for successful technology transfer," Journal of Technology Transfer, 12(1), 27-28.

Dimancescu, D., \& Botkin, J. (1986) "The New Alliance: America's R\&D Consortia." Cambridge, MA: Ballinger Publishing.

Gilman, J.R., and Kazemi, H., "Improvements in Simulation of Naturally Fractured Reservoirs," Society of Petroleum Engineers Journal, August 1983, P. 695 - 707. 
Interstate Oil and Gas Compact Commission, (March 1993). "Oil and Gas Technology Transfer Activities and Potential in Eight Major Producing States, " Vol 1, Grant Number DE-FG22-91BC14818.

Interstate Oil and Gas Compact Commission, (March 1993). "A Framework for Evaluation of Technology Transfer Programs," Vol II, Grant Number DE-FG2291BC14818.

IPAA, 1992, "Profile of Independent Producers, " Independent Petroleum Association of America, Washington, D.S., 6p.

Ives, B., \& Olsen, M.H. (1984, May), "User involvement and MIS success: A review of research." Management Science 30(5), 586-603.

Linstone, H.A., and Turoff, M. (1975), "The Delphi Method - Techniques and Applications," Addison-Wesley Publishing Company, Reading, Massachusetts,

Martin F.D., (1992) "Enhanced Oil Recovery for Independent Producers, " SPE/DOE 24142 presented at the Eighth Symposium on Enhanced Oil Recovery held in Tulsa, Oklahoma, April 22-24.

Mattax C. C., and Dalton R.L., (1990) "Reservoir Simulation," Monograph Volume 13, Society of Petroleum Engineers, 1990.

Petroleum Technology Transfer Council, (1993), "Technology Transfer to U.S. Oil and Natural Gas Producers," Washington, D.C., A Report to the United States Department of Energy.

Provus, M.M., (1971), "Discrepancy Evaluation, For Educational Program Improvement and Assessment," McCutchan Publishing Corporation, Berkeley, California.

Provus, M.M., (1975), "The Grand Experiment," McCutchan Publishing Corporation, Berkeley, California,

Rickards, T.(1985), "Stimulating Innovation, " St. Martin's Press, New York, Rogers, E.M. (1983). "Diffusion of innovations," (3rd ed.) New York: Free Press.

Rogers, E.M., \& Kincaid, D.L. (1981). "Communication networks: A new paradigm for research," New York: Free Press. 
Schoeling, L.G., (1993) "Simulation-A Tool to Improve and Test a Reservoir Description," Reservoir Description Workshop: Application of Underutilized Technologies, February 16 and 17, 1993, Kansas Geological Survery Open-file Report 93-5.

Schoeling, L.G., Green D.W., and Jackson D., (1989) "Technology Transfer Through A Liaison Program-University Working with Industry, " Presented at the Conference on Partners in Progress: The Role of Higher Education in Economic Development, Manhattan, Kansas. February 23-24.

Schoeling, L.G., Green, D.W., and Willhite, G.P., (1989) "Introducing EOR Technology to Independent Operators, " Journal of Petroleum Technology, December 1989.

Schoeling, L.G., Newell, K.D., Reynolds, R.R., Weatherbie, W.J., Michnick, M.J., Wong, J-C., Green, D.W., Watney, W.L., and Willhite, G.P., (1991) "Zenith Field A Field Demonstration Project for Improved Efficiency for Oil and Gas Recovery in Kansas," Final Report to the Kansas Corporation Commission, February, 261 pp.

Schoeling, L.G., Newell, K.D., and Wong, J.C., (1990) "Volumetric Evaluation of a Mature Oil Field Utilizing PC and Mainframe Computer Graphics Techniques," SPE 20369 presented at the 1990 SPE Petroleum Computer Conference, Denver, CO. June 25-28.

Stogdill, R.M., (1974), "Historical Trends in Leadership Theory and Research," Journal of Contemporary Business. 3, No. 4.

Stogdill, R.M., (1974), Handbook of Leadership, Free Press, New York.

Tiedemann, H., (1993), Personnal Communication

Tosi, H.L., and Slocum, J.W., (1984), "Contingency Theory: Some Suggested Directions," Journal of Management, 10, No. 1.

Tuckman, B.W., (1965), "Development Sequences in Small Groups, " Psychological Bulletin, 63.

U.S. Department of Energy, Office of Fossil Energy. (1990) Oil Research Program Implementation Plan (Washington, D.C.: DOE, April),

U.S. Department of Energy, Bartlesville Project Office, (1990), Abandonment rates of known domestic oil resource, DOE/BC--89/6/SP. 
von Hippel, E. (1988) "The sources of innovation." New York: Oxford University Press.

Warren, J.E., and Root, P.J., (1963) "The Behavior of Naturally Fractured Reservoirs," Society of Petroleum Engineers Journal, September 1963, p. 245 -255.

Williams, F., and Gibson, D.V. (1990), "Technology Transfer - A Communication Perspective, "SAGE Publications, The International Professional Publishers, Newbury Park, London. 


\section{APPENDIX A \\ Problem Identification Workshop Invitation and Evaluation Form}

Operator's Name

Operator's Address

Re: Problem Identification Workshops

Dear Sir,

This letter is an invitation to you or a representative from your company to attend what we are calling a "problem identification workshop" from 10:00 AM to 2:00 PM on Wednesday, July 29 at the Petroleum Club. You and 15 other oil operators have been selected to participate in this workshop because of your high level of activity in oil operations in Kansas. Lunch will be provided.

The Energy Research Center (ERC) at the University of Kansas has received a technology transfer grant from the Department of Energy (DOE). In that project, we are to test and develop a technology transfer model which can be utilized in other oil producing regions throughout the United States. This Kansas Technology Transfer Model (KTTM) will be an expansion of the current Tertiary Oil Recovery Project (TORP) model and will include reservoir characterization and geological analyses. It is envisioned that KTTM will serve as a model to develop technology transfer programs throughout the nation.

The scope of the KTTM will address the objectives of the near-term DOE Oil Implementation Program. The near-term objectives are to 1) reduce the well abandonment rate, and 2) increase oil recovery in existing domestic oil reservoirs using conventional technology. The time frame for near-term activities is $0-5$ years. We want to look for engineering and geological technologies which have the potential to sustain oil production in Kansas reservoirs.

The model has two major components which require a high degree of interaction with the independent operators in Kansas; 1) problem identification workshops and 2) technology workshops. A method for organizing and conducting these workshops effectively must be developed. The program will be conducted in stages in which we will 1) identify and prioritize problems of independent operators, 2) match problems with possible technical solutions, and 3) disseminate the technical solutions to the industry. 
The plan is to conduct problem identification workshops and technology workshops throughout Kansas over the next year. We are asking you to attend a problem identification workshop in the Wichita area on July 29, 1992. This is an opportunity for you to assist us in focusing on oil producing problems in Kansas.

The workshop will be organized in a manner to stimulate open discussion. We ask that oil price and tax issues not be major items of discussion because they are out of our control. We want to focus on technical issues which are controllable in the near term. There are three broad questions that we want to address in this workshop. They are:

1. What are the critical problems (other than oil price and taxes) that must be addressed to sustain production from existing reservoirs?

2. What technologies have you found useful in solving these problems?

3. What technologies need to be developed?

Results of these workshops will help focus future technology development in Kansas on actual problems experienced in the field.

As stated at the beginning of this letter, the meeting will be held at the Petroleum Club on July 29, 1992 and will start at 10:00 AM with two hours of discussion before lunch. We plan to continue after lunch and adjourn no later than 2:00 PM.

Please RSVP within the next week at (913) 864-3001. If you have any questions, please contact me at the above number.

Sincerely,

Problem Identification Coordinator 


\section{EVALUATION FORM \\ PROBLEM IDENTIFICATION WORKSHOP}

1) How can this P.I. workshop be improved?

2) What questions were not asked that you would like to respond to?

3) Cite additional methods to identify problems.

4) Do you feel that the composition of the workshop represents your industry?

5) Where is your main production or the production you are associated with?

Additional comments: 


\section{APPENDIX B - Data Sheet for Operators \\ REQUEST FOR COOPERATIVE PROJECT WTTH THE ENERGY RESEARCH CENTER}

The University of Kansas

Operator

Field

Lease Name
Legal Description

County, State

I. Brief Statement of Problem or Objective of the Cooperative Project.

Data Available:

Isopach and Structural Map

Representative Core Data

Water Analysis

Monthly Oil and $\mathrm{H}_{2} \mathrm{O}$ Prod.

Reservoir Description:

Formation

Type

Depth

BHT

Connate Water Sat.

Oil Gravity, `API

Oil Viscosity at BHT, cp
Monthly Injection Data

Electrical Logs

Completion Information
Porosity

Permeability, Avg. md

Range, md

Variation

Formation Volume Factor

Average Net Pay, ft. 


\section{Primary Recovery}

Development Surface Area, Acre

Year of Discovery

Type of Producing Drive

Peak Rate of Primary Prod. BOPD

Primary Decline, \%/YR
Well Spacing, Acre

Years of Development

Actual Recovery, bbl

\% OOIP

\# of Producing Wells

\section{Secondary Recovery:}

Has the field been waterflooded? If so, answer the following:

Year of Waterflood Initiation

Development Surface Area, Acre

Number of Injection Wells

Total Injection, BWPD

Recovery to Date on Reservoir

(Inchuding Primary)
Well Spacing, Acre

Res. Oil Sat., \%

\# of Prod. Wells

Relative Perm. Endpoint Data

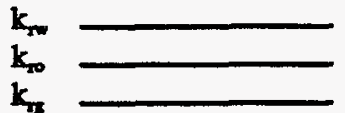

I. Tertiary Recovery:

Has a Tertiary Oil Recovery Process been implemented?

Type of Process:

Status of the Project: 
II. Desired Method of Interaction with the Energy Research Center.

Direct Interaction in the Field Implementation

ERC will have primary responsibility for the design of the project, in cooperation with the operator, and will assist in field implementation. Operator will provide supplies, field, manpower, and equipment.

\section{Advisory Capacity}

ERC will serve in an advisory capacity to the operator. ERC will assist in the design by advising the operator and will be an observer in field implementation. Operator or his designated representative will have direct responsibility for field implementation.

III. Company Resources:

Engineer on Staff

Geologist on Staff

Does staff have experience with waterflooding?

IV. Release of Information:

A condition of a cooperative effort with ERC is that information about the project will be made available for public disclosure to the Kansas Oil Industry. Are you willing to release the information? Or are there restrictions that you need to impose on the release or information? 


\section{APPENDIX C ADVANCED WATERFLOODING WORKSHOP \\ Participant's Manual}

Organized by the

Energy Research Center

The University of Kansas

October 1, 1992

Barton County Community College

Great Bend, Kansas

Project Sponsors:

KU Kansas Geological Survey

KU Tertiary Oil Recovery Project

KU Department of Geology

U.S. Department of Energy*

* Supported by DOE Grant No. DE-FG22-92BC14856 titled

A Technology Transfer Model for Additional Oil Recovery

Technology Transfer Series 92-1 


\section{ADVANCED WATERFLOODING WORKSHOP Participant's Manual}

COMPILED BY

E. Lance Cole

Energy Research Center

The University of Kansas

Lawrence, Kansas

SEPTEMBER 1993

\section{ACKNOWLEDGEMENT}

This document represents a Technology Transfer Team effort involving the Energy Research Center, the Kansas Geological Survey, and the Tertiary Oil Recovery Project at The University of Kansas. Lee C. Gerhard, Don W. Green, G. Paul Willhite, Lanny G. Schoeling, and W. Lynn Watney reviewed the document and provided project leadership. Contributing team members include E. Lance Cole, Danial F. Merriam, Michael J. Michnick, Kerry D. Parham, Timothy L. Phares, Rodney R. Reynolds, Robert S. Sawin, and Wendell J. Weatherbie.

\section{Disclaimer}

The Energy Research Center, the Kansas Geological Survey, and the Tertiary Oil Recovery Project do not guarantee this document to be free from errors or inaccuracies and disclaim any responsibility or liability for interpretations based on data used in the production of this document or decisions based thereon. This report is intended to make results of research available at the earliest possible date, but is not intended to constitute final for formal publication. 


\title{
ADVANCED WATERFLOODING WORKSHOP Instructor's Manual
}

\author{
Organized by the \\ Energy Research Center \\ The University of Kansas
}

October 1, 1992

Barton County Community College

Great Bend, Kansas

\section{Project Sponsors:}

KU Kansas Geological Survey KU Tertiary Oil Recovery Project

KU Department of Geology

U.S. Department of Energy*

* Supported by DOE Grant No. DE-FG22-92BC14856 titled A Technology Transfer Model for Additional Oil Recovery 


\title{
ADVANCED WATERFLOODING WORKSHOP Instructor's Manual
}

\author{
COMPILED BY \\ E. Lance Cole \\ Energy Research Center \\ The University of Kansas \\ Lawrence, Kansas
}

SEPTEMBER 1993

\begin{abstract}
ACKNOWLEDGEMENT
This document represents a Technology Transfer Team effort involving the Energy Research Center, the Kansas Geological Survey, and the Tertiary Oil Recovery Project at The University of Kansas. Lee C. Gerhard, Don W. Green, G. Paul Willhite, Lanny G. Schoeling, and W. Lynn Watney reviewed the document and provided project leadership. Contributing team members include E. Lance Cole, Danial F. Merriam, Michael J. Michnick, Kerry D. Parham, Timothy L. Phares, Rodney R. Reynolds, Robert S. Sawin, and Wendell J. Weatherbie.
\end{abstract}

\section{Disclaimer}

The Energy Research Center, the Kansas Geological Survey, and the Tertiary Oil Recovery Project do not guarantee this document to be free from errors or inaccuracies and disclaim any responsibility or liability for interpretations based on data used in the production of this document or decisions based thereon. This report is intended to make results of research available at the earliest possible date, but is not intended to constitute final for formal publication. 


\title{
RESERVOIR DESCRIPTION WORKSHOP: Application of Underutilized Technologies
}

Organized by the

\author{
Energy Research Center \\ The University of Kansas
}

February 16th and 17th, 1993

Auditorium

Fourth Financial Center

Wichita, Kansas

Meeting Sponsorship:

Kansas Geological Society

Kansas Geological Foundation

Kansas Well Logging Society

U.S. Department of Energy*
Kansas Geological Survey

KU Department of Geology

KU Tertiary Oil Recovery Project

\section{Organizing Committee:}

Tim Carr, Kansas Geological Survey

Bob Sawin, Energy Research Center

Lanny Schoeling, KU Tertiary Oil Recovery Project and Energy Research Center

Tony Walton, KU Department of Geology

Lynn Watney, Kansas Geological Survey and Energy Research Center

for the Societies:

Bob Cowdery, Kansas Geological Society and Kansas Geological Foundation Lanny Butner, Wichita Petroleum Section -- Society of Petroleum Engineers

Dan DeBoer, Kansas Well Logging Society

* Supported by DOE Grant No. DE-FG22-92BC14856 titled A Technology Transfer Model for Additional Oil Recovery 


\title{
RESERVOIR DESCRIPTION WORKSHOP: Application of Underutilized Technologies
}

\author{
COMPILED BY \\ W. Lynn Watney \\ Robert S. Sawin \\ Energy Research Center \\ The University of Kansas \\ Lawrence, Kansas
}

JULY 1993

\begin{abstract}
ACKNOWLEDGEMENT
This document represents a Technology Transfer Team effort involving the Energy Research Center, the Kansas Geological Survey, and the Tertiary Oil Recovery Project at The University of Kansas. Lee C. Gerhard, Don W. Green, G. Paul Willhite, Lanny G. Schoeling, and W. Lynn Watney reviewed the document and provided project leadership. Contributing team members include E. Lance Cole, Daniel F. Merriam, Michael J. Michnick, Kerry D. Parham, Timothy L. Phares, Rodney R. Reynolds, Robert S. Sawin, and Wendell J. Weatherbie.
\end{abstract}

\section{Disclaimer}

The Energy Research Center, the Kansas Geological Survey, and the Tertiary Oil Recovery Project do not guarantee this document to be free from errors or inaccuracies and disclaim any responsibility or liability for interpretations based on data used in the production of this document or decisions based thereon. This report is intended to make results of research available at the earliest possible date, but is not intended to constitute final for formal publication. 


\section{COMPUTER APPLICATION WORKSHOP: PC Software for the Petroleum Industry}

Organized by the

Energy Research Center

The University of Kansas

in cooperation with

The Wichita State University

April 16th and 17th, 1993

Marcus Center and Clinton Hall

The Wichita State University

Wichita, Kansas

\section{Workshop Sponsors:}

- KU Kansas Geological Survey

KU Tertiary Oil Recovery Project

WSU Department of Geology

U.S. Department of Energy*

* Supported by DOE Grant No. DE-FG22-92BC14856 titled

A Technology Transfer Model for Additional Oil Recovery 


\section{COMPUTER APPLICATION WORKSHOP: PC Software for the Petroleum Industry}

COMPILED BY

Robert S. Sawin

Energy Research Center

The University of Kansas

Lawrence, Kansas

MAY 1993

\section{ACKNOWLEDGEMENT}

This document represents a Technology Transfer Team effort involving the Energy Research Center, the Kansas Geological Survey, and the Tertiary Oil Recovery Project at The University of Kansas. Lee C. Gerhard, Don W. Green, G. Paul Willhite, Lanny G. Schoeling, and W. Lynn Watney reviewed the document and provided project leadership. Contributing team members include E. Lance Cole, Danial F. Merriam, Michael J. Michnick, Kerry D. Parham, Timothy L. Phares, Rodney R. Reynolds, Robert S. Sawin, and Wendell J. Weatherbie.

\section{Disclaimer}

The Energy Research Center, the Kansas Geological Survey, and the Tertiary Oil Recovery Project do not guarantee this document to be free from errors or inaccuracies and disclaim any responsibility or liability for interpretations based on data used in the production of this document or decisions based thereon. This report is intended to make results of research available at the earliest possible date, but is not intended to constitute final for formal publication. 


\title{
RESERVOIR MANAGEMENT \\ Demonstration Project
}

\author{
Prepared by the \\ Energy Research Center \\ The University of Kansas
}

AUGUST 1993

Project Sponsors:

KU Kansas Geological Survey KU Tertiary Oil Recovery Project

KU Department of Geology

U.S. Department of Energy*

* Supported by DOE Grant No. DE-FG22-92BC14856 titled A Technology Transfer Model for Additional Oil Recovery 


\title{
RESERVOIR MANAGEMENT Demonstration Project
}

\author{
BY \\ E. Lance Cole \\ Robert S. Sawin \\ Wendell J. Weatherbie \\ Energy Research Center \\ Energy Research Center \\ The University of Kansas \\ Lawrence, Kansas
}

\section{AUGUST 1993}

\section{ACKNOWLEDGEMENT}

This document represents a Technology Transfer Team effort involving the Energy Research Center, the Kansas Geological Survey, and the Tertiary Oil Recovery Project at The University of Kansas. Lee C. Gerhard, Don W. Green, G. Paul Willhite, Lanny G. Schoeling, and W. Lynn Watney reviewed the document and provided project leadership. Contributing team members include E. Lance Cole, Danial F. Merriam, Michael J. Michnick, Kerry D. Parham, Timothy L. Phares, Rodney R. Reynolds, Robert S. Sawin, and Wendell J. Weatherbie.

\section{Disclaimer}

The Energy Research Center, the Kansas Geological Survey, and the Tertiary Oil Recovery Project do not guarantee this document to be free from errors or inaccuracies and disclaim any responsibility or liability for interpretations based on data used in the production of this document or decisions based thereon. This report is intended to make results of research available at the earliest possible date, but is not intended to constitute final for formal publication. 


\title{
ACOUSTIC FLUID-LEVEL TECHNOLOGY Demonstration Project
}

Prepared by the

\author{
Energy Research Center \\ The University of Kansas
}

SEPTEMBER 1993

\section{Project Sponsors:}

KU Kansas Geological Survey

KU Tertiary Oil Recovery Project

KU Department of Geology

U.S. Department of Energy*

* Supported by DOE Grant No. DE-FG22-92BC14856 titled A Technology Transfer Model for Additional Oil Recovery 


\title{
ACOUSTIC FLUID-LEVEL TECHNOLOGY Demonstration Project
}

\author{
BY \\ Rodney R. Reynolds \\ Tertiary Oil Recovery Project \\ E. Lance Cole \\ Wendell J. Weatherbie \\ Energy Research Center \\ Energy Research Center \\ The University of Kansas \\ Lawrence, Kansas \\ SEPTEMBER 1993
}

\section{ACKNOWLEDGEMENT}

This document represents a Technology Transfer Team effort involving the Energy Research Center, the Kansas Geological Survey, and the Tertiary Oil Recovery Project at The University of Kansas. Lee C. Gerhard, Don W. Green, G. Paul Willhite, Lanny G. Schoeling, and W. Lynn Watney reviewed the document and provided project leadership. Contributing team members include E. Lance Cole, Danial F. Merriam, Michael J. Michnick, Kerry D. Parham, Timothy L. Phares, Rodney R. Reynolds, Robert S. Sawin, and Wendell J. Weatherbie.

\section{Disclaimer}

The Energy Research Center, the Kansas Geological Survey, and the Tertiary Oil Recovery Project do not guarantee this document to be free from errors or inaccuracies and disclaim any responsibility or liability for interpretations based on data used in the production of this document or decisions based thereon. This report is intended to make results of research available at the earliest possible date, but is not intended to constitute final for formal publication. 


\section{PERMEABILITY MODIFICATION Demonstration Project}

Prepared by the

Energy Research Center

The University of Kansas

SEPTEMBER 1993

Project Sponsors:

KU Kansas Geological Survey

KU Tertiary Oil Recovery Project

KU Department of Geology

U.S. Department of Energy*

* Supported by DOE Grant No. DE-FG22-92BC14856 titled
A Technology Transfer Model for Additional Oil Recovery

Technology Transfer Series 93-7 


\section{PERMEABILITY MODIFICATION Demonstration Project}

BY

Lanny G. Schoeling

Tertiary Oil Recovery Project

E. Lance Cole

Timothy L. Phares

Wendell J. Weatherbie

Energy Research Center

Energy Research Center

The University of Kansas

Lawrence, Kansas

SEPTEMBER 1993

\section{ACKNOWLEDGEMENT}

This document represents a Technology Transfer Team effort involving the Energy Research Center, the Kansas Geological Survey, and the Tertiary Oil Recovery Project at The University of Kansas. Lee C. Gerhard, Don W. Green, G. Paul Willhite, Lanny G. Schoeling, and W. Lynn Watney reviewed the document and provided project leadership. Contributing team members include E. Lance Cole, Danial F. Merriam, Michael J. Michnick, Kerry D. Parham, Timothy L. Phares, Rodney R. Reynolds, Robert S. Sawin, and Wendell J. Weatherbie.

\section{Disclaimer}

The Energy Research Center, the Kansas Geological Survey, and the Tertiary Oil Recovery Project do not guarantee this document to be free from errors or inaccuracies and disclaim any responsibility or liability for interpretations based on data used in the production of this document or decisions based thereon. This report is intended to make results of research available at the earliest possible date, but is not intended to constitute final for formal publication. 


\section{BIBLIOGRAPHY \\ Literature Used in Project Deliverables}

Prepared by the

Energy Research Center

The University of Kansas

SEPTEMBER 1993

Project Sponsors:

KU Kansas Geological Survey KU Tertiary Oil Recovery Project

KU Department of Geology

U.S. Department of Energy*

* Supported by DOE Grant No. DE-FG22-92BC14856 titled A Technology Transfer Model for Additional Oil Recovery

Technology Transfer Series 93-8 


\title{
BIBLIOGRAPHY \\ Literature Used in Project Deliverables
}

\author{
BY \\ Kerry D. Parham \\ Energy Research Center \\ Energy Research Center \\ The University of Kansas \\ Lawrence, Kansas
}

SEPTEMBER 1993

\section{ACKNOWLEDGEMENT}

This document represents a Technology Transfer Team effort involving the Energy Research Center, the Kansas Geological Survey, and the Tertiary Oil Recovery Project at The University of Kansas. Lee C. Gerhard, Don W. Green, G. Paul Willhite, Lanny G. Schoeling, and W. Lynn Watney reviewed the document and provided project leadership. Contributing team members include E. Lance Cole, Danial F. Merriam, Michael J. Michnick, Kerry D. Parham, Timothy L. Phares, Rodney R. Reynolds, Robert S. Sawin, and Wendell J. Weatherbie.

Disclaimer

The Energy Research Center, the Kansas Geological Survey, and the Tertiary Oil Recovery Project do not guarantee this document to be free from errors or inaccuracies and disclaim any responsibility or liability for interpretations based on data used in the production of this document or decisions based thereon. This report is intended to make results of research available at the earliest possible date, but is not intended to constitute final for formal publication. 


\section{PROBLEM IDENTIFICATION \\ Workshop Manual for the KTTM}

Prepared by the

Energy Research Center

The University of Kansas

SEPTEMBER 1993

\section{Project Sponsors:}

KU Kansas Geological Survey

KU Tertiary Oil Recovery Project

KU Department of Geology

U.S. Department of Energy*

* Supported by DOE Grant No. DE-FG22-92BC14856 titled A Technology Transfer Model for Additional Oil Recovery 


\title{
PROBLEM IDENTIFICATION Workshop Manual for the KTTM
}

\author{
BY \\ Lanny G. Schoeling \\ Tertiary Oil Recovery Project \\ Timothy L. Phares \\ Energy Research Center \\ Energy Research Center \\ The University of Kansas \\ Lawrence, Kansas
}

SEPTEMBER 1993

\section{ACKNOWLEDGEMENT}

This document represents a Technology Transfer Team effort involving the Energy Research Center, the Kansas Geological Survey, and the Tertiary Oil Recovery Project at The University of Kansas. Lee C. Gerhard, Don W. Green, G. Paul Willhite, Lanny G. Schoeling, and W. Lynn Watney reviewed the document and provided project leadership. Contributing team members include E. Lance Cole, Danial F. Merriam, Michael J. Michnick, Kerry D. Parham, Timothy L. Phares, Rodney R. Reynolds, Robert S. Sawin, and Wendell J. Weatherbie.

\section{Disclaimer}

The Energy Research Center, the Kansas Geological Survey, and the Tertiary Oil Recovery Project do not guarantee this document to be free from errors or inaccuracies and disclaim any responsibility or liability for interpretations based on data used in the production of this document or decisions based thereon. This report is intended to make results of research available at the earliest possible date, but is not intended to constitute final for formal publication. 